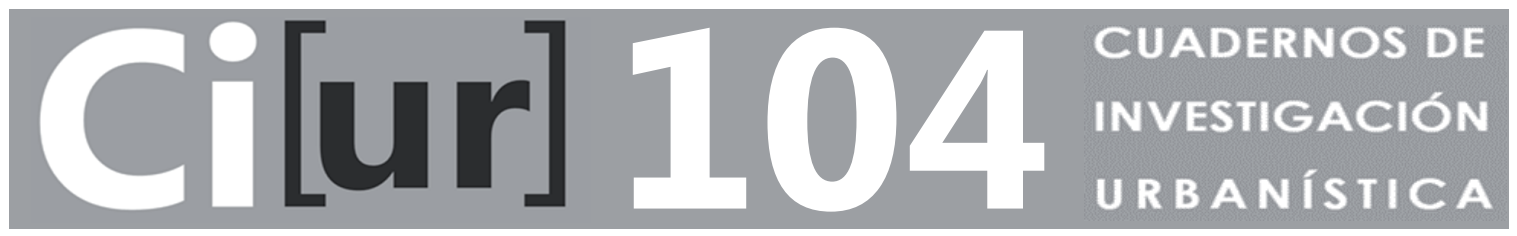

\title{
LA HUELLA EN EL TERRITORIO DEL SISTEMA AGROALIMENTARIO 1900-2015
}

\author{
LECCIONES DEL TRAMO MEDIO DEL VALLE DEL DUERO
}

(ESPAÑA)

\section{MARIAN SIMÓN ROJO}

\author{
Doctora Arquitecta
}

Este documento es un resumen de la tesis doctoral: "El Territorio en el Sistema Agroalimentario. El tramo medio del Valle del Duero 19002015", dirigida por el profesor José Fariña Tojo y Luis Felipe Alonso Teixidor, leída por su autora el día 3 de febrero de 2016 en la Escuela Técnica Superior de Arquitectura de Madrid 


\section{Director: José Fariña Tojo}

\section{Consejo de Redacción:}

Director Ester Higueras García

Jefe de redacción María Emilia Román López

Vocales Julio Alguacil Gómez (Univ. Carlos III de Madrid), Pilar Chías Navarro (Univ. Alcalá de Henares, Madrid), José Antonio Corraliza Rodríguez (Univ. Autónoma de Madrid), Alberto Cuchí Burgos (Univ. Politécnica de Cataluña), José Fariña Tojo (Univ. Politécnica de Madrid), Agustín Hernández Aja (Univ. Politécnica de Madrid), Mariam Leboreiro Amaro (Univ. Politécnica de Madrid), Rafael Mata Olmo (Univ. Autónoma de Madrid), Fernando Roch Peña (Univ. Politécnica de Madrid), Carlos Manuel Valdés (Univ. Carlos III de Madrid)

Consejo Asesor:

Ma Teresa Arredondo (Directora de Relaciones con Latinoamérica, Univ. Politécnica de Madrid), Luis Maldonado (Director de la Escuela Superior de Arquitectura, Univ. Politécnica de Madrid), Antonio Elizalde, Julio García Lanza, Josefina Gómez de Mendoza, José Manuel Naredo, Julián Salas, Fernando de Terán

Comité Científico: Antonio Acierno (Univ. Federico II di Napoli, Nápoles, ITALIA), Miguel Ángel Barreto (Univ. Nal. del Nordeste, Resistencia, ARGENTINA), Luz Alicia Cárdenas Jirón (Univ. de Chile, Santiago de Chile, CHILE), José Luis Carrillo (Univ. Veracruzana, Xalapa, MÉXICO), Marta Casares (Univ. Nal. de Tucumán, ARGENTINA), María Castrillo (Univ. de Valladolid, ESPAÑA), Mercedes Ferrer (Univ. del Zulia, Maracaibo, VENEZUELA), Fernando Gaja (Univ. Politécnica de Valencia, ESPAÑA), Alberto Gurovich (Univ. de Chile, Santiago de Chile, CHILE), Josué Llanque (Univ. Nal. S. Agustín Arequipa, PERÚ), Angelo Mazza (Univ. Federico II di Napoli, Nápoles, ITALIA), Luis Moya (Univ. Politécnica de Madrid, ESPAÑA), Joan Olmos (U. Politécnica de Valencia, ESPAÑA), Ignazia Pinzello (Univ. degli Studi di Palermo, Palermo, ITALIA), Julio Pozueta (Univ. Politécnica de Madrid, ESPAÑA), Alfonso Rivas (UAM Azcapotzalco, Ciudad de México, MÉXICO), Silvia Rossi (Univ. Nal. de Tucumán, ARGENTINA), Adalberto da Silva (Univ. Estadual Paulista, Sao Paulo, BRASIL), Carlos Soberanis (Univ. Francisco Marroquín, Guatemala, GUATEMALA), Carlos A. Torres (Univ. N ${ }^{\text {al }}$. de Colombia, Bogotá, COLOMBIA), Graziella Trovato (Univ. Politécnica de Madrid, ESPAÑA) Carlos F. Valverde (Univ. Iberoamericana de Puebla, MÉXICO), Paz Walker (Univ. de la Serena, Santiago de Chile, CHILE), Fernando N. Winfield (Univ. Veracruzana, Xalapa, MÉXICO)

Maquetación: Antonio Jesús Antequera Delgado: ciur.urbanismo.arquitectura@upm.es

Distribución: Mairea Libros: distribucion@mairea-libros.com

\section{(C) COPYRIGHT 2016}

MARIAN SIMÓN ROJO

I.S.S.N. (edición impresa): 1886-6654

I.S.S.N. (edición digital): 2174-5099

Año IX, Núm. 104, enero-febrero 2016, 74 págs.

Edita: Instituto Juan de Herrera

Imprime: FASTER, San Francisco de Sales 1, Madrid 


\section{DESCRIPTORES:}

Sector agroalimentario / Territorio / Región agraria / Resiliencia / Sostenibilidad

\section{KEY WORDS:}

Agri-food system / Territory / Agricultural region / Resilience / Sustainability

\section{RESUMEN:}

En la actualidad, cuando crece el interés en relocalizar el sistema alimentario, conviene entender cómo funcionaba el territorio cuando ese sistema se basaba en una agricultura de proximidad. Conviene entender a su vez cómo y por qué se descompuso ese sistema, aprendiendo del pasado para avanzar hacia un urbanismo comprometido con la satisfacción de las necesidades humanas de alimentos de una manera más justa y más respetuosa con el planeta. El análisis histórico se centra en el tramo medio del valle del Duero. Los sistemas territoriales que se han sucedido desde principios del siglo XX responden a tres modelos del sistema agroalimentario, que se asocian con las distintas etapas nutricionales. Hay una correlación entre modelo nutricional de superación de la desnutrición, agricultura familiar, en la zona hasta 1950; modelo de consumo de masas y sobrealimentación, agricultura industrializada, que se extiende hasta 1985; y modelo de consumo segmentado, agricultura terciarizada, que dura hasta nuestros días. En esta última fase conviven dos tendencias: una hacia la jerarquización y el productivismo tecnificado y otra hacia la multifuncionalidad y la recampesinización que se reapropia de las innovaciones técnicas. El urbanismo cuenta con herramientas y mecanismos podrían aportar una dimensión espacial y funcional hasta ahora descuidada. Hay indicios que apuntan que el momento para reconsiderar los sistemas agroalimentarios también desde el urbanismo, favoreciendo su relocalización y una transición agroecológica, ha llegado.

\section{ABSTRACT:}

The historical review of the relationship between territory and agrifood system provides key lessons to help rebuild the territorial structure, seizing the opportunity offered by a renewed interest in local and sustainable food. The historical transdisciplinary research focuses on the middle reaches of the Douro valley (Castilla y Leon, Spain). After the analysis of the evolution of the region since 1900, it can be concluded that the territory has been organized over time according to three models of food system that are in turn linked to different nutritional stages: a) the nutritional stage of overcoming malnutrition is related to family agriculture, which persists until 1950; b) the model of mass consumption and overeating, built on an industrialized agriculture, which runs until 1985; c) and, finally, the model of consumer segmentation associated with terciarized agriculture, which lasts until present time. Actually two trends coexist: one towards hierarchisation and techbased productivism, and another one towards multifunctionality and peasantization. Spatial and urban planning are already equipped with mechanisms to integrate the functional and spatial dimension in the reconsideration of agrifood systems. We are missing opportunities, but there are indications that suggest that the moment to relocalize the agri-food system and to foster agroecological transition, has arrived. 
"Any intelligent fool can make things bigger, more complex, and more violent.

It takes a touch of genius -and a lot of courage-to move in the opposite direction"

Ernst F. Schumacher, Small Is Beautiful 


\section{ÍNDICE}

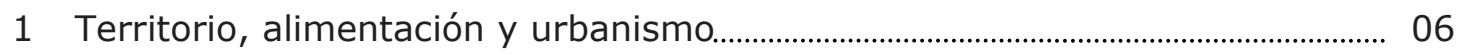

1.1 Afianzando vínculos entre urbanismo y alimentación ........................................... 06

1.2 La crisis del sector agrario y del planeamiento ................................................... 06

1.3 Recuperar la visión ecosistémica de la agricultura con vistas a una regeneración agroecológica del territorio ............................................................ 07

2 Avatares de una región agraria en un mundo cambiante. El tramo medio del valle del Duero .................................................................................................................... 08

2.1 El territorio como soporte de actividad. Condicionantes y adaptación...... 09

2.2 El reflejo en el paisaje de los cambios estructurales ...................................... 10

2.3 Población: polarización y declive ............................................................................... 12

2.4 El sistema urbano, cuando la prioridad es no desaparecer......................... 13

3 Variables, indicadores y escalas de análisis ................................................................. 15

3.1 Acotación espacio-temporal de la investigación..................................................... 15

3.2 Obtención de datos ......................................................................................................... 17

3.3 Selección de ámbitos territoriales. Aproximación multiescalar ................. 20

4 La huella en el territorio del sistema agroalimentario ................................................ 25

4.1 Caracterización socioeconómica de las tres fases del sistema agroalimentario en el siglo XX .......................................................................... 25

4.2 Caracterización del sistema tecnológico para la gestión del territorio 33

4.3 Caracterización del sistema territorial.................................................................... 36

4.4 Correlación entre sistema agroalimentario y sistema territorial .................. 48

5 Urbanismo, aprovechamiento de recursos locales y sostenibilidad ................... 55

5.1 Sostenibilidad, autonomía, estabilidad y resiliencia............................................. 55

6 La relocalización agroalimentaria en los Planes de Ordenación Territorial...... 59

6.1 La dimensión alimentaria, ausente de los Planes de Ordenación ................ 59

6.2 Actualización de la tipología de municipios y de sus interrelaciones... 62

6.3 Reconsideración de los instrumentos de planeamiento ................................. 63

6.4 Oportunidad estratégica ............................................................................................... 67

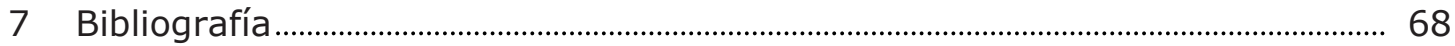




\section{TERRITORIO, ALIMENTACIÓN Y URBANISMO}

\subsection{Afianzando vínculos entre urbanismo y alimentación}

Los sistemas territoriales agroalimentarios han experimentado cambios estructurales en el último siglo y ahora se plantea su relocalización, de manera que permitan la adecuada satisfacción de necesidades humanas fundamentales como la alimentación y con ella, la subsistencia, reduciendo la presión sobre los recursos del planeta. En un planeta crecientemente urbanizado es imprescindible reducir la insostenibilidad de nuestras ciudades y para lograrlo, la alimentación puede desempeñar un importante papel.

El Pacto de Política Alimentaria de Milán ${ }^{1}$ suscrito por decenas de ciudades en 2015, señala "la estrecha relación existente entre las políticas alimentarias y muchos otros desafíos y políticas a nivel urbano - tales como la pobreza, la protección social y sanitaria, la higiene y los servicios higiénico-sanitarios, la planificación del uso del territorio, los transportes y el comercio, el sector energético, la instrucción, y la capacidad de reacción a las catástrofes".

En torno a la alimentación saludable y sostenible están convergiendo diversos temas que han aparecido recurrentemente en los debates sobre el territorio de las últimas décadas, como las relaciones urbano-rurales, el consumo de suelo y recursos, la insostenibilidad del modelo urbano y la cohesión territorial. Otros debates relacionados, como la deriva del sistema económico con la irrupción del sistema mercantil, han sido objeto de debate desde hace más de un siglo.

\subsection{La crisis del sector agrario y del planeamiento}

Observando nuestro entorno, las disciplinas relacionadas con las actividades agropecuarias como sector económico, se mueven en un contexto -el de las sociedades tericarizadas europeas- en el que el sector ha sido ampliamente cuestionado y se enfrenta a grandes desafíos ligados a la degradación de los ecosistemas, a las incertidumbres derivadas del cambio climático y a la seguridad y a la soberanía alimentarias. Por otro lado, las disciplinas relacionadas con la planificación y ordenación territorial, han quedado debilitadas y son sometidas a intensas críticas en un contexto de creciente desregulación.

Ante esta situación, el creciente interés por sistemas alimentarios más sostenibles, saludables y justos, ofrece una oportunidad única para abordar con nuevos planteamientos tanto el sector agrario como las disciplinas de ordenación y planificación espacial. No solo el modelo urbano postindustrial está entrando en crisis, también lo está haciendo el sistema agroalimentario globalizado, por su insostenibilidad, su injusticia y su incapacidad para asegurar la calidad de los alimentos producidos (Calle Collado y col., 2012). El sistema alimentario engloba "la manera en la que las sociedades se organizan para producir, distribuir y consumir

\footnotetext{
${ }^{1}$ En octubre de 2015, distintas ciudades firmaron el Pacto de Política Alimentaria Urbano de Milán, con el que se comprometieron a desarrollar unos sistemas alimentarios equitativos y sostenibles. http://www.foodpolicymilano.org/wp-content/uploads/2015/10/Milan-Urban-Food-Policy-Pact-_SPA.pdf
} 
los alimentos" (Malassis, 1994). Desde la FAO (Food and Agriculture Organization) se identifica como objetivo el lograr sistemas alimentarios sostenibles, es decir respetuosos con el medio ambiente que protegan y preserven la biodiversidad y los ecosistemas, que permitan satisfacer las necesidades nutricionales aportando alimentos culturalmente aceptables, accesibles y saludables y que proteja y mejore los medios de vida rurales, la equidad y el bienestar social. Los sistemas agroalimentarios, relocalizados y sostenibles se convierten en inesperados aliados de una nueva aproximación a los territorios agrarios y a su interacción con las áreas urbanas. El presente estudio realiza una lectura histórica para avanzar en algunas cuestiones clave que permitirían avanzar en esa redefinición territorial de los sistemas agroalimentarios localizados: ¿Qué transformaciones en la estructura territorial y espacial han acompañado la evolución del sistema agroalimentario y del modelo económico? ¿En qué situación se encuentran para responder a las cambiantes condiciones de producción y consumo? ¿Cómo se puede reorientar la planificación urbanística-territorial para dar respuesta a los retos de insostenibilidad ligados a los sistemas agroalimentarios?

Para responder a estas cuestiones, se elige una región de dilatada tradición agraria, el tramo medio del valle del Duero, en las provincias de Valladolid y Burgos (Castilla y León, España) que muestra la Figura 1. El análisis de su evolución, de las dinámicas de transformación, de los éxitos y los fracasos, se plantea con la intención de identificar con qué medidas y desde qué enfoques se han abordado esos temas, cuáles aumentan la resiliciencia, cuáles han agudizado los procesos de polarización territorial y social, y qué alternativas se vislumbran para identificar escenarios deseables que pueden guiar la evolución futura de la región.

\subsection{Recuperar la visión ecosistémica de la agricultura para una regeneración agroecológica del territorio}

Desde las instancias europeas se reconoce que la agricultura intensiva (que promovió la Política Agraria Común, PAC) ha tenido un gran impacto en el medio ambiente, con altos niveles de emisiones de contaminantes, erosión del suelo, contaminación de las aguas y pérdida de biodiversidad y de hábitats (Walls, 2006). Efectivamente, la agricultura se ha ido convirtiendo en una actividad cada vez más desligada de los sistemas ecológicos, lo que lleva a algunos autores a destacar su carácter artificial:

"Los ecosistemas naturales tienen capacidad de automantenimiento, autorreparación y autorreproducción; en tanto los sistemas manipulados por los seres humanos son inestables, requieren de energía y también materiales del exterior para su mantenimiento y reproducción. A estos ambientes transformados o ecosistemas artificiales Ilamamos Agroecosistemas" (Guzmán Casado, González de Molina Navarro y Sevilla Guzmán, 2000, p.87).

Frente a esta visión que enfatiza la componente artificial de los agroecosistemas, no podemos olvidar que, asumiendo el concepto de socioecosistemas, "los seres humanos establecen relaciones de interdependencia mediatizadas por el medio biofísico, así que sistemas humanos y ecosistemas han ido evolucionando conjuntamente" (Anderies, 2004). Los agroecosistemas previos a 
la industrialización son un ejemplo de esta integración de los grupos humanos, que constituían un elemento esencial que permitía seguir funcionado al ecosistema agrario, aportando energía y manejando el cierre del ciclo de materia. El carácter artificial al que se refiere Guzmán Casado es más evidente en la deriva hacia la tecnificación de las explotaciones intensivas actuales. Parafraseando a Hernández Aja, se podría definir el sistema agroalimentario industrial actual como "una actuación sobre el ecosistema que impide su regeneración autónoma"(Hernández Aja, 2009). En realidad el autor se estaba refiriendo a la urbanización, pero la afirmación encaja a la perfección en el ámbito territorial agrario.

Afortunadamente, en términos ambientales, la reversión de los procesos es considerablemente más factible en el caso de los sistemas agrarios que en el caso de la urbanización. Recuperar grados de regeneración autónoma de los agroecosistemas (que incluyen a las comunidades humanas que forman parte de ellos) pasa por recuperar una agricultura sostenible, que Gliessman define como "aquella que tenga el mínimo efecto sobre el medio ambiente, preserve la fertilidad del suelo, use agua en forma tal que permita la recarga de los acuiferos, haga uso de los recursos dentro del agrosistema, incluyendo a las comunidades cercanas, valore y conserve la diversidad biológica y, por último, garantice la equidad en el acceso a las prácticas agrícolas apropiadas y permita el control local de los recursos" (Haig, 2005).

Yendo un paso más allá, de la agricultura sostenible a la regeneración agroecológica del territorio, ésta bien puede inspirarse en algunos de los principios básicos que han guiado la regeneración urbana integral o la rehabilitación urbanoecológica. En ella se plantea la convergencia del urbanismo y la ecología en actuaciones sobre la ciudad existente que integren el metabolismo urbano (ahorro energético, inserción de los ciclos y flujos naturales en el entorno urbano) y la movilidad (Verdaguer y Velázquez, 2012).

Se propone aquí una similar convergencia entre planeamiento territorial y ecología, entendiendo ésta desde el principio básico de "dejar de oponerse a los ciclos cerrados de la biosfera" (Hernández Aja y Vázquez Espi, 2010). Es más, no solo ecología sino agroecología, ya que se está trabajando sobre territorios eminentemente agrarios. La agroecología incorpora las componentes social y cultural, se ocupa de la justicia social y del acceso a recursos y decisiones, así como del reequilibrio de las relaciones, de manera que dejen de establecerse en términos de dominación, y pasen a sustentarse en principios de solidaridad interterritorial e intergeneracional.

\section{AVATARES DE UNA REGIÓN AGRARIA EN UN MUNDO CAMBIANTE. EL TRAMO MEDIO DEL VALLE DEL DUERO}

Como urbanistas estamos acostumbrados a trabajar en la escala territorial sobre dos aspectos básicos: la evolución demográfica y la transformación del paisaje. Son precisamente estos dos aspectos los que se consideran en la primera aproximación a los cambios en la región agraria objeto de estudio. 


\subsection{El territorio como soporte de actividad. Condicionantes y adaptación}

Nos encontramos ante un territorio eminentemente agrario en torno al curso medio del río Duero. La cuenca sedimentaria en el norte de Castilla se caracteriza por tener un clima difícil y suelos poco favorables para la explotación agraria. En toda la zona, la baja disponibilidad de agua es uno de los aspectos críticos para el aprovechamiento agrícola. No se trata solo de un problema de relativa escasez de aguas, sino que además la mayor parte de las lluvias se produce durante el periodo de mayor rigor térmico, de noviembre a abril, de manera que no benefician la actividad biológica ni la fertilización del suelo (Junta de Castilla y León, 1988, p.23). Los potenciales aprovechamientos de pastos también se reducen ante la falta de lluvias. Dentro de la cuenca, la vega del Duero es una de las áreas relativamente más fértiles de la región. De manera que históricamente, "la vega ha estado más poblada, con una red de núcleos de mayor tamaño y más distanciados que la parte septentrional de sus respectivas provincias" (Junta de Castilla y León, 1988, p.11).
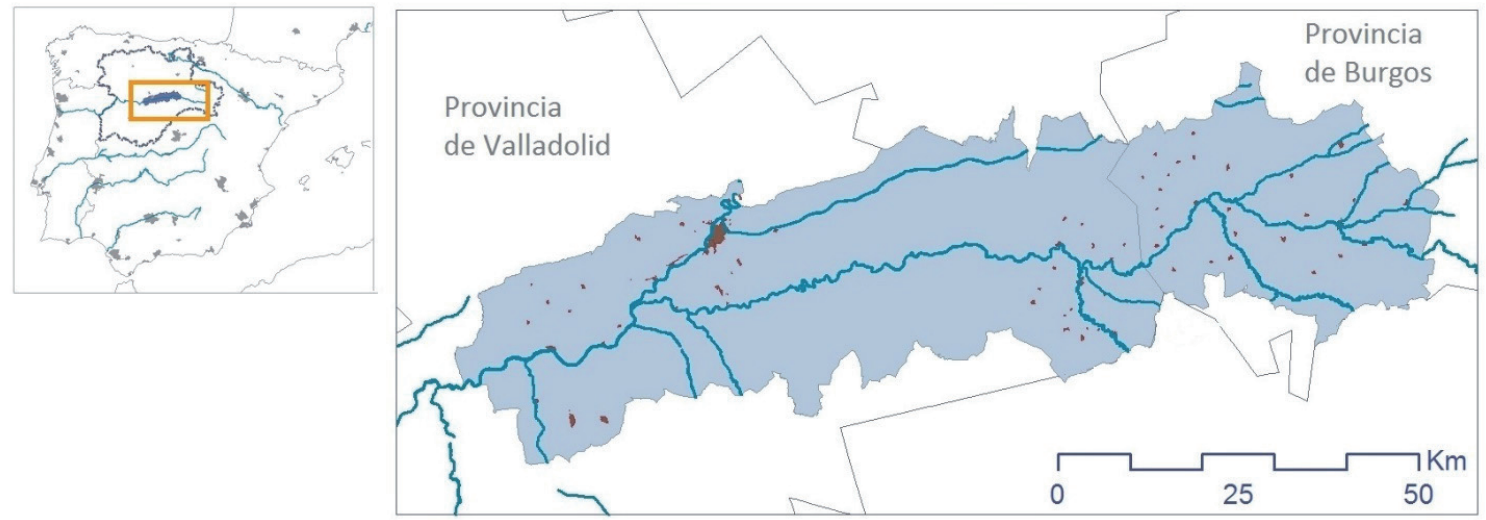

Figura 1. El tramo medio del valle del Duero (Castilla y León, España).

Fuente: Elaboración propia

El área objeto de estudio, que se muestra en la Figura 1, se extiende a lo largo de 130 kilómetros entre Aranda de Duero y Tordesillas. Dos nodos de actividad han condicionado la evolución de esta zona, crecientemente polarizada:

- Valladolid: capital de la Comunidad, importante enclave industrial y administrativo que aspira a integrarse en la jerarquía de urbes europeas,

- Aranda de Duero: polo industrial gracias a su posición estratégica en el eje de comunicación viaria N-S Madrid-País Vasco y en menor medida, E-O SoriaValladolid.

A la histórica mejor ubicación relativa de la vega, se le une su condición actual derivada de haber logrado posicionarse como uno de los territorios privilegiados por el tipo de producción en que se especializan. Alberga algunas de las regiones vinícolas más prestigiosas, que se extienden a lo largo del tramo medio del río Duero y que a lo largo de las últimas décadas, les ha ido proporcionando una marca 
de identidad incluso más allá de nuestras fronteras. Desde que en los años 1980 los vinos de la región recibieran la Denominación de Origen (Rueda en 1980, Ribera de Duero en 1982, Cigales en 1991 y Vinos de Calidad de Valtiendas en 2004), se han convertido en un sector estrella de la innovación, han transformado paisajes y estructuras y se ha multiplicado la superficie destinada a cultivos vinícolas. La zona incluida en estas denominaciones se pueden observar en la figura 2.

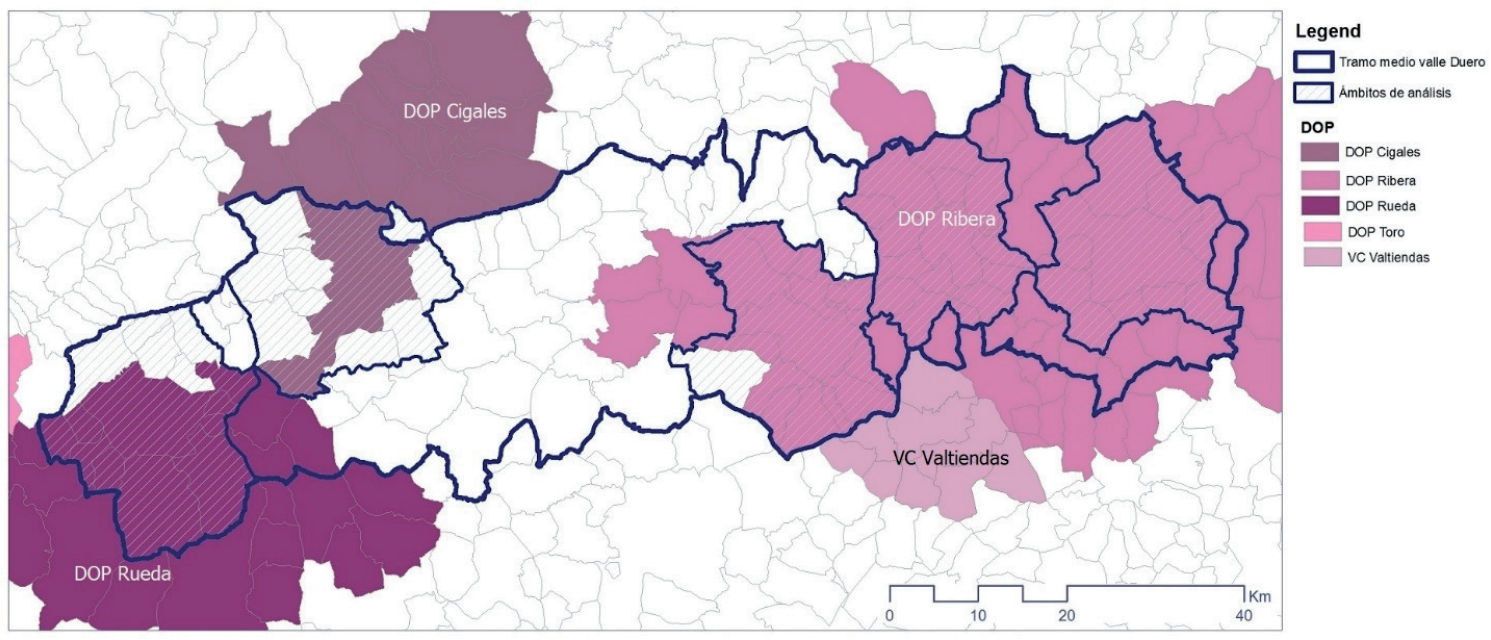

Figura 2. Zonas con DO o vinos de calidad

Fuente: Elaboración propia

\subsection{El reflejo en el paisaje de los cambios estructurales}

"Los cambios paisajísticos son indicadores de las dinámicas que subyacen a las transformaciones territoriales y económicas"(Busquets Fábregas, 2006, p.450). Un paseo por las tierras de la ribera del Duero permite reconocer cambios visibles. Las imágenes de la figura 3 muestran la evidencia material de las profundas transformaciones acaecidas:

- Las tipologías de vivienda y los sistemas constructivos adaptados a las condiciones climáticas y que se basaban en el empleo de los materiales disponibles en el entorno, dejan paso a nuevas arquitecturas indiferentes a las particularidades locales y donde se multiplican los materiales procedentes de áreas lejanas.

- La actividad productiva integrada en los núcleos deja paso a polígonos industriales aislados.

- El paisaje de cultivos locales como el viñedo, que se apoyan en mínimos equipamientos construidos con la misma tierra y perfectamente integrados en el conjunto, dejan paso a grandes instalaciones industriales con nuevos cultivos que se extienden simplificando paisajes y estructuras.

Las estructuras productivas de principios de siglo $X X$ se transformaron intencionadamente a través del desarrollo de planes y proyectos impulsados por las 
autoridades, que entendían que aquéllas no se adaptaban a las exigencias de la modernización. La década de los 1960 estuvo marcada por el éxodo rural, la industrialización y la acelerada urbanización. Se rompieron definitivamente las estructuras territoriales históricas. Sería importante "recuperar el contenido espacial y explícitamente ambiental en la narración histórica" para entender la coevolución de las relaciones sociedad-naturaleza (Mata Olmo, 2012).

Este documento es el resultado del estudio para intentar comprender los procesos que han alimentado estos cambios y para explorar cómo, desde el planeamiento, se podría contribuir a una regeneración agroecológica del territorio.


Figura 3. La materialidad de los cambios paisajísticos en el tramo medio del Valle del Duero Fuente: Archivo de la autora (2014) 


\subsection{Población. Polarización y declive}

En la figura 4 se muestra la evolución demográfica de la región estudiada a partir de las estadísticas de población municipal de las bases de datos del INE.

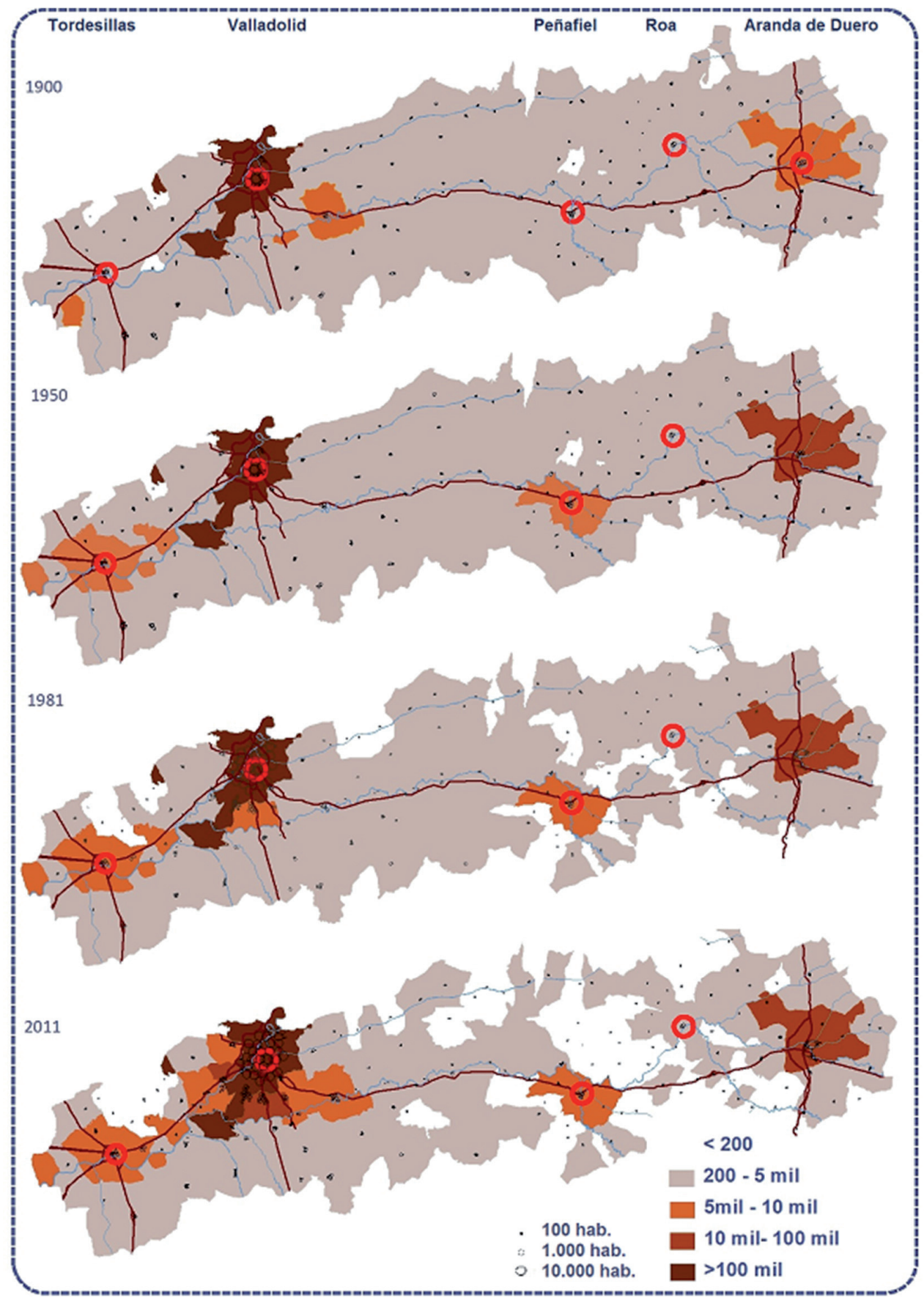

Figura 4. Evolución demográfica del Valle del Duero (1900-2011)

Fuente: Elaboración propia a partir de los censos de población del INE 
Los municipios con población superior a 5.000 habitantes aparecen en naranja, los de más de 10.000 en rojo y Valladolid, con más de 100.000 en granate. Aquellos con menos de 200 (considerado como el mínimo umbral a partir del cual la supervivencia del municipio empieza a estar seriamente comprometida) se dejan en blanco. En conjunto, se trata de un área de baja densidad poblacional, tenía 20 $\mathrm{hab} / \mathrm{km}^{2}$ en 1900 y alcanzó los 49 hab/ $\mathrm{km}^{2}$ en 1991, aunque el crecimiento se concentró casi por completo en Valladolid. Si esta ciudad se excluye del cómputo, tenemos una densidad casi estable de 13 hab $/ \mathrm{km}^{2}$ tanto en 1900 como en 1991 (aunque cambia la distribución entre municipios) y un moderado incremento desde entonces. En 1900 Valladolid acogía al 36\% de la población del ámbito analizado y llegó a albergar en el año 1991 al 74\%, mientras que en las últimas décadas los que crecen son los municipios aledaños a esta capital.

Como se puede observar, con un intervalo de unos $35-40 \mathrm{~km}$, se situaban a principios de siglo los centros comarcales de Aranda de Duero, Peñafiel y Tordesillas. Entre 1900 y 1950 hubo un cierto crecimiento demográfico distribuido por todos los municipios. Posteriormente llegó, de la mano de la mecanización agraria, la emigración rural hacia los centros industriales. En 1980 comienzan a ser significativos los "vacíos" territoriales; en 2005 es especialmente notable el vaciado demográfico entre Valladolid y Aranda, y es considerable el que se observa al norte de Tordesillas. El crecimiento de los núcleos más pujantes -en cierta medida Aranda, pero sobre todo la zona metropolitana de Valladolid- provoca una creciente polarización territorial.

Mirando a Tordesillas y sus casi 10.000 habitantes, Peñafiel, con poco más de 5.000 y Roa con apenas 2.500 , cabe preguntarse si las pequeñas ciudades a lo largo de este tramo del Duero podrían recuperar su capacidad de articular el territorio. En términos demográficos, la región objeto de estudio se enfrenta al reto de un desarrollo desigual. El campo se despuebla y es cada vez más dependiente de unas pocas ciudades que concentran el crecimiento y las funciones. Las propuestas institucionales a distintos niveles, desde la Unión Europea hasta los ayuntamientos, pasando por las Comunidades Autónomas, se esfuerzan por encontrar la manera de dinamizar las áreas rurales y promover un desarrollo más equilibrado. Esto implicaría -aunque no queda claro en qué medida- el aumento de población en los pequeños pueblos y ciudades.

\subsection{El sistema urbano, cuando la prioridad es no desaparecer}

Las primeras cifras globales apuntaban a que la región también estaba experimentando los procesos de expansión urbana descontrolada que tanto preocupaban en la Unión Europea. Analizando más en detalle el ámbito de estudio, se comprueba que, en términos cuantitativos, se trata de una zona todavía poco urbanizada, con menos de un $1 \%$ del territorio cubierto por usos urbanos, de los que el $37 \%$ corresponden a la ciudad de Valladolid. No estamos en las zonas centrales europeas profusamente urbanizadas, y a pesar de su impacto ecológico o de la poca justificación de unos crecimientos urbanos que no están apoyados en crecimiento demográfico, es difícil plantear la ocupación de suelo por usos urbanos como un grave problema en el área. Sí que se ha producido una transformación radical del modelo urbano y territorial que ha agudizado los conflictos espaciales en 
distintas escalas. El proceso implica una creciente dependencia y disparidad entre núcleos centrales y el resto del territorio; para los los pueblos de menor tamaño, la prioridad fundamental en la actualidad es no desaparecer.

Por su parte, las pequeñas ciudades intentan mantener su capacidad de atracción e influencia, incluso a costa del entorno rural. Intentan convertirse en centros de atracción de la población rural de los municipios aledaños. La estrategia adoptada se suele basar en ofertar suelo para nuevas tipologías residenciales y para atraer actividad industrial y económica. Un polinomio que buscaba aumentar el empleo y la población. Desde esa lógica se redactaron Planes de Ordenación Urbana en general expansivos. Incluso aquellos que en el contexto de crisis de los 1980, tenían un discurso de contención -como Aranda de Duero- planteaban duplicar su superficie. Las expectativas no se ajustaban a la realidad y solo una pequeña parte de los suelos propuestos se desarrollaron; otros lo hicieron mediante modificaciones puntuales. De esta manera en la región analizada según datos catastrales, en 2009 hasta un $40 \%$ de las parcelas del catastro urbano estaban constituidas por solares ${ }^{2}$.

En las últimas décadas ha habido un importante desarrollo de infraestructuras y, ligados a ellas, se han dispersado por el territorio áreas residenciales, equipamientos y zonas comerciales y de ocio. Continuó, por un lado, la expansión de construcciones fuera de ordenación en suelos no aptos para urbanizar y, por otro, el abandono y deterioro del patrimonio construido. Se trata de procesos que amenazan la vitalidad urbana y la cohesión social, que empobrecen la calidad espacial y menoscaban la identidad local, destruyendo paisajes y patrimonio natural y cultural, no solo en aquellas zonas que son urbanizadas o transformadas, sino también en los suelos aledaños que quedan bajo la influencia de lo urbano y sus infraestructuras.

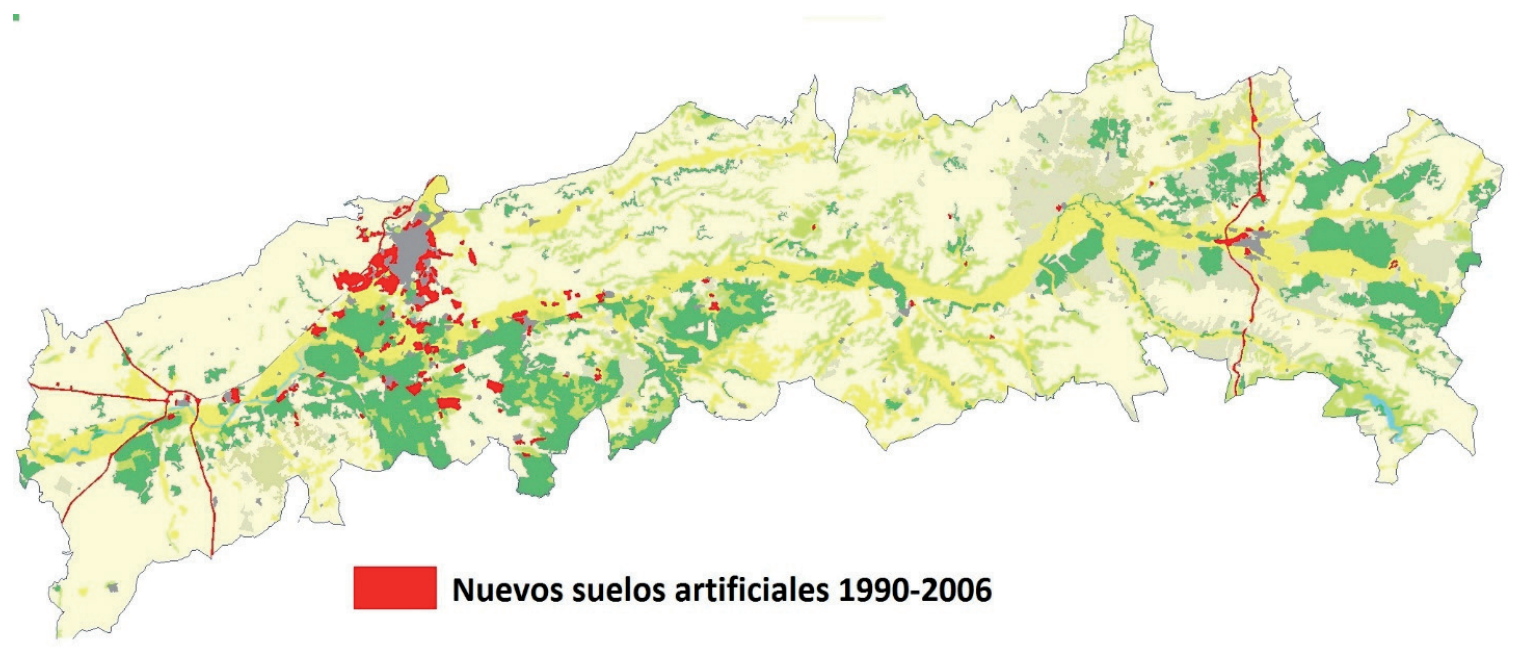

Figura 5. Nuevos suelos urbanos y artificiales según proyecto CLC 1990-2006 Fuente: Elaboración propia

\footnotetext{
2 En el catastro figuran como solares, terrenos que han sido clasificados como suelo urbano, aunque no cumplan la condición de solar de acuerdo a la legislación urbanística.
} 
El tejido urbano experimentó a su vez un cambio radical en ese mismo periodo. En 1990 el tejido urbano continuo ${ }^{3}$ constituía el 59\% de las zonas urbanas, mientras que entre 1990 y 2000 tan solo el $12 \%$ de las áreas urbanas desarrolladas se podían catagolar como tejido urbano continuo, y el $88 \%$ restante correspondía a tejido discontinuo (Simón Rojo, 2010).

\section{VARIABLES, INDICADORES Y ESCALAS DE ANÁLISIS}

\subsection{Acotación espacio-temporal de la investigación}

\section{Determinación de etapas históricas}

Para cumplir con los objetivos de la investigación, ésta debía abarcar un periodo suficiente de tiempo que incluyera diferentes etapas nutricionales de la población, que se pudieran relacionar con cambios estructurales en el sistema agroalimentario y con las transformaciones territoriales asociadas. A su vez debía ser un periodo suficientemente acotado y con una suficiente disponibilidad de datos que permitieran el análisis de esos cambios.

Las transformaciones se extienden a lo largo del tiempo y varían entre unos lugares y otros. Para acotar las etapas históricas que a nivel territorial se corresponden con las distintas fases nutricionales, se fijan tres momentos significativos en términos del paradigma de desarrollo vigente, pero no en el sentido de ofrecer una foto fija de ese año preciso y concreto.

El primer corte se sitúa en torno a 1950 y la etapa que se analiza comprende la primera mitad del siglo XX. Como señala Naredo (1995), hasta 1956 se puede hablar de agricultura tradicional y la sociedad sigue siendo considerablemente rural.

El segundo corte se sitúa en 1985. Engloba la mecanización agraria y la industrialización, el desarrollismo y el abandono de la vida en el campo. En esta época también el consumo de masas llega a la alimentación, induciendo nuevos patrones dietéticos y nuevas relaciones entre agricultura, alimentación y sociedad. El corte queda reforzado por dos hechos con influencia directa en los temas analizados, por un lado el ingreso de España en la Unión Europea de manera que pasa a ser la Política Agraria Común la que marque las lineas principales del sector y por otro, la aprobación de la Carta Europea de Ordenación del Territorio (1983) que por primera vez explicita objetivos de cohesión territorial, calidad de vida y gestión responsable de los recursos naturales encuadrándolos en el marco de la ordenación del territorio.

La tercera etapa se extiende hasta nuestros días y se toma como referencia el año 2015. Dentro de esta fase, la crisis de 2008 marca un hito que hace que en la actualidad se puedan identificar ya patrones de lo que podría ser una nueva etapa

\footnotetext{
3 La terminología del CORINE Land Cover distingue dos tipos de tejido urbano: continuo y discontinuo. El primero se refiere a áreas donde más del $80 \%$ del suelo está cubierto por superficies artificiales ( $y$ por tanto, está sellado), el segundo incluye zonas con vegetación o terreno sin pavimentar que ocupa una superficie considerable, aunque carezca de continuidad. Es decir la distinción se hace en función de la vegetación, no de la morfología urbana ni de la tipología edificatoria.
} 
en cuanto a esquemas nutricionales, sistemas agroalimentarios y organización de sociedad y territorio.

\section{Selección de los ámbitos territoriales. Aproximación multiescalar}

Para establecer las fechas de referencia, se recurre a tendencias de carácter global (nacional), pero a la hora de analizar el reflejo de esas tendencias desde lo territorial, se opta por abordar un ámbito más concreto y comprensible. Por la naturaleza de los cambios analizados, resulta pertinente centrarse en un territorio históricamente agrario, en una región del interior, menos afectada que las del litoral por dinámicas de crecimiento demográfico y económico ligadas a otros sectores.

Se elige una zona suficientemente extensa y con variedad de situaciones en su interior: el tramo medio del valle del Duero, que cubre los 130 kilómetros entre Todesillas y Aranda de Duero y abarca una extensión de unas 250 mil hectáreas. Se trata de una región que, en muchos sentidos, ha sido capaz de ligar su desarrollo a productos de la tierra. Entre ellos el vino, con sus distintas denominaciones de origen. Nótese que la escala regional no coincide con ninguna división administrativa ni se corresponde estrictamente con el concepto geográfico de región.

Estudios previos habían mostrado diferencias sustanciales en la evolución de municipios según su diferente tamaño demográfico (Simon Rojo y Hernández Aja, 2008). Es por tanto importante no detenerse en una visión global de la evolución de la región, sino descender a un análisis por ámbitos diferenciados. Aunque no exista una única escala adecuada para estudiar un sistema, no todas las escalas son igualmente útiles a todos los objetivos (Levin, 1992). La investigación se ha desarrollado en tres escalas regional, supramunicipal y municipal, con un mayor énfasis en las dos últimas.

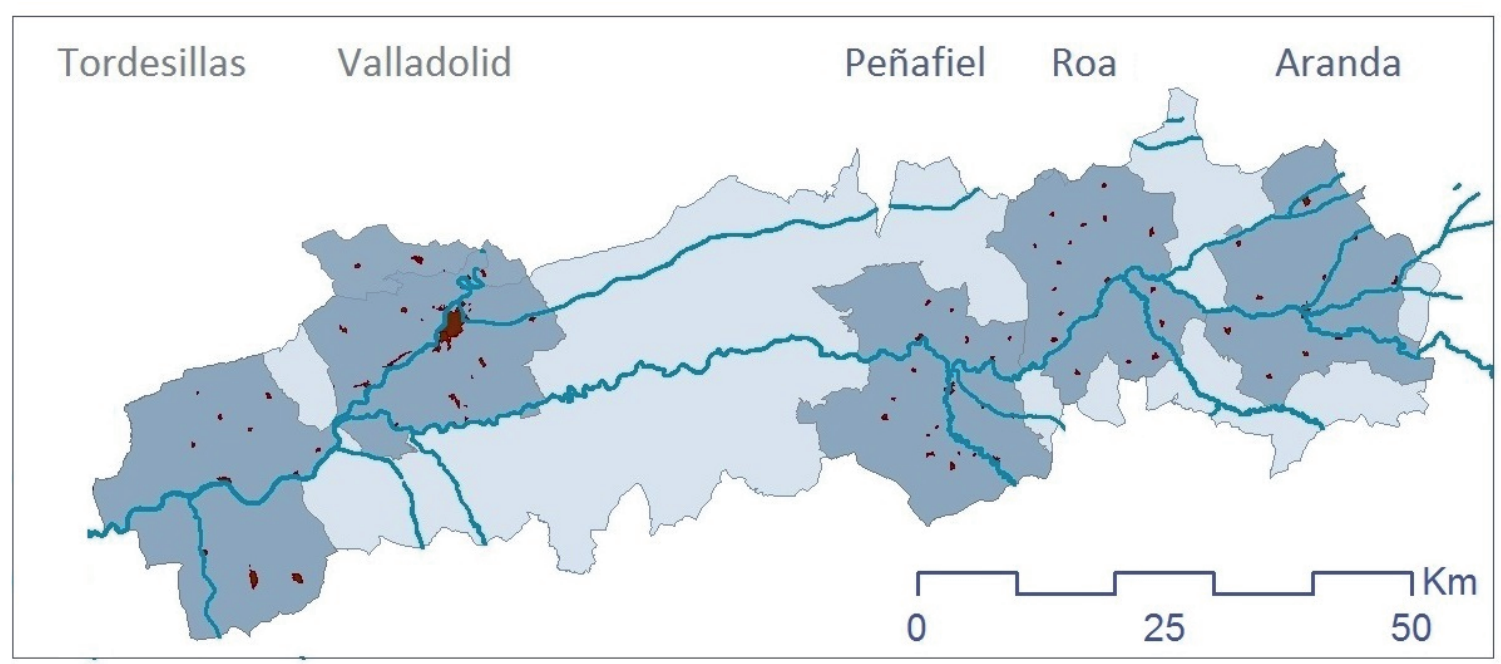

Figura 6. Análisis del sistema territorial. Ámbito supramunicipal Fuente: Elaboración propia 
Las zonas analizadas en la escala supramunicipal (asemejable a la escala comarcal, pero sin que coincida con la delimitación de comarcas) se indican en la figura 6 y abarcan un entorno de unos $10 \mathrm{~km}$. alrededor de los principales núcleos en el tramo considerado. Su disección permite identificar patrones en la evolución territorial.

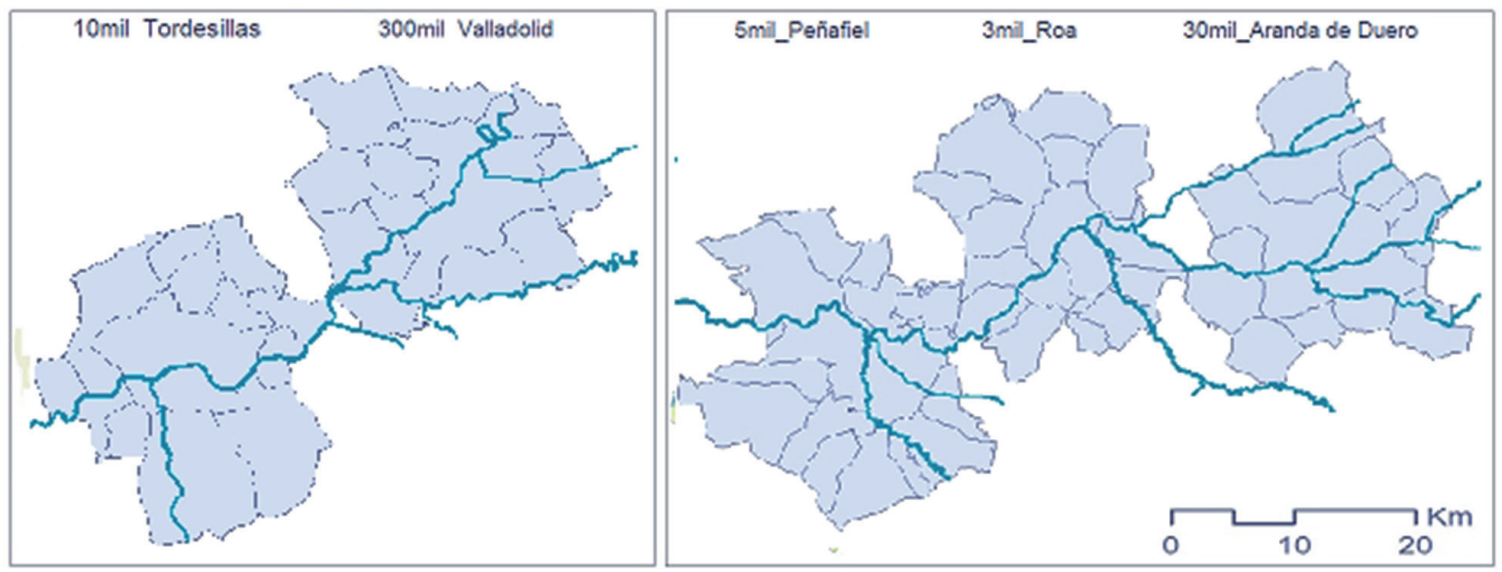

Figura 7. Análisis según tipología de municipios. Ámbito municipal Fuente: Elaboración propia

A nivel municipal se aporta una tipología de municipios y valora su distinta evolución, identificando patrones históricos preindustriales, patrones de la modernización y patrones actuales. Puesto que uno de los objetivos de la investigación consiste en discernir si la adaptación a las condiciones locales depende de la tipología del municipio, se han fijado rangos demográficos, considerando que esta es una variable relevante para entender la evolución del territorio. De todos los municipios incluidos en el territorio analizado, se seleccionan cinco: Aranda de Duero, Roa, Peñafiel, Valladolid y Tordesillas. Todos ellos han desempeñado en mayor o menor medida un papel articulador de su entorno inmediato y a su vez con ellos se cubre un amplio rango de situaciones desde un núcleo eminentemente rural (Roa) hasta una ciudad de tamaño medio (Valladolid):

- Rango 1 Valladolid 300.000 habitantes (306.830) ${ }^{4}$ (más muncipios limítrofes)

- Rango 2 Aranda de Duero 30.000 habitantes (33.065). (y municipios limítrofes)

- Rango 3 Tordesillas 10.000 habitantes (8.973) (más municipios limítrofres)

- Rango 4 Peñafiel 5.000 habitantes (5.428) (más municipios limítrofes)

- Rango 5 Roa 3.000 habitantes (2.443) (más municipios limítrofes)

\subsection{Obtención de datos}

\section{Mapas y cartografía}

A continuación se recogen las principales bases cartográficas utilizadas, con una breve valoración sobre su utilización en la investigación.

${ }^{4}$ Las cifras de población corresponden al Padrón Demográfico de 2014. Fuente: INE 


\section{- Cartografía básica histórica}

Para los análisis de la primera etapa (1950) se utiliza el Mapa Topográfico Nacional 1:50.000 del Instituto Geográfico Nacional (IGN) que en la zona de estudio se realizaron entre 1927 y 1935. De ellos se obtiene la información básica sobre usos de suelo y vías de comunicación. Para la segunda etapa (1985) se utiliza el Mapa Topográfico Nacional 1:25.000 realizado digitalmente a partir de 1985 por el IGN. De estos mapas se obtiene la información básica sobre vías de comunicación. No existe cartografía de la serie para Aranda de Duero y se recurre en ese caso a la cartografía del Ejército, a escala 1:50.000, pero la diferente escala hace poco viable la comparación. Para la tercera etapa (2010) se utiliza el Mapa Topográfico Nacional a 1:25.000 del IGN. De estos mapas se obtiene la información básica de las vías de comunicación.

\section{- Mapas sectoriales y bases de datos geoespaciales}

El Mapa de Clases Agrológicas editado por la Junta de Castilla y León, se usa como base de referencia para valorar la adecuación de los sucesivos cultivos o usos del suelo, a la capacidad productiva del mismo. Los Mapas de Cultivos y Aprovechamientos, de 1980-1990 del Ministerio de Agricultura, Pesca y Alimentación y de 2000-2009 del Ministerio de Medio Ambiente y Medio Rural y Marino resultan esenciales para ver la evolución de cultivos con carácter global aun siendo conscientes de que no reflejan fielmente la realidad. Aunque ambos están disponibles a escala 1:50.000, el nivel de precisión es mucho mayor en los mapas de la segunda serie. Se complementa con los sucesivos Inventario Forestal del Ministerio de Agricultura y Medio Ambiente, que ya cubre un periodo de 50 años (1965-2015). En los Mapas del Inventario Nacional de Erosión de Suelos a escala 1:50.000 se obtiene la información básica de los principales procesos de erosión del suelo en la región analizada. La base de datos europea de ocupación del suelo a escala 1:100.000 del proyecto del Corine Land Cover se utiliza para el análisis de la evolución de coberturas de suelo a escala regional, entre 1990 y 2006, con una versión no definitiva de 2012. La combinación de la cartografía vectorial con los datos catastrales de la Oficina Virtual de Catastro, disponibles para cada municipio ofrece información tanto sobre usos de suelo como sobre las edificaciones. Se utiliza el catastro de rústica y el catastro de urbana, ambos para fechar e identificar el tipo de edificaciones existentes en los ámbitos de estudio supramunicipales y cuantificar las mismas.

\section{Fotos aéreas y ortofotos}

Se completa la estructura parcelaria, la presencia de vegetación, las dimensiones de los núcleos y la existencia de edificaciones en suelo rústico mediante el estudio del vuelo americano de 1956 georreferenciado, que está disponible en el servidor ftp del Instituto Tecnológico Agrario de Castilla y León (ITACYL). También están disponibles la mayoría de las ortofotos del vuelo del IRYDA entre 1977 y 1983. En los casos en que no es posible la descarga del archivo, se consulta la ortofoto correspondiente, bien procedente del IRYDA, bien del vuelo interministerial de 1986, a través de la Fototeca Digital del IGN. En la tercera etapa se trabaja sobre las 
ortofotos del Plan Nacional de Ortofotografía Aérea (PNOA) de 2010 a 2014, según disponibilidad.

\section{Datos estadísticos}

Se han utilizado los censos de población desde 1900, para obtener datos sobre la evolución demográfica de la población en los municipios de la región analizada. Sin embargo, el análisis de la evolución de la vivienda en términos estadísticos censales, no se puede remontar hasta principios de siglo, pues el primer Censo de Población y Vivienda data de 1991. A partir de esa fecha (es decir en la tercera etapa) se puede analizar la relación entre tipo de vivienda, régimen de tenencia y uso. De las épocas previas se pueden extraer algunas conclusiones basadas en estimaciones y en algún caso, en información aportada en los planes municipales de ordenación urbanística.

Los datos sobre las explotaciones, superficie, régimen de tenencia, mecanización y mano de obra se extraen de los censos agrarios elaborados por el Instituto Nacional de Estadística. El de 1962, que es el primero disponible, se utiliza para la primera etapa; el análisis de la segunda etapa se hace a partir del censo de 1982 y para la tercera se emplea el censo agrario de 2009. La información recogida ha ido variando entre censos, por ejemplo en el de 1962 se cuenta con un análisis de maquinaria disponible y de ganado de labor. Cuando es posible se trabaja con datos desagregados a nivel municipal, pero para muchas de las variables únicamente se cuenta con datos a nivel provincial.

En cuanto a la productividad y el comercio, se recurre a los Anuarios Estadísticos históricos y actuales, del Instituto Nacional de Estadística, que ofrecen datos de superficies y producción para distintos cultivos y alimentos. De ellos también se extraen los datos de las balanzas comerciales, desglosados por grupos de alimentos. Para disponer de información más específica sobre actividad empresarial se recurre a las páginas web con directorios empresariales como informa, y los de las Diputaciones Provinciales.

\section{Planes de ordenación}

A través de los vigentes Planes Municipales de Ordenación Urbanística, disponibles en el Archivo de Planeamiento Urbanístico y Ordenación del Territorio de Castilla y León, se obtiene información cualitativa y cuantitativa sobre los desarrollos urbanísticos, las delimitaciones de cada clase de suelo y su regulación. Resulta especialmente interesante comparar las previsiones con lo ejecutado en la realidad. También permiten conocer las propuestas de ordenación del territorio y la consideración que merecían los distintos suelos no urbanizables.

Los planes históricos que no están cargados en el servidor se han consultado en el Archivo Histórico de Valladolid o en los respectivos ayuntamientos (Peñafiel, Aranda de Duero).

El Plan Regional de Ámbito Territorial del Valle del Duero y Plan Regional del Canal de Castilla son una valiosa fuente de información y datos, tanto por los apartados de información que acompañan a los documentos, como por lo que tienen 
de reflejo del modelo territorial en cuanto al tratamiento de los distintos sistemas y suelos. Lo mismo sucede con otros documentos de carácter territorial, que también han sido analizados: las Directrices de Ordenación Territorial de Valladolid y su Entorno (el documento de 2000 y su revisión) o las Directrices de Aranda de Duero y su entorno.

Los planes sectoriales que se han analizado son el Plan de Carreteras, el Plan Hidrológico de la Confederación Hidrográfica del Duero de 2009 y la Propuesta 2015-2020, así como los Planes de Ordenación de Recursos Naturales.

Los Planes de Concentración Parcelaria también se han descargado del ITACYL y aportan información sobre el estado de ejecución y la superficie afectada por cada plan.

\section{Otras fuentes}

El Modelo Digital del Terreno del IGN se utiliza para obtener el mapa de pendientes. El Diccionario geográfico-estadístico-histórico de España (Madoz, 1849) aporta información sobre usos preindustriales en cada municipio, así como el tipo de equipamientos, industrias y comercios existentes en cada municipio

\subsection{Selección de factores y definición de indicadores}

El análisis de la evolución territorial se realiza a partir de la selección de factores clave. Para cada uno de ellos se fijan las variables relevantes a estudiar y se definen una serie de indicadores que permiten rastrear los cambios en las distintas escalas.

\section{Población. Intensidad demográfica}

Se fijan cuatro umbrales de población que permiten establecer cinco rangos demográficos: 0 a 200, 200 a 3mil, 3 mil a 10 mil, 10 mil a 100 mil y más de 100 mil. Se clasifican a su vez las poblaciones según su evolución demográfica en términos cuantitativos, fijándose cinco umbrales y seis rangos en función de la tasa de crecimiento:

- Crecimiento demográfico negativo: pérdida de población mayor del $50 \%$, de 50 a $10 \%$, de 10 a $0 \%$

- Crecimiento demográfico positivo: aumento de 0 a $50 \%$, de 50 a $100 \%$ y superior al $100 \%$.

\section{Ocupación de suelo por usos urbano-artificiales. Intensidad edificatoria}

La intensidad edificatoria se evalúa en dos espacios diferenciados, el urbano y el rural. Por lo que se refiere a los núcleos de población se consideran dos indicadores: 
- Consumo de suelo por habitante: medido en $\mathrm{m}^{2}$ suelo urbano/hab y teniendo en cuenta no el suelo clasificado como urbano, sino únicamente el que ha sido desarrollado.

- Grado de dispersión los núcleos de población: $D_{x}$, dispersión o desparrame del suelo urbano, expresa la relación entre el perímetro de un núcleo y el perímetro que tendría en el caso de mayor compacidad posible, es decir de una circunferencia de igual superficie a la del núcleo en cuestión. La expresión matemática es:

$$
D_{x}=P_{x} / P_{e q}(3.1)
$$

donde $\mathrm{P}_{x}$ es el perímetro del núcleo $\mathrm{x}$ analizado y $\mathrm{P}_{\text {eq }}$ es el perímetro equivalente, calculado así:

$$
P_{e q}=2 \Pi r_{e q}(3.2)
$$

el radio equivalente $r_{e q}$ se calcula:

$$
r_{e q}=\left(\mathrm{s} / S_{x}\right)^{1 / 2}(3.3)
$$

donde $S_{x}$ es la superficie real del núcleo $x$.

\section{Instalaciones, infraestructuras e intensidad de la explotación}

Se utilizan dos variables fundamentales para explicar las diferencias en cuanto al aprovechamiento de recursos locales según municipios. La primera se refiere a la intensidad de los usos implantados que, al relacionarlos con las características agrológicas del lugar permiten reconocer la adecuación agrológica de los usos, lo que sirve como primera aproximación al grado de sobreexplotación de los recursos primarios del término. La segunda variable se refiere a la intensidad de infraestructuras y edificatoria, que se emplean como proxy sobre si los recursos que se explotan se aprovechan directamente en la propia comunidad. Para el primer indicador, se analiza la superficie de suelo destinada a cada uso. Desde un punto de vista ecológico, no se debería limitar a la cobertura, pues tanto o más importante que ésta es el tipo de prácticas de manejo agrario. En la medida de lo posible se tiene en cuenta este manejo agrario, interpretado a partir de la revisión de documentos que lo abordan.

\section{Adecuación agrológica. Aprovechamiento de recursos locales}

Para valorar la adecuación agrológica se comparan dos variables, por un lado la calidad agrológica del suelo según el Mapa elaborado por la Junta de Castilla y León y por otro el tipo de uso y cultivo. Respecto a la primera variable, el propio Mapa Agrológico establece siete clases:

- Clase I. Cultivable. Suelos con alta productividad (inexistentes en Castilla y León por el clima riguroso)

- Clase II. Cultivable con alguna limitación. Restringe la gama de plantas cultivables o necesitan prácticas de conservación moderadas 
- Clase III. Cultivable con limitaciones. Limitaciones más severas que en las clase II Terrenos aptos para cultivo pero con severas limitaciones

- Clase IV Cultivable con limitaciones. Solo apto para dos o tres especies y con rendimientos bajos y/o requiere un manejo muy cuidadoso

- Clases II-IV, IV-III y IV-VI Cultivable con limitaciones. Terrenos no aptos para el cultivo

- Clase V. No cultivable. Restringida su explotación al aprovechamiento de pastos, bosques o reserva natural

- Clase VI y VII. No cultivable. Limitaciones que obligan a explotarlos para pastos y bosques o como reserva natural. En la clase VI es posible la mejora de pastos mediante siembra, encalado, fertilización, drenaje, etc.

- Clase VIII. Solo se puede destinar a recreo, reserva natural, abastecimiento de agua o fines estéticos (inexistente en el ámbito analizado)

Si bien se trata de un enfoque productivista y la clasificación se plantea exclusivamente en términos del suelo como recurso para explotación, se considera una clasficación apropiada a los fines de la investigación. Las clases agrológicas II, III y II-III se agrupan en la categoría $p C$ potencial Cultivo, por su mayor potencial como superficie Cultivable. Las clases III-IV y IV se agrupan en $p M$, potencial Medio, con suelos cultivables pero con limitaciones considerables.

Por último las clases V, VI y VII se consideran como $p N$, potencial Natural es decir suelos no aptos para su explotación agrícola que son adecuados para bosques o reserva natural.

La superposición del uso de suelo con la clasificación agrológica permite categorizar las zonas según la adecuación del uso a las características del suelo. En el cuadro queda representada la correlación entre capacidad agrológica del suelo y destino del mismo. Las celdas sombreadas en marrón son aquellas en las que el desajuste entre ambos parametros es máximo, porque se está cultivando en zonas inadecuadas que deberían destinarse a espacios semi-naturales o forestales. En el otro extremo, las celdas sombreadas en verde incluyen áreas donde la intensidad del uso es inferior a su potencial desde un punto de vista agrológicio, por ejemplo donde los espacios más fértiles no se dedican a labor sino que son ocupados por matorral o especies forestales. En las celdas sombreadas en gris sí que hay una adecuación entre capacidad agrológica y destino del suelo.

Por último se asignan valores a cada tipo de relación uso-capacidad, de manera que se obtiene una reclasificación de las zonas en función de la adecuación entre explotación y capacidad de los suelos.

- Equilibrio 0: Reducida diferencia entre explotación y capacidad. Se distingue entre 0c suelos cultivables y On suelos no cultivables

- Presión 1: La intensidad explotadora es superior a la que corresponde por la capacidad agrológica del suelo. 1C cuando esta presión proviene de la existencia de cultivos de labor o regadíos, $1 \mathrm{M}$ cuando se debe a cultivos menos intensivos (viñedo, pastos) 
- Presión 2C: La intensidad explotadora es todavía superior, en este caso se debe a la existencia de cultivos de labor o regadío en suelos cultivables con serias limitaciones o directamente en suelos no cultivables

- Infraexplotación: Los usos suponen una explotación productiva inferior a la que sería posible por la capacidad agrológica del suelo. En el caso de suelos cultivables destinados a matorral o bosques no maderables el valor alcanza $-2 \mathrm{~N}$, cuando se emplea para viñedos o pastos es -1M. En suelos cultivables con limitaciones donde se desarrollan pastos o bosques la infraexplotación se le asigna un valor $-1 \mathrm{M}$ y $-1 \mathrm{~N}$ respectivamente.

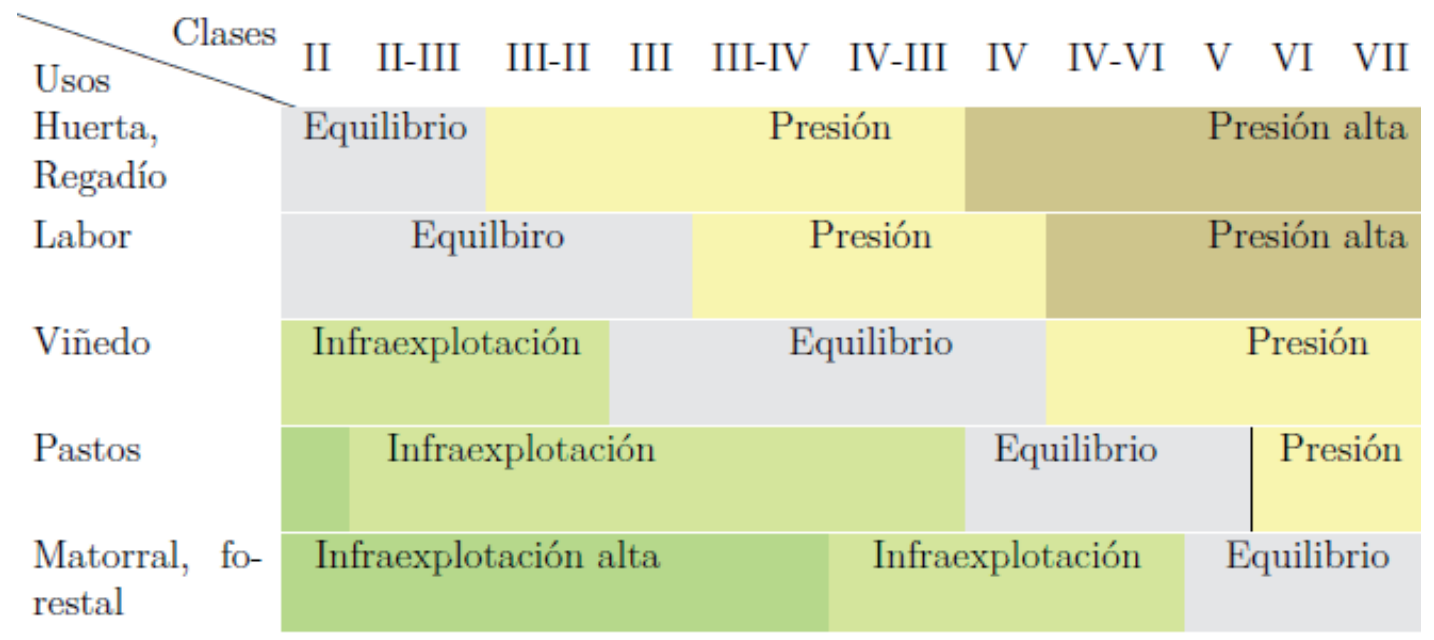

Figura 8. Reclasificación de valores Usos-capacidad agrológica

Fuente: Elaboración propia

El indicador de adecuación agrológica se aplica en los análisis a escala supramunicipal y muncipal, en las tres épocas consideradas, permitiendo de esta manera comprobar si se ha producido una intensificación sobreexplotadora, o una pérdida de aprovechamiento de potencial agrológico a lo largo del tiempo.

\section{Accesibilidad y conectividad. Intensidad de infraestructuras}

Otro de los aspectos considerados para identificar unidades territoriales, se refiere al nivel de cobertura de la red viaria, que permite distinguir zonas por un lado en función de su accesibilidad local, a través de caminos o carreteras locales y por otro según su conectividad hacia otros territorios a través de carreteras de rango superior. Se caracterizar el territorio desde el punto de vista de la red viaria, según las condiciones de accesibilidad (a) y conectividad (c). Se diferencian dos grandes niveles jerárquicos: local (que prima la accesibilidad intraterritorial) y general (que prima la conectividad interterritorial). En primer lugar se asocia la función primordial de cada viario a una u otra función, conforme a la jerarquía del mismo. Para ello se trabaja sobre la base topográfica de Castilla y León escala 1:10.000. Puesto que el trazado de la red carece de continuidad y cada camino o carretera está 
descompuesto en múltiples tramos, se prepara la base previamente a la aplicación de las herramientas de análisis espacial.

\section{- Accesibilidad intraterritorial}

La accesibilidad intraterritorial parte del análisis de la red de caminos, sendas y vías pecuarias, que cubren el territorio facilitando el acceso desde parámetros de proximidad. Si bien en su origen las vías pecuarias eran claramente una red interterritorial, que atravesaba la península para la trashumancia, en el siglo XX ya habían perdido ese carácter. En la primera mitad del siglo serían asimilables a caminos, en ocasiones singulares, por sus dimensiones. Desde hace un par de décadas algunas cumplen funciones de conexión interterritorial ligada a ocio, que no se considera asimilable a la de las carreteras para tráfico motorizado de mayor velocidad. La caracterización de un área en términos de accesibilidad se basa en el grado de cobertura de la red local en dicha zona. Para el cálculo de esos valores se aplica la herramienta densidad de líneas de Arcgis, según la fórmula:

$$
V \text { axr }=\Sigma\left(L_{n} X P_{n} / \Pi r^{2}\right)(3.4)
$$

Para cada celda se establece un radio de influencia. La densidad de líneas se obtiene para cada celda a partir del cálculo en un radio de influencia fijado previamente, de la suma de las longitudes viarias multiplicadas por el rango jerárquico repectivo de cada vía, dividido por la superficie del círculo. Se toma como radio $500 \mathrm{~m}$ y los valores de jerarquía que se establecen son:

- Vías pecuarias y caminos. Valor de accesibildad: 3

- Sendas. Valor de accesibilidad: 1

No se consideran necesario cálculos de densidad más complejos, como el método Kernel, que aplica una función de densidad en función de las condiciones en torno a los valores muestrales sin seguir un modelo conocido (Normal, Binomial, Exponencial, etc). Los resultados se pueden corregir en función de la existencia de barreras como ríos o cuestas.

\section{- Conectividad interterritorial}

La mayor o menor conectividad entre territorios viene dada por la posibilidad de acceder a una vía de comunicación que discurre hacia otros lugares. Para su análisis se tienen en cuenta las carreteras comarcales, regionales, nacionales e internacionales. Se elabora una red topológica de nodos y enlaces. Los nodos son aquellos puntos de confluencia de carreteras y los enlaces las vías que unen nodos. Normalmente en el caso objeto de estudio, los nodos corresponden a núcleos de población, aunque también se grafían los puntos donde confluye la red de carreteras comarcales o donde dos carreteras se cruzan. Mención aparte merece la red ferroviaria, que se explicará más adelante. El valor "n "asignado a cada nodo es función de los enlaces con los que cuenta y depende a su vez del nivel jerárquico de la vía que confluye en el nodo, según se recoge en el cuadro anterior. 


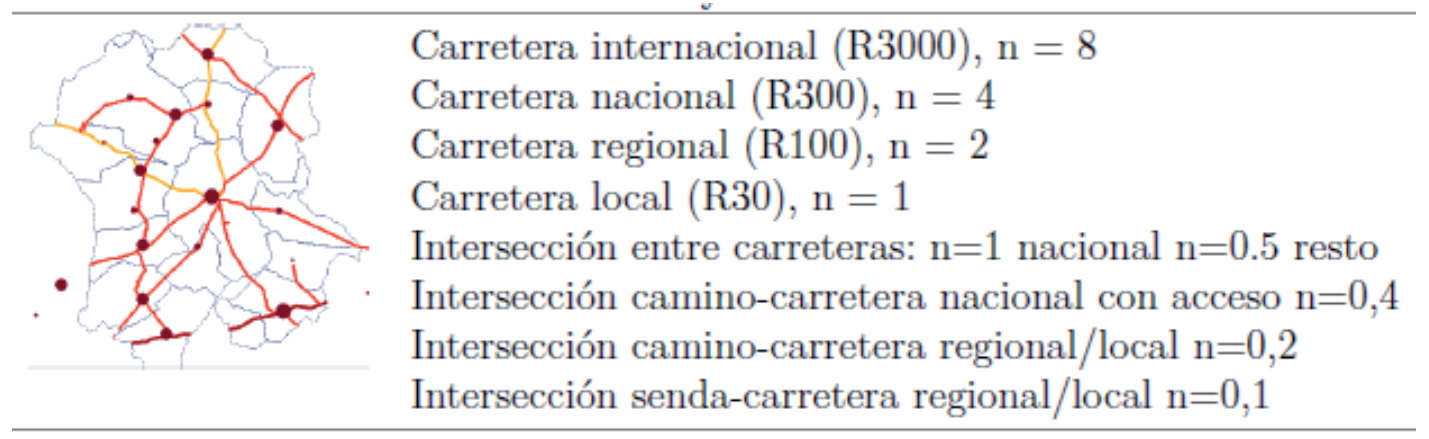

Figura 9. Red de nodos y enlaces. Valores de cálculo para Roa (Burgos)

Fuente: Elaboración propia

Una vez que se tiene el mapa con los nodos y sus valores en función de los enlaces, se aplica una interpolación mediante la técnica de distancia inversa ponderada (IDW en Arcgis) considerando un radio de 500 metros. En el caso del acceso a carreteras desde caminos, o de intersecciones de carreteras, la carretera se considera una barrera de cara a la interpolación, pues el territorio que aumenta su conectividad solo será aquel situado en el margen de la carretera donde está el camino. Suma de nodos y acceso a carreteras en su trayecto. Finalmente se definen los valores de la red viaria que permiten identificar unidades territoriales, es decir zonas homogéneas según la confluencia de valores altos, medios o bajos de accesibilidad y conectividad.

\section{LA HUELLA EN EL TERRITORIO DEL SISTEMA AGROALIMENTARIO}

\subsection{Caracterización socioeconómica de las tres fases del sistema agroalimentario en el siglo XX}

El análisis adopta los grandes periodos en cuanto a la dieta y la actividad física definidos por Popkin (1997). La categorización de Popkin está planteada desde las ciencias de la salud, y relaciona la transición nutricional con la demográfica y la epidemiológica: 1) recolectores, 2) hambruna, 3) superación de la desnutrición, 4) sobreabundancia y 5) cambio de comportamiento.

En el siglo XX se han sucedido las tres últimas fases, que son las que se analizan en la investigación. El "cambio profundo en los sistemas alimentarios" es una de las manifestaciones más evidentes del desarrollo económico del siglo XX (Cussó Segura y Garrabou Segura, 2010, p.70). Durante la etapa de superación de la desnutrición se logró mejorar la ingesta sustancialmente y aunque todavía persistieron ciertos niveles de anemia, fue clave para lograr una lenta reducción de la tasa de mortalidad.

En la fase de sobreabundancia coinciden un aumento de grasa, azúcares y alimentos procesados y una reducción en los patrones de actividad, marcados por un creciente sedentarismo, con la emergencia de enfermedades degenerativas; aun así el aumento en la esperanza de vida es notorio. 
En la última fase, de segmentación del consumo y cambio de comportamiento ante los problemas de salud provocados por el modelo anterior, comienzan a revertirse las tendencias, reduciéndose al menos para una parte de la población el consumo de grasas en favor de más frutas, verduras y fibra, además de niveles más altos de actividad física.

Para demostrar que la organización territorial refleja sucesivamente los tres modelos del sistema agroalimentario asociados a las tres etapas nutricionales, se han caracterizado en primer lugar dichos sistemas, según las variables socioeconómicas de explotación agraria, producción, distribución y consumo de alimentos. Esta caracterización se aplica de modo general para el conjunto del estado español, que se matiza en la medida de lo posible para la región de estudio. Las principales fuentes de verificación proceden del análisis documental de otras investigaciones e informes. Hay una considerable equivalencia entre fase nutricional, modelo agrario y sistema agroalimentario:

- La fase de superación de la desnutrición se corresponde con un modelo de agricultura familiar con altos niveles de autoabastecimiento.

- La fase de sobreabundancia se corresponde con un modelo agroindustrial orientado al consumo de masas.

- La fase de cambio de comportamiento se corresponde con un modelo agrario terciarizado y un consumo segmentado.

\section{0: Sistema agrario para la subsistencia}

\section{- Nutrición}

En esta primera fase, de superación de la desnutrición ${ }^{5}$, el sistema agroalimentario se fundamentaba en el sector agrícola, que producía los alimentos prácticamente en el formato en que se consumían. La base de la dieta (el $64 \%$ del total) la constituían los hidratos de carbono complejos y la fibra (cereales, patatas y legumbres), que aportaban además el $70 \%$ de las proteínas. Con una ingesta calórica media de unas 2.500 kilocalorías al día, valor próximo al mínimo necesario para la supervivencia en la época, los niveles de alimentación eran bastante bajos en términos de nutrientes esenciales, proteínas y calorías, con grandes diferencias en función de la renta y de la clase social (Simpson, 1989; Cussó Segura y Garrabou Segura, 2010; Collantes, 2009). El incremento en la producción y en la alimentación se tradujo en mejoras en los niveles de alimentación y en la esperanza de vida (Guijarro Garvi y Peláez Herreros, 2009, p.196).

\section{- Regulación}

Hay un marcado proteccionismo frente a la producción exterior, que se carga con aranceles y se limita con cuotas. El intervencionismo estatal continúa tras la Guerra Civil con un sistema de precios regulados y el monopolio de la producción

5 Correspondiente a la tercera en la escala de las sucesivas transiciones nutricionales de Popkin (1997). 
triguera para garantizar un pan barato en tiempos de gran escasez material (Barciela López y López Ortiz, 2003). La ordenación del territorio se plantea desde premisas económicas y con un enfoque sectorial: colonización y desarrollo de infraestructuras de comunicación y también de regadío (Abad Balboa y col., 1994).

\section{- Producción}

Los sistemas agrarios eran poco intensivos y el incremento de la producción se logró a base de extender los campos de cultivos, muchas veces en tierras poco adecuadas. Con la agricolización, es decir la extensión de cultivos agrícolas por áreas previamente ocupadas por sistemas silvícolas o semi-naturales, se debilitaron los sistemas agrosilvopastorales con los que antes (hasta el siglo XVIII) se había gestionado de manera integral el territorio (Garrabou Segura y Sanz Fernández, 1985; Tello Aragay, 2006). La economía natural agraria era capaz de producir ciertos excedentes y de reponer la mayor parte de las materias primas empleadas en el proceso productivo(Naredo, 1996). Cada zona se especializa según sus ventajas comparativas (González de Molina, 1996), que son el cereal y el vino en el caso del tramo del valle del Duero analizado. Al finalizar la Guerra Civil, con el aislamiento, se llega a un alto nivel de autosuficiencia alimentaria. La producción permite cubrir la práctica totalidad de los alimentos consumidos en el país (más del $95 \%$ ) cifra que sería incluso superior si se incluyera la producción que no se canaliza a través del mercado y que por tanto no queda registrada en las balanzas contables. El balance comercial del Estado solo arroja valores negativos en los cereales y en la carne.

\section{- Procesado y distribución}

La agricultura de proximidad y los mercados locales juegan un papel esencial en el abastecimiento de alimentos, que fundamentalmente opera a pequeña escala. La gran mayoría del procesado de alimentos se realiza en el ámbito del hogar, especialmente si nos referimos a un entorno rural. La parte de la producción que se destina al mercado se distribuye en buena medida de manera "artesanal", con portes de reducidas dimensiones por la provincia y espacios aledaños, como los carreteros que llevaban vino a Santander y traían a la vuelta las carretas cargadas con pescado. El transporte por ferrocarril fue clave para ampliar el alcance de la distribución a nuevos mercados. Con la llegada del tren en el siglo XIX, Valladolid se constituyó en un enclave estratégico para la comercialización del cereal. Después, durante la primera mitad del siglo XX recuperó protagonismo el transporte por carretera, ya motorizado (Frax y Madrazo, 2001; Barreiro Gil, 2009).

\section{- Consumo}

El abastecimiento se realizaba fundamentalmente a partir de la agricultura local. Se había producido ya una especialización productiva orientada a los mercados urbanos $y$, en menor medida, internacionales, pero el grueso de la alimentación en el mundo rural se satisfacía mediante la autoproducción. Las familias agrarias combinaban autoabastecimiento con mercado, de manera que los cultivos 
principales se complementaban con huertos para autoconsumo y pequeños animales (gallinas, conejos, etc) que se mantenían al interior o en el borde de los núcleos. Como fuente de aprovisionamiento, los linderos de las parcelas de cultivo jugaban un papel fundamental en la diversificación de la dieta y en el mantenimiento de biodiversidad, tanto por la existencia de algunos frutales como por su vegetación, que era el hábitat de especies de caza menor (perdices, zorzales, etc) y según el caso, algo de pesca (trucha, barbo, etc). El alto nivel de autoabastecimiento se fue reduciendo, de manera que en 1950 las familias tenían que destinar en torno al $60 \%$ de los ingresos a la compra de alimentos.

\section{- Explotación}

Perviven las pequeñas explotaciones familiares en una sociedad que sigue siendo eminentemente agraria. En la región conservan mayoritariamente la propiedad de la tierra y los medios de producción. Funcionan a través del pleno empleo de la mano de obra familiar y sin seguir una lógica capitalista (Naredo, 1996). Destaca el pequeño tamaño de las parcelas, con un 74\% de las mismas por debajo de una hectárea en la parte vallisoletana y un $97 \%$ en la zona burgalesa. Una misma explotación suele tener varias parcelas repartidas por el territorio, el modelo de explotación intensiva en mano de obra se adapta a esa situación, pues las distintas parcelas se trabajan en distintas jornadas y se accede a ellas a pie o a lomos de un animal.

\section{5: Sistema agroindustrial para el consumo de masas}

\section{- Nutrición}

Con el desarrollo económico y el aumento de los niveles de ingreso se generaliza el consumo de carne y se diversifica la dieta, que dejó de estar basada en hidratos de carbono complejos, al ser sustituidos éstos por alimentos de origen animal, grasas y azúcares (Cussó Segura y Garrabou Segura, 2007; Collantes, 2009). El consumo medio de leche y fruta se duplica entre 1955 y 1980 (de 58 a 104 litros y de 67 a 144 kilos por habitante y año) y el de carne casi se quintuplica (de 14 a 69 kilogramos por habitante y año) (Barciela López y col., 2005). No solo hay cambios en la composición de la dieta, también aumenta sustancialmente el consumo de calorías y proteínas. En 1982 la ingesta calórica media se sitúa en 3.007 kilocalorías por persona y día, lo que supone un aumento del 20\% respecto a 1950 (Cussó Segura, 2005). Con la sobrealimentación se empiezan a vislumbrar problemas de salud ligados al sobrepeso.

\section{- Regulación}

En un contexto en el que se da prioridad a la industria, las políticas van encaminadas a favorecer su inserción en un sistema agroalimentario industrializado. Esto implica la mecanización de las explotaciones, alentada desde las instancias públicas (Naredo, 1996) y una transformación profunda de todo el proceso productivo: la actividad en la explotación se incardina con las industrias de suministro de maquinaria e insumos y a su vez la industria alimentaria se convierte en el destino de su producción. De hecho, los subsidios transferidos a 
los agricultores a través de las subvenciones, se orientaron fundamentalmente (entre el 60 y el $75 \%$ ) a cubrir los gastos derivados del uso de insumos externos (combustible, semillas y abonos) (Fernández García, 2008). No solo se aplicaron políticas estructurales, además la regulación se llevó a cabo aplicando precios de garantía. Algunos productos continuaron estando regulados. Es el caso del trigo, que funcionó en régimen de monopolio estatal hasta 1984 (Briz Escribano, 1985). A su vez se fomentó la producción ganadera y la reestructuración de algunos sectores, como el vitivinícola (en este caso animando al arranque de cepas) y el remolachero. Las políticas de colonización y de concentración parcelaria iban encaminadas a facilitar la implantación de los nuevos sistemas de explotación industrializados. En el área analizada, los procesos de concentración afectaron al $75 \%$ de los municipios, lo cual da una idea de la envergadura que adquirieron estas políticas, especialmente relevantes en el caso de Castilla y León. En la misma línea de favorecer la adaptación a los nuevos requerimientos productivos se implantaron los Servicios de Extensión Agraria, que además de otras medidas formativas, impulsaron el cooperativismo como vía de mejorar el posicionamiento de las pequeñas unidades de explotación de cara a la mecanización y al acceso a los mercados (Gómez Benito y Luque Pulgar, 2007).

\section{- Producción}

La zona de estudio refleja claramente el declive del viñedo sustituido por otros cultivos más rentables -los cereales- y cómo, con el despliegue del regadío, se extienden cultivos industriales, en este caso principalmente la remolacha azucarera. En cuanto a la ganadería, los rebaños de ovino que pastaban en las tierras de barbecho y en los montes, dejaron paso a una cabaña porcina y vacuna estabulada y alimentada por piensos, en buena medida importados. En conjunto, el país agudiza su dependencia de las importaciones de cereales forrajeros y también de carne, pues a pesar del aumento de la producción interna, ésta es insuficiente para cubrir la creciente demanda. La mecanización y el empleo de agroquímicos permiten aumentar la producción agraria sin aumentar la superficie cultivada, pero es un proceso que no refleja la tierra virtual necesaria para mantener esa producción (González de Molina e Infante, 2010).

\section{- Procesado y distribución}

La agricultura se convierte en proveedora de la industria alimentaria. La dinámica del consumo de masas favorece las economías de escala, por lo que se van concentrando las industrias, que aumentan su tamaño operativo. También se amplía la extensión de los territorios que suministran las materias primas a cada una de las fábricas. Sucede con las harineras, las azucareras y también con las bodegas, instalándose por ejemplo bodegas cooperativas, que aúnan a decenas de viticultores para la gestión de su producción y para la comercialización. El abaratamiento del coste del transporte facilita el aumento de las distancias viajadas por los alimentos desde su producción hasta los puntos de procesado y posteriormente, su distribución a los puntos de venta. 


\section{- Consumo}

La autoproducción pasa a ser irrelevante y el consumo depende en buena medida del mercado. Es decir, no solo ha habido un cambio en cuanto a composición y cantidad de la dieta, sino también en cuanto a las pautas de adquisición de alimentos, que cada vez se orienta más a los supermercados, sobre todo para los productos industriales, procesados y envasados para que no sean (tan) perecederos. Así los alimentos procesados pasan a suponer el 30,5\% del gasto en alimentación, y se reducen los productos frescos. El peso de la alimentación en los presupuestos familiares se reduce a la mitad, en favor de otros como las vacaciones o la casa. Aun así, en 1980 constituye todavía el principal gasto (30,5\% del total) en el mundo no urbano y el segundo en el urbano $(27,7 \%)$ (Abad Balboa y col., 1994).

\section{- Explotación}

El sector reduce su presencia en la economía general, también en la economía rural y sus actores pierden en general capacidad de ahorro (Leal y col., 1975). Hay un importante proceso de mecanización e intensificación de las explotaciones. Sin embargo la capacidad de los distintos actores para incorporarse al proceso industrializador es muy desigual, lo que conduce a la expulsión de parte de la población agraria (Naredo, 1996). A su vez y en paralelo, se van polarizando las explotaciones: perviven buen número de pequeñas explotaciones familiares, pero la tendencia general es a aumentar el tamaño de las que tenían medianas dimensiones. Los procesos de concentración parcelaria abordan los problemas de la dispersión parcelaria desde la racionalidad modernizadora. La mecanización penaliza la dispersión de las parcelas de una misma explotación, por el coste (en recursos y en tiempo) que supone trasladarse de una a otra con el tractor o la maquinaria.

\section{5: Sistema agrotercerizado para un consumo segmentado}

\section{- Nutrición}

Hacia el año 2000, la ingesta calórica media diaria se sitúa en unas 3.500 calorías, claramente por encima de las necesidades biológicas. Los efectos nocivos de la obesidad y los alimentos industriales sobre la salud, los nuevos cánones estéticos y los escándalos alimenticios van a animar un cambio en las pautas de consumo (Gutiérrez-Fisac y col., 2003). La relación entre aumento del nivel de ingresos y el aumento de ingesta calórica se rompe y la diferenciación social se traslada de la cantidad a la calidad de los alimentos. En ese sentido, las empresas del sector se afanan en desarrollar alimentos con un mayor valor añadido, tanto por sus cualidades como por su formato. Las empresas diversifican sus productos y estrategias para dirigirse a un mercado que aparece segmentado en numerosas parcelas. Los alimentos y su publicidad se diseñan para llegar a nichos de mercado concretos: alimentos ecológicos, alimentos a los que se atribuyen propiedades saludables o adelgazantes, alimentos específicos para determinadas edades, etc. 


\section{- Regulación}

Desde el reconocimiento de los problemas ecológicos y de bienestar animal asociados a las prácticas agrarias intensivas fomentadas por la PAC, ésta experimenta sucesivas reformas. Las ayudas a la producción son sustituidas por ayudas a la renta de titulares de las explotaciones (desacople), se fijan cuotas y van introduciéndose requisitos ambientales. Se incorpora un segundo pilar para financiar programas de desarrollo rural y se institucionaliza la idea de que la agricultura multifuncional es característica de Europa. Por otro lado, a raíz de la tendencia liberalizadora la capacidad y voluntad de los gobiernos para regular el sistema alimentario van quedando mermadas, aunque en paralelo va surgiendo una prolija normativa y regulación de la actividad agraria y de transformación, poco adaptada a la realidad de las pequeñas explotaciones. En nuestro caso, se dan además profundos cambios en el modo de regulación: el Estado se queda sin buena parte de las competencias en materia de agricultura y ganadería, que son transferidas a las Comunidades Autónomas. Además con la incorporación de España a la Unión Europea, debe aplicar la Política Agrícola Común.

\section{- Producción}

El capitalismo financiero alcanza al sector de la alimentación, que se desliga de la realidad física y material, pero también de las necesidades concretas de alimentos (McMichael, 2005). En esta época donde la calidad sustituye a la cantidad como elemento de diferenciación social, cobran importancia los mecanismos para garantizar (certificar) esa calidad (De Felipe y Briz, 2001). El caso de las Denominaciones de Origen de Ribera de Duero o Rueda, claves en la evolución del viñedo y de la economía en la zona analizada, son un buen ejemplo de ello. A escala estatal, la producción ecológica certificada experimenta un crecimiento exponencil, en un alto porcentaje ésta se orienta a los mercados internacionales. Hay también otras figuras como la producción integrada, las Indicaciones Geográficas Protegidas o directamente sellos que sirven de paraguas para la producción cuidadosa de toda una región. Así por ejemplo la marca de garantía Tierra de sabor abarca al conjunto de la Comunidad de Castilla y León. Las cadenas de producción y distribución se hacen más largas y complejas y ya no están acotadas a un espacio local o regional (Friedland, 2004). En la última década cobran fuerza los intentos por relocalizar los sistemas de alimentación y la seguridad alimentaria ha entrado de lleno en la agenda de la Unión Europea. España sigue siendo deficitaria en cereales y soja para piensos compuestos con los que alimentar la cabaña ganadera.

\section{- Procesado y distribución}

Los alimentos se consumen cada vez más procesados, más elaborados y en envases crecientemente tecnificados. Las grandes corporaciones de la distribución controlan en los países industrializados cerca del $80 \%$ de los alimentos que se comercializan (Montagut y Vivas, 2009). La concentración de la actividad en pocas corporaciones lleva a una asimetría creciente de poder, recursos y capacidad de toma de decisiones. Los escándalos por la especulación con los alimentos han activado movimientos ciudadanos que plantean poner control al 
poder del capital (Kaufman, 2010; Schutter, 2010). En paralelo emergen grupos que cuestionan el sistema agroalimentario industrializado y globalizado. Ese cuestionamiento les lleva a poner en marcha proyectos basados en nuevos modelos de consumo impulsados por la ciudadanía organizada, como cooperativas integrales y grupos organizados que compran directamente a los agricultores. Con el tiempo también aparecen iniciativas institucionales, que en distintos niveles, promueven los circuitos cortos de comercialización.

\section{- Consumo}

El consumo se segmenta. Se consolida una estrategia comercial que se apoya en el fomento de la compra compulsiva más allá de las necesidades (Keller, 2012) y que acaba generando unas cantidades ingentes de alimentos que se desperdician. Según datos oficiales del Ministerio, cada año España, 8 millones de toneladas de alimentos en buen estado terminan en la basura (MAGRAMA, 2013), la cifra sería del $20 \%$ a escala global según la FAO. Los cambios en las pautas de consumo se intensifican, reduciéndose (aunque no desaparece) el papel de los hogares en la elaboración de las comidas frente a la restauración colectiva, tanto por trabajo o educación, como ligada al ocio. El consumo de alimentos fuera del hogar supone una tercera parte del presupuesto total (MAGRAMA, 2011); con la crisis los hogares con menos ingresos han reducido esta práctica mientras que los de altos ingresos continúan acentuándola.

\section{- Explotación}

Los actores tradicionales están cada vez más atomizados y con funciones más específicas, pierden autonomía, mientras que crece el control sobre la industria alimentaria por parte de las grandes corporaciones (Delgado Cabeza, 2010). En la región se acentúa la polarización, conviven pequeñas explotaciones (para las que la agricultura hace tiempo que dejó de ser su principal fuente de ingresos) con otras grandes que siguen aumentando su tamaño. En el caso del viñedo, es notorio cómo, acompañando el proceso de adscripción a la DO se ha ido generalizando la inclusión de enólogos y agentes comerciales. Irrumpen en el sector nuevos empresarios; grupos y fondos de inversión entran en el negocio. Se multiplican las bodegas, pero no todas son capaces de resistir la crisis. Las bodegas impulsadas por familias de la zona esgrimen su pedigrí histórico como un factor de calidad. El proceso externalización de servicios está presente, pero no ha adquirido por el momento dimensiones notables. Van irrumpiendo nuevos actores con distintos perfiles que introducen maneras innovadoras de gestionar la explotación y la relación con el público. A diferencia de lo que había sucedido tradicionalmente, no necesariamente proceden de familias de agricultores ni trabajan sobre explotaciones heredadas. Exploran nuevas fórmulas para diversificar ingresos. Se advierte una tendencia todavía moderada y considerablemente circunscrita a algunas explotaciones hortícolas y vitivinícolas a diferenciarse del resto incorporando nuevas actividades y ofreciendo nuevos servicios, como por ejemplo el enoturismo. 


\subsection{Caracterización del sistema tecnológico para la gestión del territorio}

\section{Explotación orgánica fruto de la necesidad}

En esta etapa el sistema tecnológico tiene un carácter distribuido, que permite satisfacer las necesidades básicas de manera integral, pero con un nivel de consumo reducido; un nivel muy inferior al que se promovió y alcanzó posteriormente. Hay una considerable continuidad con la producción orgánica preindustrial, no se han generalizado todavía ni los combustibles fósiles ni los fertilizantes químicos. Esto es así porque, con un sistema tecnológico de fuerte enraizamiento local y pocos aportes externos, la necesidad lleva al máximo aprovechamiento de los recursos locales. Se basa en el aprovechamiento de la energía solar, que se incorpora al sistema gracias a las plantas, que actúan como conversores biológicos (Naredo, 1996, p.348). Persiste a su vez un bajo nivel de mecanización de las unidades agrarias, donde las operaciones de explotación y transporte seguían basándose en el empleo de energía animal.

Las políticas agrarias buscaban aumentar la producción, para ello intentaron promover mejoras técnicas en el manejo agrario y desarrollar infraestructuras de regadío. Pero en la práctica, el incremento en la producción de alimentos vino de la mano de la ampliación de la superficie destinada a cultivo, en un proceso de agricolización del territorio que precisamente conllevaba la ruptura de los sistemas agrosilvopastorales, sistemas de gestión integral del territorio integral. De todas formas, aunque los sistemas agrosilvopastorales hayan desaparecido, las prácticas de explotación siguen siendo poco intensivas, pues la agricultura se tiene que adaptar a las condiciones climáticas y naturales sin grandes aportes externos. Se utiliza la rotación y el barbecho para contrarrestar la limitada capacidad agrológica. Para reponer la fertilidad del suelo, el principal recurso consistía en sembrar únicamente una tercera parte o la mitad de las tierras cada año. Los barbechos servían para su aprovechamiento a diente por el ganado ovino. La superficie de tierras de cultivo abonadas sigue siendo reducida, el $28 \%$ en tierras burgalesas y el $33 \%$ en las vallisoletanas. La producción sigue siendo fundamentalmente orgánica, pero van introduciéndose lentamente los abonos químicos, de manera que en 1956 en la región, prácticamente igualaban a los obtenidos de estiércoles (Castro Rodríguez, 1957, p.51).

En cuanto a la gestión del agua, este sigue siendo un recurso escaso, disponible únicamente en las riberas, ya sea por los cursos naturales o por las canalizaciones de regadío. Las infraestructuras se concentran en la parte vallisoletana, con mejores tierras. En esta gestión y satisfacción integral de las necesidades en el mundo rural, juega un papel fundamental el conocimiento local y la gestión compartida de recursos. Las razas autoctónas adaptadas a las condiciones locales o el cultivo del viñedo es un ejemplo de adaptación histórica que convirtió unos condicionantes limitantes (rigor climático y suelos sueltos, poco fértiles y con pendiente) en un factor de oportunidad (Molinero Hernando, 1979). Por su parte, los barrios de bodegas interdependientes excavadas en las laderas ejemplifican la gestión individualizada de elementos que forman parte de un conjunto común (Cañas y col., 2012, p.288). 
Este sistema tecnológico es el resultado de un proceso lento de construcción colectiva del conocimiento. Mediante prueba y error se fue decantando, a lo largo de los siglos, el conocimiento popular, que facilitaba la apropiación del mismo por parte de la población. Figuras como las Sociedades de Amigos del País podían jugar a veces un papel de catalizador en la difusión de innovaciones. El segundo factor que caracteriza el sistema es su condición distribuida, buena parte de los medios para la transformación conservaban una pequeña escala y se repartían por el territorio conformando toda una red productiva vinculada a la población local (por ejemplo molinos, aceñas, batanes, pósitos, eras, etc).

\section{Modernización intensificadora}

Los profundos cambios que se viven en estas décadas refuerzan a quienes piensan que con las mejoras técnicas y organizativas es posible contrarrestar las limitaciones físicas y naturales y mejorar la productividad. Porque efectivamente, analizando exclusivamente los resultados a nivel de la unidad productiva, los rendimientos aumentan, y mientras el análisis se limite a esa escala y no incorpore las externalidades negativas que se trasladan a territorios lejanos, el balance arroja resultados positivos.

Con una visión economicista de corto alcance, el optimismo tecnológico y la convicción en las bondades de la industrialización y las economías de escala se generalizan. Se extiende el regadío para superar las limitaciones climáticasy se extiende la mecanización y el empleo de agroquímicos para superar las limitaciones de disponibilidad y calidad de la tierra. Todo ello va acompañado de medidas como la reparcelación para superar las limitaciones de la estructura de la propiedad. Además la industria agroalimentaria experimenta un desarrollo sin precedentes. Son cuatro procesos que están interrelacionados y que modifican por completo la manera de explotar el territorio, la relación entre agricultura y ruralidad y entre agricultura y alimentación:

- Las condiciones de entorno facilitan la extensión del regadío: por un lado las concentraciones parcelarias hacen rentable la inversión y por otro, el desarrollo de técnicas de sondeo y aspersión y el abaratamiento de sus costes permiten implementar sistemas individuales sin tener que depender de las obras de infraestructuras públicas (Baraja Rodríguez, 2011).

- El conjunto de las políticas y medidas permiten que se afiance una agricultura tecnificada y mecanizada. Se sustituye la tracción animal por otra motorizada, que liberó nuevas superficies productivas que ya no tuvieron que destinarse a producir grano para alimentar mulos y bueyes. En paralelo, la mecanización permitió reducir la mano de obra asalariada.

- Se generaliza el empleo de fertilizantes y pesticidas. Con ellos se introducen nuevas razas y nuevas especies de cultivos, para que la aplicación de insumos químicos resulte más eficaz. Esta vez será la ganadería la que ejemplifique las implicaciones de esta transformación. Se sustituyen las razas autoctónas, pues en términos de producción láctea no podían competir con las importadas. El cambio tiene repercusión no solo a nivel de la explotación, sino en el conjunto del 
sistema, ya que se desaprovechan los recursos forrajeros locales y se pierde su potencial de abonado y de regeneración de suelos (Naredo, 1996; González de Molina y col., 2007).

El cambio conlleva una creciente externalización de los costes ambientales, que por el momento no se tiene en cuenta en ningún balance. El paso del sistema familiar al industrial implica un cambio de escala y la reducción de puntos de procesamiento, al concentrarse estos en determinadas localizaciones con facilidades de transporte (Valladolid, Aranda y Peñafiel en la zona analizada).

El carácter incremental de las transformaciones e innovaciones propio de la sociedad tradicional se rompe con el modelo desarrollista. Frente al desarrollo de innovaciones e infraestructuras blandas de uso y gestión, propio de la época anterior y que eran fruto de la necesidad, se pasa a la aplicación de nuevas tecnologías y al desarrollo de infraestructuras duras, según criterios exógenos y mediante decisiones que quedan fuera del alcance de la población local. Es decir se implanta un modelo tecnológico que es radicalmente diferente al anterior, primando las soluciones duras, cerradas e irreversibles, frente a las soluciones blandas, abiertas y reversibles.

La difusión del nuevo modelo implicaba la implantación de un nuevo paradigma cultural: especialización, aumento de escala y abandono de las prácticas tradicionales. La profunda transformación tecnológica de esta época se produjo en un muy corto periodo de tiempo. La rapidez con la que se sucedieron los cambios fue posible gracias entre otros factores, a las políticas públicas que los apoyaron y a la creación de un servicio de Extensión Agraria. Este servicio va a hacer una intensa labor de capacitación y orientación en las nuevas técnicas, y también se encargará de promocionar el asociacionismo entre ganaderos y entre agricultores, impulsando la creación de coperativas.

\section{Las nuevas lógicas de la creciente tecnificación}

En estas décadas se intensifican las tendencias consolidadas anteriormente, como el empleo de insumos químicos o el alargamiento de la cadena de producción, pero además se produce un cambio cualitativo en lo que se refiere a la organización del sistema, posibilitado por la irrupción de las nuevas tecnologías de información y comunicación. Estas nuevas tecnologías permiten complejizar la organización, con una creciente concentración del sector alimentario en un reducido número de corporaciones y sistemas productivos globales, con cadenas crecientementes fragmentada en la que los actores tradicionales quedan cada vez más atomizados y desempeñan funciones cada vez más específicas.

Los efectos negativos del modelo intensivo agroindustrial hacen que se cuestionen las prácticas intensivas industrializadas por su impacto sobre la salud y sobre los ecosistemas en términos de pérdida de actividad biológica suelo, empobrecimiento de materia orgánica, contaminación de las aguas, etc.

Como se expuso en el punto anterior, el empleo de pesticidas y fertilizantes tiene ya un largo recorrido. Lo que sí resulta novedoso en estas décadas es la búsqueda de nuevas soluciones para los cultivos basadas en la ingeniería genética y la biotecnología, así como la apropiación por parte de algunas corporaciones de un 
patrimonio genético que hasta entonces se entendía que era de la humanidad y de las culturas que lo habían preservado. Además de las innovaciones tecnológicas, otro factor que caracteriza esta etapa es el continuo incremento de los aportes energéticos no renovables a la cadena productiva agroalimentaria:

- El creciente nivel de mecanización y de procesamiento hace que aumenten los consumos energéticos a lo largo de toda la cadena de producción ${ }^{6}$.

- Aumenta a su vez el consumo energético asociado al empleo de fertilizantes inorgánicos. El consumo de fertilizantes nitrogenados se disparó. Los valores medios para el conjunto del Estado han pasado de 4,5 kg/ha en 1985 a 74,6 $\mathrm{kg} / \mathrm{ha}$ en 2003 (Tamames, 2008).

- El incremento de las distancias que recorren los alimentos aumenta proporcionalmente el consumo de energías fósiles (Simón Fernández y col., 2014).

\subsection{Caracterización del sistema territorial}

El sistema territorial comparte características básicas comunes en las cinco áreas objeto de análisis; pero aunque formen parte de una misma estructura territorial se pueden reconocer diferencias entre la conformación espacial y ecosocial de los distintos tipos de municipios de cada área. La tipología de municipios se define a partir de la situación a principios del siglo XX, cuando el peso de las condiciones locales era mayor. Posteriormente las variables que inciden en la evolución de cada núcleo exceden ese localismo y su parametrización se vuelve más compleja. Se han distinguido tres tipos de municipios en 1950:

a) Rango 1. Municipios de referencia: aquellos con mayor superficie de clases agrológicas aptas para el cultivo, que a su vez albergan a las poblaciones de mayor tamaño, más de 3.000 habitantes.

b) Rango 2. Municipios aliados: aquellos con una capacidad agrológica media y con poblaciones entre 1.000 y 3.000 habitantes y cuya conexión con el núcleo de referencia les marca una evolución en cierta medida acompasada a la de éste.

c) Rango 3. Municipios vulnerables: aquellos con menor suelo con clases agrológicas aptas para la agricultura y una población inferior a 1.000 habitantes, con dificultades históricas para seguir el ritmo de desarrollo del municipio de referencia.

\section{El territorio de proximidad}

\section{- Población y red de asentamientos. Intensidad demográfica}

El sistema agrolimentario propio de esta época, basado en la agricultura tradicional y de proximidad, se caracteriza por una distribución de la población

6 Según Pelletier y col. (2011), el cocinado, la conservación y la congelación de los alimentos suponen en torno al 15-20\% del consumo de energía ligado a la alimentación en los Estados Unidos. 
relativamente homogénea en el territorio, ligada a la explotación directa del mismo, con una movilidad dependiente de la tracción animal y basada en las distancias cortas. En el corredor del Duero se puede hablar de una desconcentración concentrada. Aunque Valladolid destaca poderosamente, en 1900 más del 60\% de la población en el área estudiada se reparte por el resto del territorio. La capacidad productiva de un término municipal, por su calidad agrológica y por la extensión de sus dominios, influía sobremanera en el tamaño de la población, que es parte integrante y activa de un ecosistema basado en la energía solar y los biodigestores. Históricamente los asentamientos se han localizado en las áreas más fértiles, para aprovechar los recursos inmediatos. Aquí la mayoría se sitúan en las zonas ribereñas, beneficiándose de la proximidad del agua y de los suelos de mejor potencial productivo. Apenas hay asentamientos en las cuestas. El servicio de bienestar más básico de educación se encuentra distribuido, de manera que cada pueblo cuenta con escuela y maestro o maestra residente. Prácticamente todos los pueblos tuvieron también casa consistorial, iglesia y hasta el siglo XX, cárcel.

\section{- Ocupación de suelo por usos urbanos-artificiales. Intensidad edificatoria}

Los planes urbanísticos se circunscriben a los principales municipios, ya sea por sus dimensiones o por contar con un intenso pasado histórico. Valladolid, en su condición de capital y nodo principal de actividad industrial y terciaria, ha experimentado un gran crecimiento con tipologías urbanas y arquitectónicas propiamente urbanas. En Aranda también se han desarrollado algunas promociones con nuevos tejidos, pero en el resto de los pueblos y villas, de crecimiento orgánico y estructura urbana compacta y adaptada al terreno, las nuevas parcelas de borde incorporadas al núcleo suelen conservar un carácter agropecuario. El consumo medio de suelo urbano por habitante (excluyendo Valladolid) se sitúa en unos $140 \mathrm{~m}^{2}$. Buena parte de las necesidades se satisfacían a escala familiar, lo que hacía que los asentamientos combinaran usos productivos y residenciales. Eran habituales pequeños huertos familiares integrados en el núcleo, pero también corrales con gallinas, conejeras o incluso algún cerdo. El ganado de labor también se alojaba en el pueblo, a veces en la planta baja de las viviendas, proporcionando calor en invierno. En muchos sentidos tienen un carácter multifuncional y contribuyen a cerrar ciclos, se alimentan de los restos de comida, o de los terrenos en barbecho, según el caso, y aportan estiércol para abonado. Más de la mitad (52\%) de las construcciones en suelo rústico se levantan a menos de 500 metros del núcleo, y el $72 \%$ están situadas en un radio de 1 kilómetro. En muchos casos, la mayoría son bodegas, que se excavan por lo general junto a los núcleos (también hay complejas galerías bajo el tejido urbano, por ejemplo en Aranda). Fuera del núcleo había pocas edificaciones, normalmente estaban asociadas a la explotación agraria, aunque también aparecen algunos usos singulares. La construcción se realiza básicamente a partir de materiales locales, construcción en tierra, crujías de reducidas dimensiones y con vigas de madera, la piedra se reserva para las edificaciones más nobles. El ladrillo es el material más habitual en nuevas instalaciones. No hay diferencia en los sistemas constructivos entre los distintos tipos de municipios, aunque sí se da una mayor concentración de edificios 
singulares o nobles, con mayor consumo de materiales, en los municipios de referencia. En estos municipios también es donde aparece un mayor número de edificaciones dispersas en el territorio, pero sigue siendo una cantidad muy baja.

\section{- Instalaciones e infraestructuras de apoyo a la explotación}

Las infraestructuras de regadío incluyen los canales del Duero y de Tordesillas con las derivación de Villamarciel y el canal de Guma (Berlangas, La Cueva, Castrillo, Fresnillo y Fuentespina). Su trazado discurre próximo al Duero por municipios de todos los rangos, pues responde a la idoneidad técnica y a la disponibilidad de agua. La presión sobre los recursos hídricos es baja. En la época preindustrial, la existencia de medios locales, sean o no colectivos o comunales, es fundamental para el funcionamiento del sistema. Aunque en 1950 ya estaba asentado el modelo con las industrias en los principales núcleos, se explica el sistema anterior por su relevancia en términos de organización territorial. Estas infraestructuras de apoyo a la producción agraria o a su transformación se reparten por el territorio en un modelo de baja intensidad. Como era de esperar, los municipios de cabecera aúnan un mayor número y más variado de instalaciones como molinos, aceñas, batanes, etc. mientras que el mayor porcentaje de municipios que carecen de estas instalaciones (incluso de algo básico como una era) son precisamente los de rango 3, los vulnerables. El campo es el medio de vida y la fuente de recursos para la mayoría de la población, las construcciones que se edifican son las imprescindibles para la explotación (o para las celebraciones colectivas, como las ermitas). Existen algunas instalaciones pecuarias, granjas en el suelo rústico, pero son escasas.

\section{- Accesibilidad y conectividad. Intensidad infraestructuras de comunicación}

Los caminos son esenciales para la articulación interna de un territorio caracterizado por la dispersión concentrada de su población en una red de asentamientos interconectados. Con una agricultura basada en el empleo de ganado de labor los agricultores explotan tierras próximas, muchas veces repartidas en parcelas dispersas, que son accesibles a pie o a lomos de un animal. Por la condición intensiva del trabajo, se puede organizar este repartiendo las jornadas entre las parcelas dispersas, todas ellas accesibles desde el núcleo central. Los mapas reflejan una tupida red de caminos radioconcéntricos que parten desde los núcleos habitados y que satisfacen las necesidades de accesibilidad intraterritorial. La red principal de carreteras pasa por Valladolid y Aranda, la secundaria conecta el resto de los núcleos y no siempre se encuentra en buen estado de mantenimiento. También discurren por este territorio varios tramos de la red de ferrocarriles. Como nodo central en el que confluyen lineas norte-sur y este-oeste (Valladolid-Ariza que en los ámbitos analizados contaba con estaciones en Aranda de Duero, Castrillo de la Vega, Berlangas, Roa, Bocos, Peñafiel y Laguna), Valladolid se convirtió en enclave estratégico para la redistribución de mercancías, especialmente del cereal. 


\section{- Usos agrarios. Intensidad de la explotación}

A lo largo de toda la primera mitad del siglo XX continúa el proceso de agricolización y se sustituyen policultivos y sistemas agrosilvopastorales por monocultivos. En los planos de evolución de los cinco ámbitos de estudio, se puede ver cómo el viñedo sigue siendo un cultivo muy importante en los entornos de Roa y Aranda de Duero, pero incluso así los cultivos de secano destacan por encima del resto. El área en torno a Peñafiel es el caso más extremo, con un $88 \%$ de los terrenos destinados a labor cerealista, ocupando la práctica totalidad del término municipal en municipios como Roturas, Valdearcos, Torre de Peñafiel o Canalejas, hecho que se repite también en Berceruelo, Velilla o Velliza, próximos a Tordesillas, en Villanubla junto a Valladolid, o en Anguix en las proximidades de Roa. Puesto que las tierras son poco aptas para cultivo y apenas hay aportes externos, los sistemas de explotación no pueden ser intensivos, recurriendo a la rotación de cultivos y al barbecho que servía para su aprovechamiento a diente por parte del ganado (sistema de año y vez o tres hojas) (Molinero Hernando, 1979). La pequeñas dimensiones de parcelas y explotaciones conllevan vulnerabilidad frente al mercado, pero en términos ecológicos contribuían a la prevención de plagas y a la biodiversidad. Esta biodiversidad se concentra en la vegetación de los linderos y en elementos lineales como arroyos o canales, con setos, matorrales o frutos silvestres, que jugaban un papel importante para mejorar las condicones de vida local. Destaca la importancia de los elementos de pequeña escala para el mantenimiento de esa biodiversidad.

\section{- Adecuación agrológica. Intensidad en el aprovechamiento de recursos locales}

La sobreexplotación provenía de la extensión de cultivos, localizados en lugares inapropiados. La eliminación de los recursos forestales por roturación de los montes hizo que sus funciones inmediatas por ejemplo como proveedor de leña para calentar el hogar, se supliera con las gavillas de las cepas, cuando era posible. El sistema de explotación era poco intensivo con cultivos solo cada dos o tres años, ya que la tierra necesitaba recuperarse. La otra vía para adecuar la explotación a la capacidad agrológica pasaba por adoptar cultivos especialmente adaptados. Es lo que sucedió con el viñedo, que incluso se beneficiaba de las condiciones que hacían inviables otros cultivos (Molinero Hernando, 1979). Los municipios de menor rango, los vulnerables, presentan una mayor proporción de usos inadecuados, de sobreexplotación ligada a la intensidad de unos usos poco adaptados a la calidad agrológica del suelo. Con términos municipales de reducidas dimensiones, con escasa (o nula) superficie adecuada para su explotación agrícola, la manera que tienen de sumarse a la corriente agricolizadora, que aumenta la producción, es roturando terrenos inadecuados y extendiendo usos demasiado intensivos para la capacidad de carga local. Los municipios vulnerables' en torno a Roa son una excepción a esta regla al haberse orientado hacia el viñedo. En el extremo opuesto encontramos los municipios de cabecera, que si se comparan con los de su entorno, presentan menores niveles medios de sobreexplotación. Al contar con una mayor extensión de terrenos bajo sus dominios, sus habitantes disponen de más margen para localizar los cultivos donde más productivos van a ser, algo que les beneficia tanto a ellos como a los 
ecosistemas. En ellos hay mayores zonas con vegetación semi natural, muchas veces gracias a la existencia de Montes de Utilidad Pública, otras ligadas a grandes propietarios. Son zonas donde los usos no agotan la capacidad productiva de los suelos. Un último apunte sobre la sobreexplotación de los recursos locales. Si su consumo es mayor a la capacidad de reposición natural, los efectos de esa presión sobreexplotadora se hacen patentes en el propio lugar, alertando a sus habitantes sobre la necesidad de reorientar la actividad.

\section{La industrialización deconstruye el territorio}

\section{- Población y red de asentamientos. Intensidad demográfica}

En esta etapa, la agricultura deja de dominar la vida económica del país (Leal y col., 1975), el cambio de modelo y las políticas orientadas a la industrialización repercuten en la estructura demográfica del territorio, debilitando a los núcleos rurales en favor de los nodos industriales. La población rural que suponía casi la mitad de la población en 1950 (48 \%) desciende a poco más de una cuarta parte en 1981 (27\%). Es la época de las grandes migraciones campo-ciudad con la consiguiente polarización demográfica, porque los núcleos principales e industrializados crecen a costa del vacíado del territorio rural. Destaca la creciente concentración de capacidades y recursos. La concentración propicia las economías de escala inherentes a un modelo de desarrollo que se fundamenta en el consumo de masas. Las relaciones de dominación urbana abarcan cada vez mayores extensiones territoriales que dejan de ser operativas por sí mismas. Los núcleos de referencia abordan sucesivos desarrollos urbanísticos, también aquellos que apenas crecen demográficamente, mientras que la mayoría de los más rurales se mantienen al margen de la expansión urbana. En el caso de Valladolid, el crecimiento comienza a desbordar la capital y se extiende por municipios limítrofes. En el resto de las zonas, se elevó el umbral poblacional a partir del cual los núcleos de referencia, que históricamente habían jugado un papel de cabeceras comarcales, mantienen su capacidad de atracción y de articular los asentamientos en su entorno. El resultado es un descalabro demográfico de pueblos y villas que ven su población mermada y envejecida.

\section{- Ocupación de suelo por usos urbanos-artificiales. Intensidad edificatoria}

Los planes de ordenación urbanística todavía no se habían generalizado y los de ordenación territorial apenas habían hecho aparición. Hay un incremento de la superficie urbana en los núcleos principales (tanto en los que experimentan importante crecimiento demográfico como en los que no), mientras que la mayoría de los más rurales se mantienen al margen de esa expansión edificatoria. Los desarrollos se basan en nuevas tipologías residenciales, urbanas en las ciudades y viviendas unifamiliares en hilera o aisladas en los municipios más rurales. Los trazados de estas expansiones son regulares. La renovación del patrimonio edificado fundamentalmente se realiza por sustitución, ya que no se reconoce el valor de la arquitectura popular, antes al contrario, se asocia las arquitecturas en tierra con un pasado de pobreza. Se abandonan las técnicas y sistemas constructivos del pasado para adoptar otros con materiales estandarizados, con vocación universal. Cuando los núcleos se desbordan, se 
rompen las zonas de borde través de las que se conectaba el pueblo y su entorno. En algunos casos se mantienen los usos tradicionales, pero es habitual que se instalen nuevos usos de considerable impacto paisajístico y con los que se pierde esa conexión. También aparecen nuevos desarrollos desligados de los núcleos, en un crecimiento a saltos con unidades inconexas. Aumenta la cantidad de edificaciones en suelo no urbanizable, ya no necesariamente orientadas a la explotación agropecuarias; en este sentido la actividad deja de estar vinculada al núcleo central y empiezan a dispersarse viviendas y edificaciones asociadas a otros usos. Entre 1950 y 1985 la superficie construida en suelo no urbanizable se multiplica prácticamente por 5, pero con una distribución desigual, siendo en los municipios de cabecera donde hay una mayor presión.

\section{- Instalaciones agropecuarias e infraestructuras de regadío. Intensidad de equipamientos.}

La extensión del regadío va acompañada del desarrollo de infraestructuras al efecto, tanto canales como dispositivos individuales de riego por aspersión. Los nuevos canales de Aranda, Riaza y Duratón discurren por municipios vulnerables próximos a Aranda de Duero (Quemada y Vadocondes) y a Roa (Hoyales). La combinación del empleo generalizado de abonos químicos con la nueva disponibilidad de agua a través de los canales, permite intensificar la producción en terrenos inicialmente muy poco apropiados. En el resto de los municipios anteriormente de secano, los nuevos regadíos responden a la puesta en funcionamiento de sistemas de riego por aspersión. Únicamente los situados en los últimos escalafones permanecen al margen de la puesta en regadío de los terrenos. Los equipamientos agrarios de carácter concejil y comunitario pertenecen a otra época. Se produce un abandono y deterioro de infraestructuras e instalaciones en desuso, que había comenzado ya antes de 1950. Así por ejemplo las eras pierden su papel frente a las trilladoras mecanizadas y los molinos harineros desaparecen en favor de un menor número de fábricas de harina. A la par que desaparecen las pequeñas instalaciones de transformación, distribuidas por el territorio inmediato y de pequeña escala, se desarrollan unas nuevas instalaciones de mayor importancia. Las nuevas fábricas se convierten en el destino de la producción agraria mayores extensiones de terreno que las de los sistemas preindustriales. Es muy evidente en el caso de las harineras. La puesta en marcha de plantas azucareras en Peñafiel y Aranda de Duero están indisolublemente ligadas a la promoción y extensión del regadío a lo largo de la vega del Duero. El nuevo sistema agroalimentario necesita de una nueva organización del territorio. Los nuevos centros se localizan en los municipios de cabecera, el resto pierde autonomía y quedan supeditados a la actividad de aquellos. Para algunas agroindustrias la localización próxima a potenciales grandes mercados de consumidores es importante. Así por ejemplo, un importante porcentaje de la industria avícola provincial dedicada a la producción huevos frescos en granjas industriales se localiza en las inmediaciones de la ciudad de Valladolid. Las bodegas evidencian también el cambio de modelo. Se pasa de un sistema de bodegas interdependientes en barrios, presentes en todos los municipios con importante producción vitivinícola, a la construcción de un menor número de bodegas de mayor tamaño, la mayoría funcionando en régimen 
de cooperativas. En este caso, sin embargo, prima la trayectoria vitivinícola por encima del tipo de municipio, y se pueden encontrar estas bodegas en municipios de todos los rangos, no limitándose únicamente a los de cabecera. Sigue siendo un procesado muy enraizado en el territorio, aunque ha cambiado la manera de gestionarlo y comercializar el producto, en un intento de ganar fuerza.

\section{- Accesibilidad y conectividad. Intensidad infraestructuras}

Mejora la red de carreteras, especialmente con la autopistas del Norte y Noroeste. Por el contrario, el corredor Este-Oeste se debilita, por un lado debido al cierre del Ferrocarril Valladolid-Ariza, primero a pasajeros y luego también a mercancías, por otro lado porque la carretera a lo largo del Duero sigue siendo secundaria. Las concentraciones parcelarias borran los caminos históricos y deshacen la estructura previa. Hay una importante red de vías pecuarias pero todavía no se reconoce suficientemente su valor ecológico y cultural, los tramos aparecen dispersos y carecen de continuidad.

\section{- Usos agrarios. Intensidad de la explotación}

Entre 1950 y 1985, en consonancia con el objetivo de obtener el máximo rendimiento posible a la tierra, los regadíos experimentaron un crecimiento sin precedentes. De ocupar entre un 0,1 y un $2 \%$ de los territorios analizados, pasaron a suponer entre el 14 y el $22 \%$, alcanzando el segundo lugar por extensión de cultivos, por encima de los viñedos. Se trata sobre todo de cultivos industriales e implican una intensificación de la explotación que aumenta su productividad paliando las limitaciones climáticas con infraestructuras para regadío. La ampliación de los cultivos de regadío, más intensivos, sustituye a los anteriores de secano, menos rentables. Se produce en su mayoría en las zonas de ribera donde es más sencillo acceder al agua y los terrenos son más fértiles. La intensificación productiva por conversión en regadío es más acusada en los municipios de rango 2 , mientras que se quedan al margen la mitad de los municipios vulnerables (rango 3), que partían de unas condiciones peores. Por el contrario y como refleja la figura 10, el viñedo experimenta una considerable contracción. Hay fenómenos masivos de arranque de cepas que son sustituidas por cereales, más rentables. La productividad decreciente resultado de una inadecuada intensificación de los usos se palia con aportes externos. La distribución de los viñedos seguía una lógica geográfica, no por jerarquía de municipios, y por tanto su transformación sigue patrones también geográficos, destacando en las comarcas donde predominaba. En torno a Roa el $25 \%$ de los cambios en el uso del suelo correspondieron a tierras en las que se arrancaron las viñas para dejar paso a cultivos de secano. La cifra asciende hasta el $46 \%$ en el entorno de Aranda de Duero, donde además otro $17 \%$ de los cambios correspondieron a terrenos de viñedo transformados en regadío. En el ámbito de Tordesillas también un $17 \%$ de las transformaciones se debieron a la sustitución del viñedo por tierras de labor. 


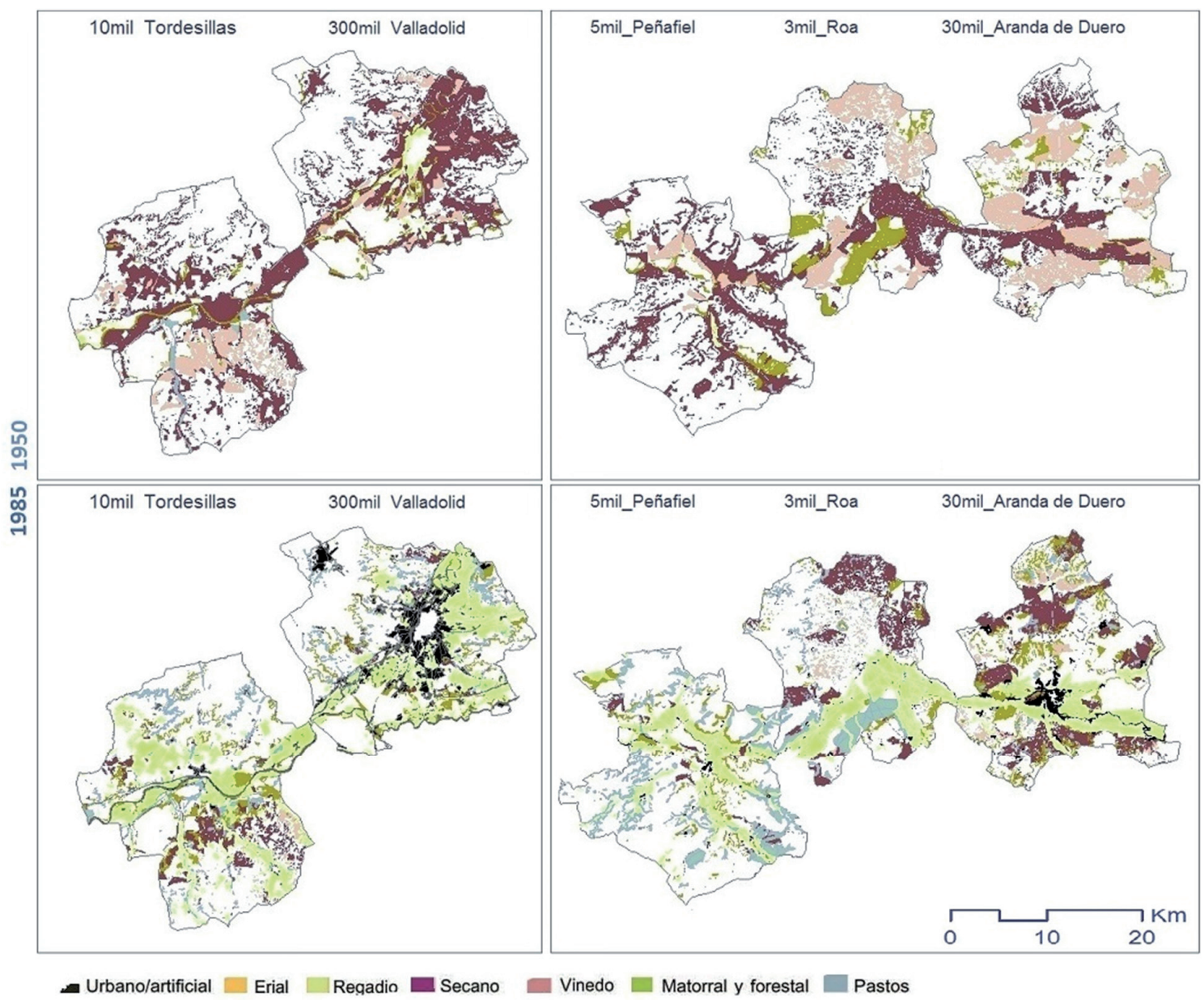

Figura 10. Cambios en los usos del suelo 1950 y 1985

Fuente: Elaboración propia

\section{- Adecuación agrológica. Intensidad en el aprovechamiento de recursos locales}

Un factor de gran incidencia, aunque estrictamente no suponga cambio de uso, es el cambio en las prácticas agrarias y de gestión de cultivos. El paso a la agricultura industrializada no se refleja en un cambio de uso, pero tiene un fuerte impacto ambiental paisajístico, este último especialmente notable en el caso de mediar proyectos de concentración parcelaria. La agricultura industrializada que extiende los monocultivos y se apoya en el aumento del tamaño de las explotaciones, homogeneiza el territorio y acaba con los elementos que introducían diversidad ecológica y paisajística. Los niveles de sobreexplotación alcanzan las mayores cuotas de la historia, en todos los municipios, pero de manera especialmente acusada en los más vulnerables, que se suman al proceso intensificador, abandonando prácticas tradicionales a pesar de contar con terrenos poco adecuados para su explotación agrícola. Mientras que una parte importante de terrenos intensificaba su producción, otros terrenos de labor se naturalizaban 
y dejaban paso a matorrales e incluso a formaciones arbóreas. El proceso es más acusado en los extremos, en los municipios cabecera y en los vulnerables. Las dinámicas responden a una reducción de la actividad agraria, en los primeros por canalizarse hacia otros sectores y en los últimos, por abandono del pueblo. También hay fenómenos de reforestación auspiciada por Planes Estatales en zonas inadecuadas para los cultivos (municipios vulnerables) o reforzando zonas ya existentes en las periferias de Valladolid o Aranda (municipios de referencia).

\section{El territorio polarizado de la globalización}

\section{- Población y red de asentamientos. Intensidad demográfica}

A pesar de las políticas de desarrollo rural y de las medidas para garantizar servicios, la polarización demográfica sigue agudizándose. Todos los pueblos del entorno de Roa y Peñafiel pierden habitantes (tres de ellos, próximos a Roa, pierden más de la mitad), solo estos dos núcleos ven aumentar ligeramente su población. En Peñafiel, en 2001 pasa a ser mayor el número de habitantes en el núcleo central que en el conjunto de municipios circundantes. Su crecimiento y capacidad de atracción no alcanza a los municipios próximos, antes parece que drena sus recursos hacia el único municipio un poco mayor. En el caso de Tordesillas y Aranda de Duero no solo crecen ellos, sino también algunos de los municipios aledaños, aunque de manera muy moderada. En 2011 apenas consiguen mantener en conjunto la población que tenían en 1985. Aranda de Duero sí que crece considerablemente (20\%) mientras que Tordesillas sigue un ritmo lento. Valladolid es un caso aparte, sus dinámicas de metropolización siguen pautas similares a otras grandes ciudades, donde el núcleo central ve mermada su población mientras que los términos limítrofes experimentan crecimientos casi exponenciales. Se trata de núcleos que habían sido rurales pero han cambiado por completo su carácter.

\section{- Ocupación de suelo por usos urbanos-artificiales. Intensidad edificatoria}

La ordenación del territorio cobra importancia creciente y entra en la agenda europea. En la zona se suceden los planes de ordenación de los espacios naturales, del ámbito periurbano del entorno de Valladolid y del conjunto del corredor del Duero. La mayoría de los municipios cuentan con un Plan General de Ordenación Urbana (PGOU), que por lo general suelen estar orientados a la ordenación de un hipotético y anhelado crecimiento urbano. Aun así, en el ámbito supramunicipal de Roa, 9 de sus 14 municipios carecen de PGOU y uno se aprobó en 2014 por lo que a todos los efectos para este análisis ha carecido de Plan en el periodo analizado. En el caso de Peñafiel y su entorno, tres de los 14 municipios no tienen Plan General y otros dos se rigen por las normas provinciales y cuentan con Delimitación de Suelo Urbano. En la práctica, en el tramo medio del corredor del Duero, los datos globales muestran una expansión sin precedentes de los suelos artificiales. La expansión de los municipios con plan es de media considerablemente superior a la de los que carecen de plan, donde no hay plan es señal casi inequívoca de total atonía. En cualquier caso, tanto el ámbito de Roa como el de Peñafiel presentan de media los índices más bajos de expansión urbana. Independientemente de si cuetan con un plan urbanístico o 
no, el factor determinante es la escasa dinámica económica de la zona y su relativa lejanía respecto de núcleos urbanos de cierta relevancia. Se confirma que es un error pensar que plantear planes expansivos que faciliten la llegada de inversiones, consiguen su objetivo de revitalizar el núcleo, en el mejor de los casos no sucede nada, pero pueden crear expectativas que distorsionan el precio de suelo e incluso, en el peor de los casos, se da vía libre a nuevas construcciones que refuerzan el fenómeno de abandono y ruina o degradación de áreas existentes que han dejado de ser funcionales. Las nuevas edificaciones ni traen población (pues suelen ser segunda residencia) ni redundan en dinamización de economías locales más allá del propio proceso de construcción.

Los crecimientos urbanos no guardan relación con un incremento similar de población. De hecho casi la mitad de los municipios arandinos y tordesillanos, a pesar de los nuevos desarrollos urbanos, han perdido población entre 1985 y 2015. El resultado es que hay un alto porcentaje de segunda residencia o de viviendas vacías entre las nuevas construcciones residenciales, a la vez que siguen aumentando las viviendas en desuso en los cascos. Algo similar sucede con las edificaciones destinadas a usos agropecuarios: granjas, almacenes y otras instalaciones que resultan inadecuadas para las exigencias actuales, se abandonan y degradan, y en paralelo se levantan otras modernas en nuevas zonas, muchas veces más alejadas del núcleo. Por ejemplo en Peñafiel entre el Plan General de 1990 y el de 2012 se ha pasado de 28 a 71 actividades en suelo no urbanizable, incluidas naves "agrícolas" que corresponden a empresas de construcción. En las edificaciones en suelo rústico, destaca el fenómeno de la segunda residencia dispersa, que tienen un efecto distorsionador de las dinámicas agrarias. Además se desarrollan un número importante de urbanizaciones residenciales aisladas. El hecho no es nuevo, puesto que antes ya había algunas urbanizaciones, pero ahora se plantea en un mayor número de municipios. A su vez, muchos núcleos se prolongan a lo largo de las carreteras, en un crecimiento discontinuo, con intersticios, desestructurados, que ofrecen una imagen desordenada y poco armónica y acaba derivando en disfuncionalidades.

\section{- Instalaciones agropecuarias e infraestructuras de regadío. Intensidad de equipamientos}

La dinámica de concentración de la producción también se aplica a la región, eliminando centros de tamaño mediano en aras de logar una mayor competitividad y beneficiarse de las economías de escala. El resultado es el desmantelamiento de fábricas de la industria alimentaria en los núcleos intermedios, como sucedió con las azucareras de Peñafiel y Aranda o con las harineras. A nivel de las explotaciones agrarias, los efectos no se notan de manera inmediata pues hay un compromiso de la empresa para seguir comprando la producción, que en el caso de Peñafiel se traslada a Toro, en Zamora. Las instalaciones, de gran extensión, quedan abandonadas y su reconversión o reutilización resulta compleja. La implantación territorial de las bodegas e infraestructuras de transformación del sector vitivinícola también experimentan intensos cambios. En primer lugar hay una profusión de nuevas bodegas, algunas recuperan y renuevan instalaciones existentes (por ejemplo de cooperativas), pero muchas son levantadas desde la nada. Hay una clara 
intención de utilizar la propia arquitectura como seña de identidad de la empresa vinícola, llevada al extremo en el caso de las bodegas Protos, en Peñafiel, que recurren a un arquitecto de renombre internacional, Richard Rogers para diseñar una bodega-icono, o el caso aún más extremo de bodegas Portia en Gumiel de Izán (al norte de Aranda de Duero), diseñadas por Norman Foster. Lo que queda claro es que las nuevas bodegas, que florecen por doquier "no se agrupan en barrios en torno a los núcleos de poblamiento, ni se construyen sobre las faldas de un cerro elevado para aprovechar mejor la sequedad de los terrenos más altos, sino que se distribuyen dispersas, sembradas en el campo, dominando pagos vitícolas organizados en su entorno, al estilo de los cortijos andaluces o de los chateaux franceses" (Molinero Hernando, 2012). Los silos constituyen otro ejemplo de cómo la organización territorial se adapta al nuevo sistema. Al acabar el régimen de monopolio estatal triguero, estos almacenes pierden su función. Estaban localizados en los municipios de cabecera más rurales ( 2 en Peñafiel y 1 en Roa) y en los municipios de rango 2 (Simancas y San Martín de Rubiales) en un modelo de desconcentración concentrada de la actividad productiva transformadora. Todos ellos son núcleos que van a perder protagonismo en el nuevo sistema productivo. Los regadíos siguen creciendo, pero ya únicamente de manera independiente y dispersa. La decisión queda en manos de la propiedad, no depende de gestión colectiva de un sistema de regadío. De hecho algún canal se abandona. Sí que se ponen en marcha proyectos de modernización de canales como en el caso del canal de Guma, para reducir las pérdidas de agua.

\section{- Accesibilidad y conectividad. Intensidad de infraestructuras}

La diferencia entre los distintos niveles jerárquicos - vías de alta capacidad y carreteras comarcales- se agudiza. Los planes de carreteras insisten en la necesidad de ampliar la red, con el objetivo de mejorar la conexión entre municipios y ese objetivo se convierte en la esperanza de los municipios rurales para no devenir irrelevantes. El caso del ferrocarril es todavía más acusado. En 1985 se cierra a los pasajeros la linea de ferrocarill Valladolid-Ariza, y en 1992 también a mercancías. Se desmantela la linea convencional que había servido para transportar viajeros y mercancías y se construye la linea de alta velociad AVE, que mejora la relación de Valladolid con Madrid. En defensa del AVE y las vías de alta capacidad se esgrime su potencial como elemento revitalizador de las ciudades, sin embargo resulta absolutamente impermeable a los territorios que atraviesa, tal y como reconoce el PEIT (2005). El tejido de comunicación histórico también vive una cierta dualidad. Por un lado hay un lento y aparentemente inexorable proceso de cierre de caminos, estos van quedando interrumpidos o desaparecen. Por otro lado las vías pecuarias han ido ganando rango de protección. Un último aspecto a reseñar es el de las infraestructuras de comunicación telemática. Las nuevas tecnologías de información y comunicación han posibilitado nuevas formas organizacionales de la cadena alimentaria (Delgado Cabeza, 2010).

\section{- Usos agrarios. Intensidad de la explotación}

La evolución de los cultivos responde a decisiones que se toman en ámbitos cada vez más alejados de las agricultoras y agricultores, ya sea por la aplicación de 
cuotas máximas de producción acordadas en la Unión Europea o por cierre o traslado de plantas de la industria agroalimentaria decididos por la correspondiente gran empresa. La pérdida de importancia de los cereales en la producción final agraria del país, que muestran las estadísticas económicas (Molinero 2006), se refleja en el territorio. La reducción de tierras de labor apreciable en la figura 11 es, con diferencia, el cambio más significativo en esta época. El nuevo destino de estas tierras cerealistas varía según las zonas. En el caso de Roa, que vive un auténtico resurgir del viñedo, mayormente se están transformando en explotaciones vitivinícolas, mientras que en los entornos de Tordesillas y Valladolid, se convierten en regadío en un proceso coherente con la mejor capacidad agrológica de esos ámbitos. En menor medida también sucede en Peñafiel, pero ahí sin una clara justificación agrológica. En las zonas de Aranda de Duero y en Peñafiel, las tierras de labor que se dejan de cultivar en cereal acaban en una buena parte (33 y $35 \%$ respectivamente) cubiertas por matorrales y en procesos de reforestación. El reconocimiento internacional de la calidad de los vinos locales, impulsada por las Denominaciones de Origen (DO), hace que este cultivo experimente un auténtico resurgir. La expansión del viñedo no es homogénea por el territorio.

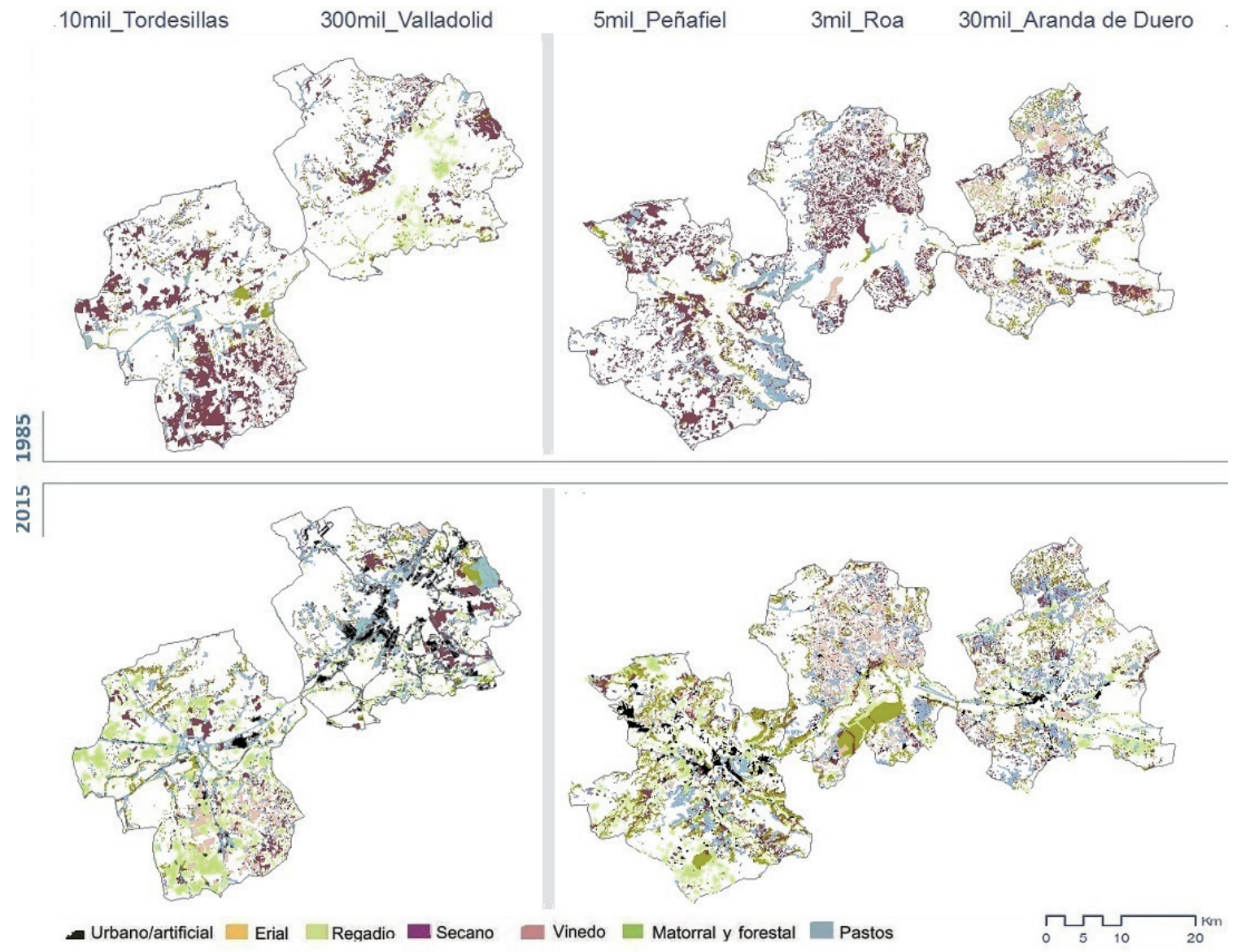

Figura 11. Cambios en los usos del suelo 1985 y 2015

Fuente: Elaboración propia 
Por un lado depende fundamentalmente de las condiciones adecuadas para las vides y de la inclusión o no de la zona en la delimitación acogida a una DO. Es llamativa la poca repercusión de este cultivo en los municipios intermedios, los de rango 2, que se mantienen continuistas con las dinámicas previas y no se embarcan en el sector vitivinícola.

\section{- Adecuación agrológica. Intensidad en el aprovechamiento de recursos locales}

Después de haber alcanzado los niveles máximos de sobreexplotación en los años 1980, se va produciendo un reajuste en los usos y cultivos. La dinámica más significativa en los municipios intermedios de rango 2, es que sigue la expansión de regadíos, intensificando por tanto la explotación del territorio con aumentos de la producción que se benefician de la combinación de empleo de abonos químicos y agua. En los municipios vulnerables los terrenos de labor en secano reducen su presencia significativamente, por su transformación en regadío, por replantarse con viñedos, por su reforestación o abandono y por el crecimiento de matorrales. Aunque no destaquen por su extensión, en comparación con otros fenómenos, cabe destacar la repoblación de laderas en Valladolid, por ser ejemplarizante en el sentido de recuperar estos espacios y luchar contra la fuerte erosión de los suelos que las afectaba. Desde la Comunidad Autónoma se fomentan los cultivos forestales, pero en la zona no hay plantaciones importantes de especies de crecimiento rápido como chopos o eucaliptos, que ejercen mucha presión sobre los recursos acuíferos.

\subsection{Correlación entre sistema agroalimentario y sistema territorial}

La combinación de las variables socioeconómicas con las principales características de la organización físico espacial a escala urbana y territorial, evidencia la incidencia del sistema agroalimentario dominante en la estructura y funcionamiento del sistema territorial.

\section{Territorio estructurado para el autoabastecimiento con agricultura familiar de proximidad}

Cuando era el territorio inmediato el que proveía una parte sustancial de la dieta, ésta se basaba en los alimentos que ese territorio permitía producir. Como se explica en el plano de la figura 12, hasta 1950 hay un alto grado de autoabastecimiento a partir de la gestión integral del territorio y de una agricultura de proximidad. Los núcleos eran multifuncionales, no solo residenciales, la intensidad edificatoria y de las infraestructuras es baja mientras que la intensidad demográfica se adapta a las condiciones locales. El sistema estaba organizado para permitir ese consumo local de alimentos. Los asentamientos se distribuyen según un esquema de desconcentración concentrada. Pequeños núcleos (pero por regla general no menores de 1.000 habitantes) se reparten por el territorio. Forman la base del sistema urbano que se apoya también en unos núcleos intermedios de referencia y una serie de ciudades de mediano tamaño, en este caso Valladolid con 
125 mil habitantes. La población así distribuida por el territorio puede gestionarlo directamente. De hecho el tamaño de la población en los núcleos rurales guarda estrecha relación con la capacidad productiva de la tierra, en una adaptación práctica a la capacidad de carga del territorio. El campo es fundamental para su subsistencia, puede que por ello no se construyan edificaciones más allá de las estrictamente imprescindibles.

Las tierras de cultivos se destinan fundamentalmente a cereales y viñedos, con parcelas de reducidas dimensiones que se corresponden con pequeñas explotaciones familiares. Una tupida red de caminos garantizaba la accesibilidad a las tierras de cultivo, que tenían que estar a una distancia asumible a pie. Las explotaciones eran intensivas en mano de obra, no se habían mecanizado y para los trabajos se contaba únicamente con la energía humana y animal. En esas condiciones la dispersión parcelaria (que luego se verá como un problema que impide la mecanización) no era fuente importante de conflictos, porque habitualmente no había que abarcar parcelas lejanas en una misma jornada. Históricamente los pueblos contaban con equipamientos de apoyo a la producción como eras para trillar o molinos y aceñas para moler el grano. También disponen de lagares y bodegas, éstas aunque sean de propiedad privada forman un sistema colectivo, auténticos barrios de bodegas interdependientes. Es decir, localmente se cuenta con los medios para asumir el proceso de conversión de la producción primaria en alimentos, tanto el cereal como el vino. Para la distribución de la producción se va pasando de las carretas al ferrocarril, gracias al cual se puede llevar hasta los centros mercantiles para su comercialización. Además de la producción para el mercado, era fundamental garantizar el autoabastecimiento de una gran parte del consumo alimentario.

Los asentamientos están organizados de manera que facilitan la producción para autonsumo. Rebaños de ovejas, gallinas, conejos y cerdos, ganado de labor, etc. encuentran su acomodo en el núcleo urbano, junto al hogar y contribuyen a cerrar ciclos, se alimentan de restos y producen abono para las tierras. También se dispone de huertos y frutales para autoconsumo ya sea en patios dentro del núcleo o en parcelas de borde. El hogar es, a su vez, la unidad básica de transformación y preparación de la inmensa mayoría de los alimentos, desde pan o conservas hasta la matanza. La mayor ocupación de suelo urbano por habitante en núcleos rurales respecto a los urbanos, se debe pues a que los primeros incluyen en la trama urbana actividades y usos agropecuarios. No se pueden comparar sus valores de consumo de suelo urbano con los de las ciudades que satisfacen sus necesidades sirviéndose de otros territorios. 


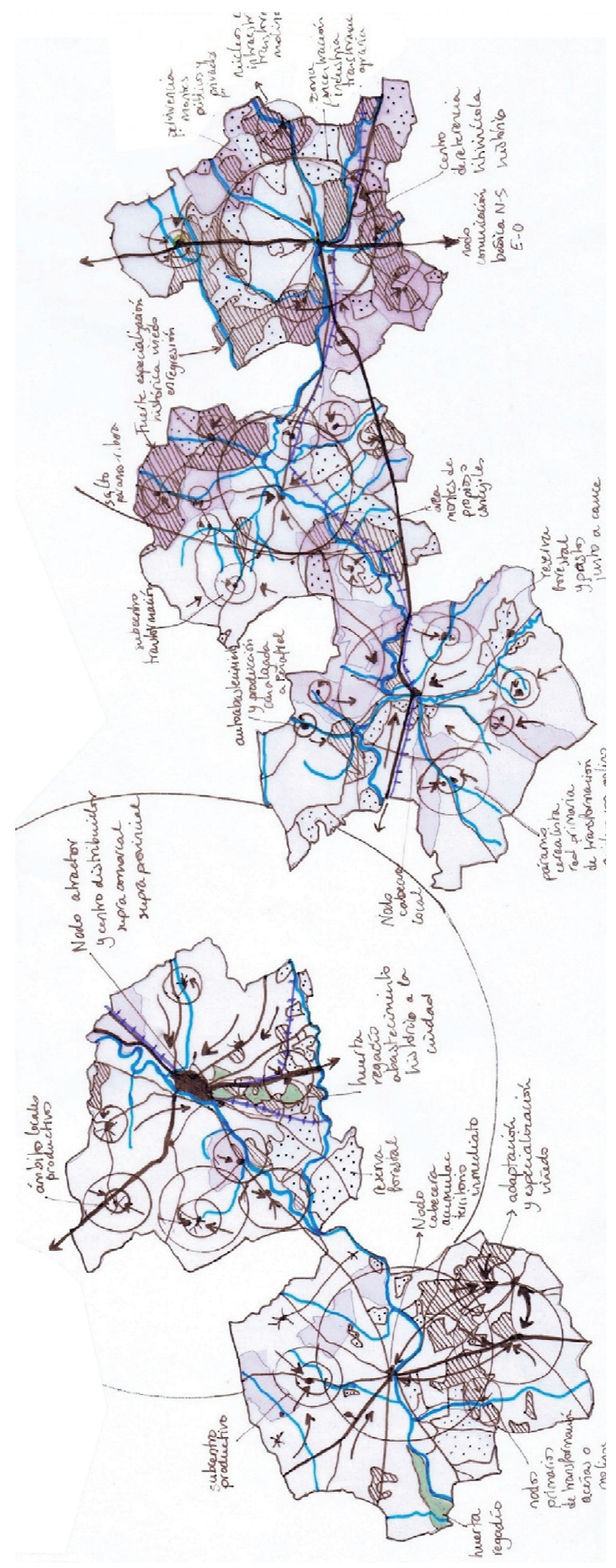

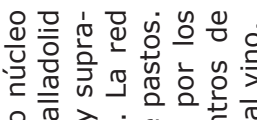

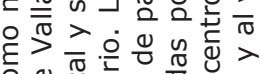

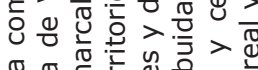

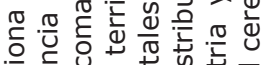

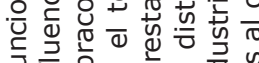

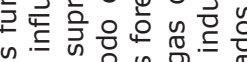

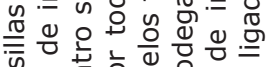

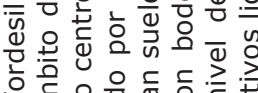

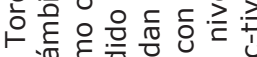

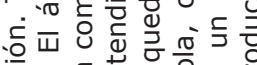
喵

동 운 등

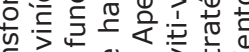

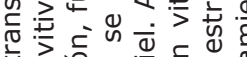

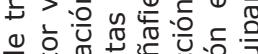

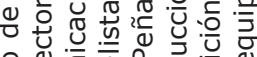

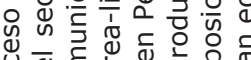
ปัव

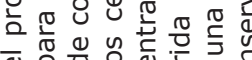
ฮั

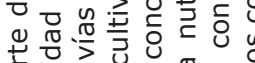

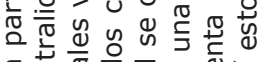
屯

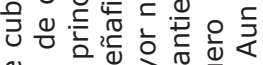

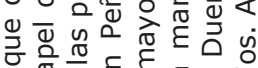

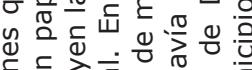

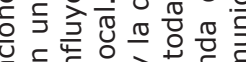

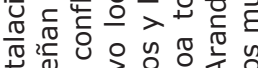

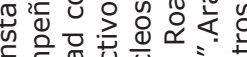

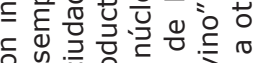

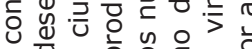

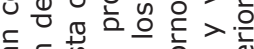

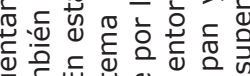
उ 施

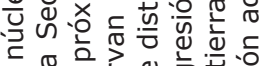

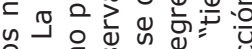
으 > ه

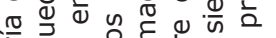

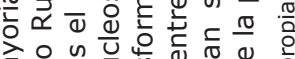

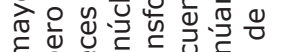
ช

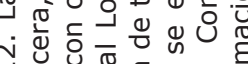

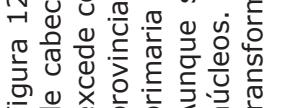




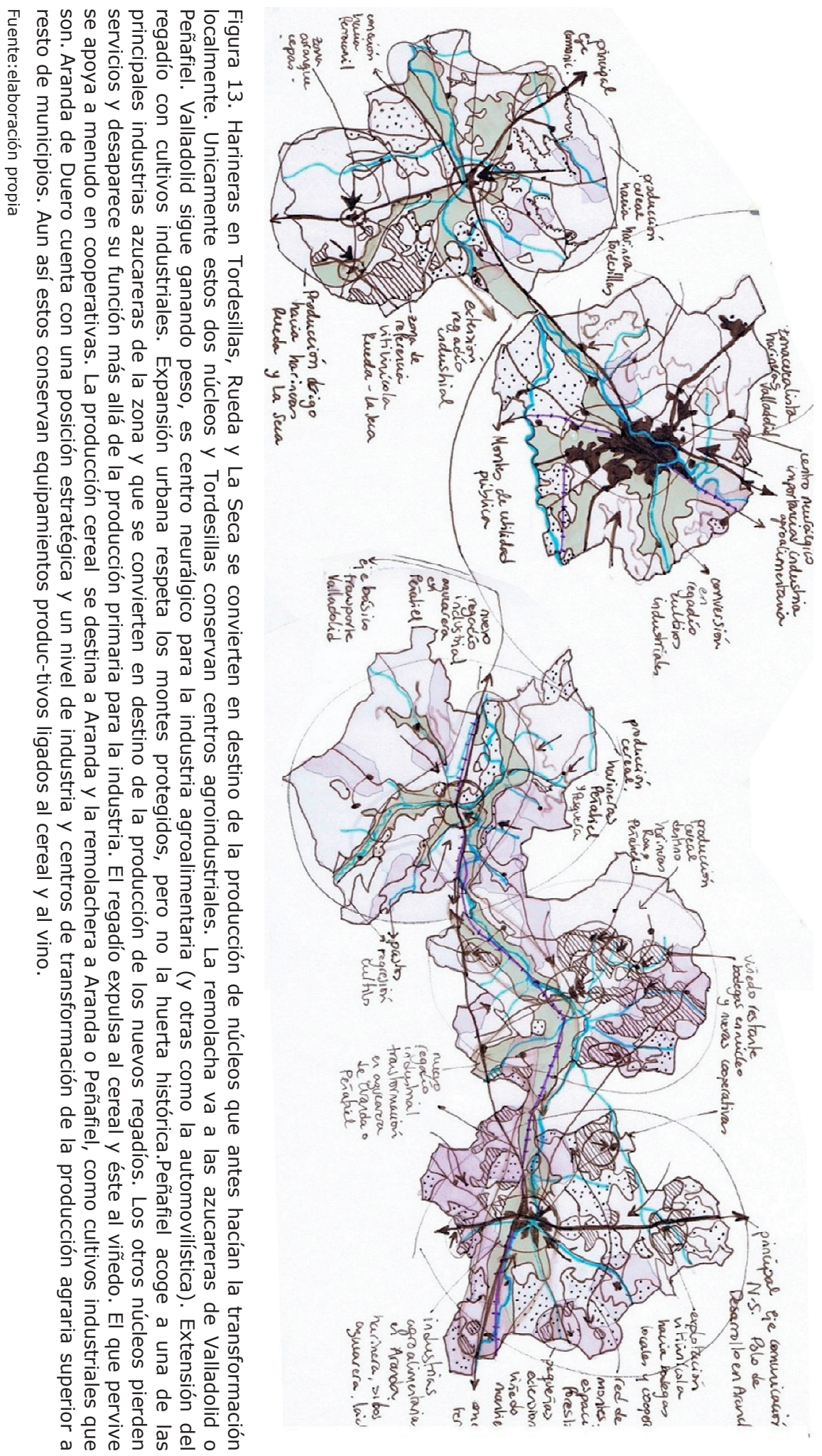




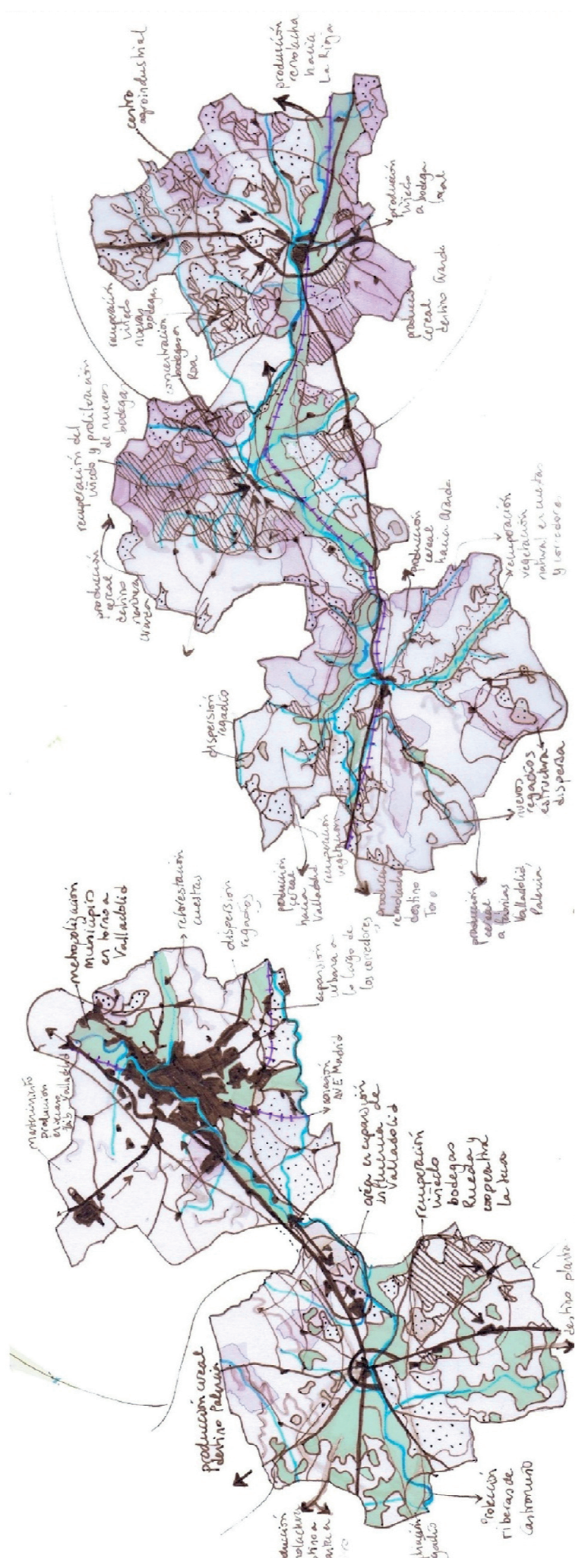

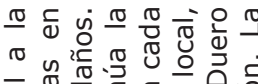

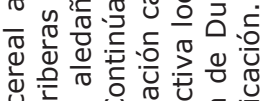

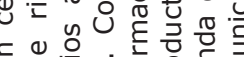

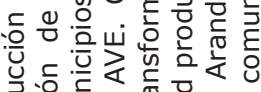

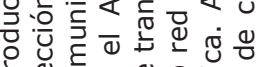

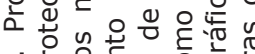

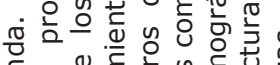

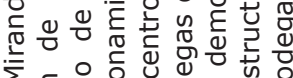
$\Sigma \simeq$ 은

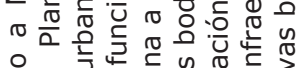

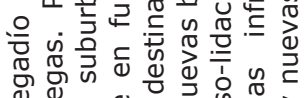

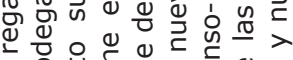

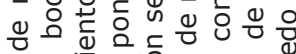

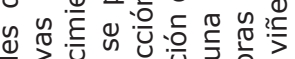

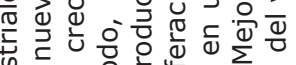

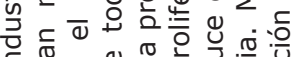

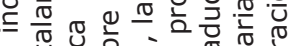

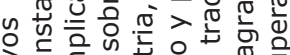

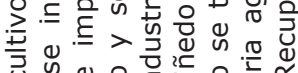

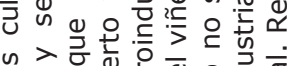

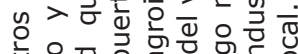

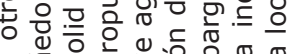

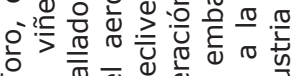

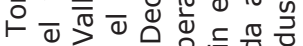

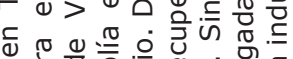

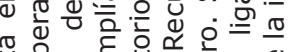

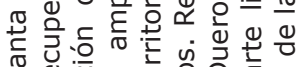
은

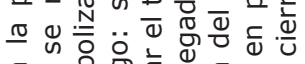

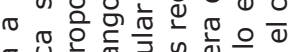

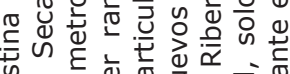
ขึ

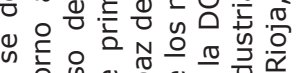

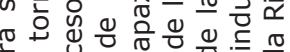

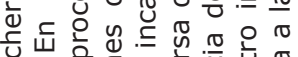

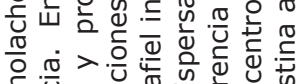
है.

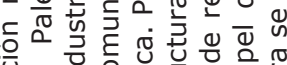

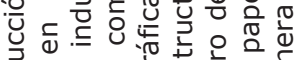

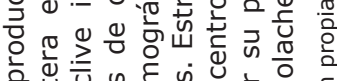

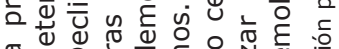
匹

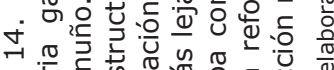
-1

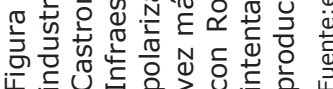




\section{Reestructuración territorial para la producción industrial y el consumo de masas}

Bajo la lógica del desarrollismo el territorio se organiza para abastecer a la industria y la industria alimentaria se organiza para asumir por completo la producción de alimentos. Para que el modelo funcione hay que cambiar radicalmente tanto el sistema de producción como el de consumo, haciendo que ambos giren en torno a la industria alimentaria. Comenzando por el consumo, evidentemente hay una mayor presencia de alimentos industriales y un cambio en la dieta: las legumbres y cereales pierden protagonismo y se generalizan alimentos que ya no es posible obtener localmente. Es esencial favorecer la concentración de la demanda y el consumo de masas. La emigración campo ciudad no solo sirve para garantizar suficiente mano de obra para la industria, también concentra la población. Valladolid y Aranda como polos de desarrollos que son, multiplican su población por 2,5. Valladolid supera los 330.000 habitantes. Se pasa a un esquema de concentración concentrada.

Por un lado, los emigrantes pierden su conexión directa con los medios de producción y el autoabastecimiento se reduce a aquellos productos con los que vuelven cargados después de visitar el pueblo de origen. Por otro lado, el sistema basado en el consumo de masas se beneficia de la concentración de la demanda que favorece la distribución a gran escala. Los hogares siguen siendo el principal lugar donde se cocinan y preparan los alimentos, pero ya no los cultivan, y además se introduce una creciente cantidad de productos elaborados o semielaborados que se adquieren en el mercado (yogures, pan, pasta, embutido, carne...).

Si se analiza la producción, con la agricultura industrial el medio rural se debilita, se simplifican las estructuras sociales y ecológicas. El paradigma productivo pasa a estar basado en la especialización y en la ampliación del tamaño de las explotaciones, cuando es posible, apoyándose en cooperativas. Cada territorio debe especializarse según sus ventajas comparativas, en este caso los cereales, mientras que el viñedo se destierra por su menor rentabilidad, o por su mayor dificultad para la mecanización. Explotaciones más grandes y especializadas justifican la inversión en maquinaria y, en su caso, en instalaciones individuales de regadío. Los planes de concentración parcelaria contribuyen a consolidar el modelo. La mecanización penaliza la dispersión parcelaria y el reducido tamaño pues plantean problemas de ineficiencia, se emplea más tiempo en trasladarse entre parcelas que en trabajarlas. Cambia la estructura parcelaria y de caminos, se extienden los monocultivos transformando el paisaje.

El nuevo esquema productivo rompe con el sistema integral anterior. Ahora que ganadería y agricultura se gestionan de manera separada, el modelo industrial también llega a las granjas. La ganadería estabulada se localiza en granjas fuera del núcleo habitado y se alimenta de piensos compuestos, desligándose pues del territorio inmediato. A su vez la agricultura pasa a depender de agroquímicos para reponer nutrientes y enfrentarse a las plagas. Las nuevas explotaciones ganaderas, de grandes dimensiones, ya no son compatibles con la residencia, por lo que los núcleos pierden buena parte de su carácter multifuncional. La concentración de actividad y del consumo van de la mano de la construcción de vías de comunicación 
más rápidas y de mayor capacidad. La combinación de todas las medidas del proceso modernizador tiene un efecto de deconstrucción del territorio, se desintegran las estructuras que le permitían funcionar como un todo unitario. Las estructuras y edificaciones inadecuadas para el nuevo sistema agroalimentario, se abandonan. Los medios locales de apoyo al proceso de producción de alimentos desaparecen, ya sea porque se vuelven innecesarios como sucede con las eras o porque se concentra la actividad transformadora en un número más reducido de localidades.

\section{Enclaves territoriales para satisfacer un consumo segmentado}

La globalización también llega al sistema agroalimentario, su organización, su lógica y su funcionamiento trasciende los límites nacionales. Tiene además que responder (y alentar) a una demanda cada vez más segmentada, de manera que las empresas presentan varias lineas del mismo producto, cada una orientada hacia un público específico. El sistema agroalimentario y el sector primario no siempre van de la mano, y para este último son necesarias nuevas estrategias para afrontar la crisis agraria en la región. Algunas de las estrategias relativizan la producción agraria en favor de otros servicios que presta la agricultura y la ganadería.

De cara al territorio, se exacerba la tendencia a la polarización iniciada con la industrialización, se acentúa tanto en términos demográficos como funcionales. El consumo ya no organiza el territorio, se satisface mediante los puntos de comercialización, donde van ganando terreno las grandes superficies, también en el medio rural. Constituyen otra forma de enclaves territoriales, superpuestos al territorio pero sin apenas interacción con él. Excepto por alguna contada excepción, por ejemplo en el sector lácteo, los productos en los lineales tienen poco que ver con el territorio o esa relación está mediatizada por algún gran grupo empresarial. La tendencia a reducir el número de explotaciones y aumentar el tamaño de las resultantes, continúa. A esto se le une ahora una tendencia similar en el tejido agroindustrial. En varios sectores como el galletero o el lácteo se reduce el número de empresas, se producen fusiones y concentraciones en un cada vez más reducido número de grupos empresariales.

Con cada concentración empresarial hay un reajuste del sistema productivo. Se reducen los centros de transformación y se concentra la actividad agroindustrial en un menor número de enclaves. El aumento de la escala de producción y la selección de los enclaves no se plantean ya en clave regional, a veces incluso ni siquiera en clave nacional, sino internacional. Como resultado, se eliminan agroindustrias en el territorio (azucareras y harineras, por ejemplo). El alejamiento de las fábricas convierte al territorio en mero proveedor de unas pocas materias primas, se pierden muchos de los encadenamientos productivos anteriores y el tejido industrial y empresarial local queda debilitado ante la reducción de empleos y funciones. Las dinámicas del sector vitivinícola muestran otro camino.

Al hilo de la reducción de la actividad agraria, se desarrollan planes regionales de reforestación de tierras agrícolas. Al cambio de funcionamiento del territorio, desligado del tejido local, se le añaden las dificultades por las que pasa el sector agropecuario que hacen que en las últimas décadas se cuestione continuamente su 
viabilidad frente a la competencia exterior. No se ve la necesidad de preservar el campo ni su función productiva, se puebla de nuevas instalaciones y edificaciones ajenas a la lógica productiva agropecuaria, que reflejan una suerte de negación agraria. También se multiplican las segundas residencias y otras edificaciones, muchas veces fuera de la legalidad, que desde el imaginario colectivo ya no se ven como un problema que interfiera con las dinámicas agrarias. En la misma línea, en las últimas décadas del siglo $X X$ se produce el salto urbano en parte de los municipios, la expansión ya no es continua, se dispersan los desarrollos urbanos.

Enfrentados a la crisis agropecuaria, se intenta potenciar la agricultura multifuncional y con ella el paisaje y la identidad como elementos de valor para los productos de calidad. Unos valores que dependen del quehacer de las personas de las explotaciones agropecuarias. Frente al modelo globalizador que niega el territorio, resurgen otros núcleos, que son una suerte de "antienclaves", como en Piñel de Abajo, que recupera una gestión integral del territorio y se vincula directamente con colectivos urbanos que los apoyan. Emergen otros proyectos ligados a circuitos cortos y a grupos organizados de consumidores urbanos comprometidos con un modelo agroalimentario diferente. Pero son iniciativas todavía dispersas y la mayoría con una capacidad reducida de reestructurar el territorio poco más allá de su propia finca.

\section{URBANISMO, APROVECHAMIENTO DE RECURSOS LOCALES Y SOSTENIBILIDAD}

\subsection{Sostenibilidad, autonomía, estabilidad y resiliencia}

Estabilidad, resiliencia y autonomía, estos son de nuevo los tres principios básicos de la agroecología que se toman como referencia para interpretar la evolución del sistema territorial en función del sistema agroalimentario e identificar los factores clave de adaptación a las condiciones locales que pemitirían reducir la insostenibilidad del sistema. Se entiende además que los grupos humanos forman parte de los ecosistemas. Las figuras 12 a 14 representan las relaciones territoriales que se han identificado en cada una de las etapas analizadas. La descripción del sistema tecnológico es válida con carácter general para todo el territorio, pero el grado de adopción de las innovaciones, la forma concreta que éstas adoptan y el papel de cada zona varía según el tipo de municipios de que se trate.

\section{Autonomía y resiliencia de sistemas de base orgánica}

En la medida en que el territorio conservaba elementos de los modelos agrosilvopastoral y preindustrial, conservaba también importantes niveles de autonomía. Los medios para la explotación agraria estaban al alcance de una amplia capa de la sociedad, al fin y al cabo en esta zona perduraba una agricultura mayormente familar basada en la auto explotación. Los grupos más precarios dependían del acceso a los recursos comunales, y su desafección les puso en dificultades. No hay que entender la autonomía desde la unidad de explotación, pues ésta forma parte de un sistema. 
La autonomía se extiende a todos los municipios, pues una mayoría de los de menor rango, los frágiles, cuentan con alguna de estas instalaciones o equipamientos para la puesta en valor de la producción directa y para su inserción en el circuito de consumo -o de autoconsumo-. El sistema territorial, sin ser estático, conserva un cierto grado de estabilidad. Desde la agroecología el término se aplica a la estabilidad en la producción, aquí se amplía a la estabilidad del grupo social, es decir a la capacidad de auto reproducción social que ofrece el sistema. Entre los municipios vulnerables ya hay una tendencia demográfica regresiva, y la mitad de los municipios perdieron población entre 1900 y 1950, lo mismo sucedió en el 40\% de los municipios de rango 2. De todas formas, desde la dimensión humana, la estabilidad es mayor a la que se va vivir en las siguientes etapas. Que fuera estable no quiere decir que fuera siempre satisfactorio, como dan cuenta las referencias históricas y literarias sobre la dureza de las condiciones de vida.

La relativa estabilidad demográfica está relacionada con la estabilidad en la producción. La presión sobreexplotadora es mayor en los municipios vulnerables, donde la agricolización no ha respetado las restricciones naturales. El aumento de producción que en otras áreas más septentrionales se logra mediante la aplicación de abonado animal, aquí está más restringida, pues a pesar de dejar un tercio de las tierras en barbecho, de manera que pueden ser aprovechadas a diente, la falta de agua no facilita el crecimiento de los pastos y las posibilidades de alimentar el ganado cuyo estiércol serviría para enriquecer los suelos, son limitadas. Así que la producción es relativamente estable y relativamente escasa. Puesto que es una economía de base biológica, no hay residuos como tales, ya que todo puede revertirse al sistema ecológico, todo tiene una utilidad. Por último, hay que destacar dos aspectos que contribuyen a la resiliencia del sistema. Por un lado la biodiversidad asociada al empleo de variedades adaptadas a las condicones locales, decantadas a lo largo de siglos. Biodiversidad también en modestas estructuras

territoriales, los linderos entre parcelas, que ofrecían con frecuencia un complemento para la dieta de las familias campesinas, pues en ellos encontraban desde frutos silvestres hasta caza menor de especies que tenían su hábitat natural en setos y vegetación de separación de parcelas o junto a elementos lineales como arroyos o canales.

Por otro lado, para el mantenimiento del sistema es fundamental el conocimiento local y la inserción de la población en los procesos ecológicos del ecosistema agrario del que son parte.La resiliencia emana de la capacidad de reconocer fallos en el sistema, en tanto que sus efectos se hacen patentes en el mismo territorio, no se trasladan a otros lejanos y el reconocimiento de ese territorio forma parte de la cultura de las personas que lo habitan. La lentitud con la que hasta entonces se habían producido los cambios, con dinámicas de prueba y error, hace que las soluciones que se adoptan sean blandas y adaptables, y el sistema resultante, más resiliente.

\section{Ruptura con la autonomía local, inestabilidad inducida}

La progresiva capitalización de las explotaciones, con un creciente grado de mecanización y dependencia de recursos externos, provoca una pérdida de autonomía del sistema. Es algo promovido y potenciado por las políticas públicas que 
se diseñan desde un paradigma de desarrollo basado en la especialización y en el que los mercados y los intercambios tienen que ganar protagonismo. Se pierde autonomía a nivel de municipio, a nivel de comarca los núcleos de referencia (rango 1) siguen conservando una función central que articula la producción de su entorno, de hecho de entornos cada vez más amplios para beneficiarse de las economías de escala. Entre los municipios que logran mantener estructuras de transformación, vinculadas a la agroindustria, ganan peso las variables logísticas y de capital. La evolución de Aranda de Duero frente a Tordesillas lo ejemplifica. En paralelo, la creación de cooperativas permite compartir recursos y dotarse de infraestructuras comunes (tractores o bodegas, por ejemplo). Es cierto que mejora su autonomía y su capacidad de negociación de precios, pero no mejoran la autonomía del sistema en términos ecológicos. Las cooperativas tienen mayor presencia en los municipios de cabecera y en los de rango 2. Con la ampliación de escala de producción, las granjas industriales avícolas incrementan su presencia en torno a los núcleos de referencia. Pueden abastecer una parte importante de la demanda desde el entorno inmediato, pero con un sistema industrializado sin base ecológica local.

El sistema prima los núcleos mejor comunicados (municipios de cabecera) para canalizar la producción hacia el mercado. Una producción que ha aumentado respecto la etapa anterior y que alcanza la estabilidad a costa de incorporar una creciente cantidad de insumos externos. Es decir, no es una estabilidad inherente al ecosistema, no cumple el criterio agroecológico. También los monocultivos, favorecidos por el sistema agroalimentario, son un factor de inestablidad que aumenta la vulnerabilidad. En términos demográficos la inestabilidad es la nota predominante, la reducción de población en los municipios vulnerables es constante, en los de rango 2 también, exceptuando los que se encuentran en el área de influencia de Valladolid. De esta manera, en la dinámica demográfica el factor ecológico (capacidad de carga) del término municipal deja de ser una variable con incidencia, desaparece en favor de la proximidad al núcleo con mayor actividad económica. En definitiva, la reorganización del territorio para adaptarlo a los nuevos modos de producción, deshace el complejo sistema territorial, simplificando estructuras ecológicas y ambientales.

Los procesos impulsados por los gobiernos para facilitar los sistemas de explotación mecanizados se trasladan a todos los municipios, independientemente de sus condiciones de partida. El resultado es que la resiliencia se ve reducida, hay una pérdida de control y capacidad de respuesta por parte de los agentes locales. También se ha perdido la relación directa y la comprensión de los efectos inmediatos que tiene la presión agrícola sobre el propio ecosistema.El conocimiento tradicional es sustituido por otro exógeno asociado a las nuevas tecnologías y prácticas de manejo. La aproximación del modelo productivista implica una gran movilización de recursos y la transformación de infraestructuras. Para los ámbitos rurales este enfoque duro conduce a una fuerte diferenciación en la estructura territorial entre los nodos de alto rango y el resto del territorio.

\section{Desconexión del ecosistema}

En esta época se agudizan los fenómenos detectados antes, de pérdida de autonomía, estabilidad y resiliencia, pero frente a esta tendencia que es general, 
surgen nuevas formas organizativas y productivas, que pueden utilizar las nuevas tecnologías para crear un sistema paralelo que avanza en la dirección opuesta, planteando como Schumacher en la cita que abre el cuaderno, que no siempre más y mayor, es mejor. La pérdida general de autonomía de los agroecosistemas locales (y de los socioecosistemas) se hace más extrema. Por una parte se alarga la cadena productiva y gana fuerza la presencia de grandes grupos alimentarios y corporaciones, cuya lógica de inversiones y estratégica escapa al control de la población local. Con alguna contada excepción (en los municipios de referencia de Valladolid y Aranda y en el sector vitivinícola), las explotaciones agrarias en los distintos tipos de municipios se limitan a ser proveedoras de materias primas, no de alimentos. Después de la cosecha se inicia un largo proceso de transformación y distribución a la que resultan completamente ajenos, más allá de convertirse en meros consumidores de los productos finales.

En el caso de las bodegas, es cierto que éstas se instalan en todo tipo de municipios, también en los de menor rango, pero lo hacen en una proporción muy inferior a las que se instalan en los municipios de referencia. Ante la progresiva concentración empresarial y la entrada de capital de inversión y de grupos que buscan diversificar su producción, entra en cuestionamiento el auténtico enraizamiento local de un sector como el vitivinícola, histórica y materialmente ligado al territorio. Precisamente en este contexto de creciente competencia y ante la llegada de nuevos actores, aquellos que cuentan con un pasado familiar vitivinícola lo anuncian y exponen omo un valor más de sus bodegas.

Por otra parte, en todos los sectores, con el aumento del tamaño medio de la explotación y de la complejización del proceso productivo, las pequeñas explotaciones familiares se vuelven cada vez más vulnerables. La vía de externalizar la producción, con la entrada de empresas de servicios que se encargan de todas las tareas productivas es el caso más extremo de pérdida de autonomía y anula en la práctica a los actores locales. En cuanto a la estabilidad, los ecosistemas dan muestras claras de agotamiento, que se evidencian tanto a nivel local como global. En el ámbito local, se observa en los procesos de erosión de suelo o contaminación de las aguas, en el ámbito global el cambio climático induce una progresiva desertificación que pone en riesgo los agrosistemas de estas tierras.

Frente a este agotamiento se ponen en marcha proyectos de regeneración (como los sucesivos programas regionales de forestación de tierras agrícolas) y hay una progresiva reducción de la superficie cultivada. Pero no tiene un carácter estructural, son actuaciones dispersas, la mayor parte de las veces sin un plan común. La estabilidad de la producción está sometida también a los vaivenes de las políticas y subvenciones, incluso con una nueva valoración de la agricultura como elemento clave del paisaje, proveedora de servicios y que fija población rural, donde se subvenciona su mantenimiento sin que la producción sea lo importante. La inestabilidad demográfica continúa, es más, la polarización demográfica se agudiza. Si bien Valladolid, el principal de los municipios de cabecera, pierde población, lo hace en beneficio de los municipios aledaños con los que en la práctica pasa a formar una unidad funcional. La evolución de los de rango 2 y 3 depende más de su localización en relación a un municipio con suficiente capacidad de atracción, que a sus propias características intrínsecas. 
La situación más crítica se da en los entornos de las cabeceras de menor tamaño, incapaces ya de contribuir a articular el territorio en derredor, que pierde población a grandes pasos y la que permance está muy envejecida, quedando en una situación muy delicada de cara al futuro.

En este contexto la resiliencia se resiente. Se trata de agrosocioecosistemas en los que las personas relacionadas con el sector agrario han perdido el control y el conocimiento sobre los medios de producción y sobre el propio sistema. La biotecnología, o los organismos modificados genéticamente llegan a conformar un sistema integral independiente, que engloba semillas, pesticidas, fertilizantes... y que se superponen a los ecosistemas locales sin relación con el medio local. La capacidad de reacción desde la explotación ante alguna perturbación es prácticamente nula, se va difundiendo un sistema opuesto a la redundancia y la diversidad propia de la naturaleza y de los sistemas agrarios tradicionales. Surgen grupos autónomos que conscientemente construyen nuevos nodos desligados del sistema mayoritario para poner en marcha proyectos con criterios de resiliencia, estabilidad y autonomía.

\section{LA RELOCALIZACIÓN AGROALIMENTARIA EN LOS PLANES DE ORDENACIÓN TERRITORIAL}

Como remate de la investigación se explora la manera en que cada instrumento de ordenación permitiría actuar sobre los factores clave y redundarían en una mejora del sistema según los criterios de la agroecologia (autonomía, estabilidad y resiliencia). Los resultados de una investigación anterior (Simón Rojo, 2013) mostraban que el $75 \%$ de los municipios españoles de tamaño medio -entre 50.000 y 250.000 habitantes- podían satisfacer sus necesidades de alimentos aprovechando la capacidad agropecuaria existente en un radio de 10 kilómetros. Pero evidentemente, abastecer de alimentos no es solo cuestión de contar con la superficie productiva suficiente, esa producción primaria tiene que transformarse en alimentos y llegar hasta los consumidores. Con hortalizas y verduras la venta directa puede ser prácticamente inmediata (excepto para las conservas) pero no sucede así con toda la producción.

\subsection{La dimensión alimentaria, ausente de los planes de ordenación}

El planeamiento se encarga de asegurar la disponibilidad de recursos necesarios para la vida urbana (aire, agua, alojamiento), mediante la ordenación y normas de usos del territorio. Sin embargo, no han tenido en cuenta la dimensión alimentaria y no se han definido medidas para asegurar la producción local, la calidad y la accesibilidad para la población local. Hasta ahora la planificación urbanística se ha orientado fundamentalmente a definir un proyecto urbano que se expande sobre el territorio, en un proceso con nefastas consecuencias ambientales y sociales. En adelante debería tener como objetivo ordenar los recursos locales en un proyecto territorial complejo. 
Los Planes de Ordenación Urbana y Territorial definen la organización de ciudades, pueblos y territorios y sus propuestas tienen una gran incidencia en las relaciones que se establecen entre la ciudad, sus habitantes y el entorno periurbano y rural. La Estrategia Española de Sostenibilidad Urbana y Local (EESUL) publicada por el Ministerio de Medio Ambiente en 2009 destaca que la lucha contra el cambio climático depende entre otras cosas de los estilos de vida y la gestión de los flujos metabólicos que deberían responder a una utilización racional de los recursos naturales, que hagan posible conjugar la calidad de vida con la calidad ambiental.

La revisión de los Planes de Ordenación Municipal y de los principales planes de ordenación territorial, analizando la manera en que toman en consideración los factores identificados en el apartado anterior, permiten reconocer las carencias de estos instrumentos en cuanto al tratamiento de los espacios agrícolas y del sistema agroalimentario. El marco legal al que están sujetos los Planes de Ordenación queda establecido mediante la Ley del suelo o la Ley de Urbanismo. Lo primero que hay que señalar es que no hay ninguna referencia a la alimentación (sí a otros servicios básicos que deben quedar garantizados, como los suministros y los equipamientos públicos de salud, educación, deporte, etc).

Es la legislación agronómica la que aborda parcelaciones, infraestructuras, usos del suelo agrícola, etc. No parece haber hasta el momento ninguna confluencia ni interacción entre ambos campos. A pesar de que abarcan el conjunto del municipio y no solo la parte urbana, los planes de ordenación municipal se plantean en términos fundamentalmente urbanos, y con unos objetivos de oferta de suelo para nuevas actividades y para la canalización y planificación de nuevos desarrollos edificatorios. Teniendo en cuenta este marco general, no es de extrañar que los Planes de Ordenación no se ocupen prácticamente de ninguno de los factores identificados anteriormente.

\section{Clasificación y regulación de usos de suelo}

Los suelos actualmente con usos agrícolas se clasifican como suelo no urbanizable común o suelo de especial protección o simplemente de protección (la terminología varía), entre otros por su especial valor agrícola, forestal o ganadero (tal y como recoge la Ley) o matizando estas cualidades en los propios planes, para referirse a su cualidad agrológica o a su valor productivo. Lo habitual es que el suelo no urbanizable común sea el más extenso y que se permitan los usos racionales para la explotación de sus recursos naturales, aludiendo a la legislación específica para una mayor concreción. En el suelo no urbanizable de protección agrícola o agropecuaria se toleran construcciones agropecuarias o vivienda unifamiliar si están ligadas directamente a la explotación. Suele afectar a ámbitos más reducidos, por ejemplo en Peñafiel solo las zonas del norte, en los meandros del Duero, son de especial protección, eso sí, dando continuidad a otros suelos agrícolas protegidos de la Ribera.

Conforme a la clasificación de suelo, en los planes se plantea una regulación de usos genérica que no aborda ninguno de los aspectos señalados en el apartado anterior, ni la adecuación de usos a las cualidades del terreno, ni el fomento de la biodiversidad mediante elementos lineales ni la interacción con espacios semi 
naturales. Los planes sí que han optado por proteger por su valor ambiental algunos terrenos degradados por una inadecuada explotación agrícola. En algunos casos han sido objeto de planes de restauración ecológica o al menos de forestación. En Aranda, Valladolid y Peñafiel las riberas de los ríos en las proximidades o a lo largo de los núcleos, han sido acondicionadas como espacios de recreación y red de espacios verdes.

\section{Definición de la red de equipamientos e infraestructuras}

En ningún caso se considera ampliar o reforzar la red de equipamientos para procesado. Los planes se orientan preferentemente hacia la definción de nuevas zonas logísticas o industriales, incluso en algún caso especifican su vocación agroindustrial, pero según una lógica alejada de la relocalización de los sistemas alimentarios. Cuando quedan vestigios de elementos históricos para transformación de las materias primas, éstos se suelen valorar y proteger. Es un enfoque patrimonialista, por supuesto necesario, pero que obvia cualquier reflexión sobre el sentido funcional en el pasado como elemento estructurante en la gestión integral del territorio. Es lo que sucede por ejemplo con los molinos sobre el Duratón en Peñafiel, catalogados como BIC con protección integral (PG 1999). Los barrios de bodegas son otro claro ejemplo de este tratamiento de preservación formal del patrimonio. Es frecuente que se proteja el área de bodegas, por ejemplo las situadas en el borde del núcleo histórico de Peñafiel (PG 1999) donde delimita un área de bodegas merenderos. El Plan únicamente explicita como objetivo el de "mantener en la medida de lo posible la imagen de los antiguos vendederos" (PG, p. 41 del documento de Normativa) con una ordenanza específica.

\section{Calificación, regulación de usos y destino de las edificaciones}

Hay una regulación escueta de la posibilidad de edificar en el suelo agrícola, limitada por lo general a aquellas edificaciones necesarias y vinculadas con las explotaciones agrarias en el caso de los suelos protegidos. Cuando se trata de suelo no urbanizable común, las limitaciones van encaminadas a evitar la formación de núcleo de población. Destaca la escasa capacidad real de controlar las nuevas construcciones, un problema de falta de disciplina urbanística para evitar las construcciones ilegales y fuera de ordenación. Es frecuente el desarrollo de urbanizaciones desconectadas del núcleo histórico en suelo de buena calidad agrológica. No hay una visión de las edificaciones integradas en el sistema agroalimentario, que se entiendan interrelacionadas y que funcionan formando parte de un conjunto. Hay un problema añadido en lo que se refiere a edificaciones y zonas que han perdido su función o ya no están operativas. El abandono de la actividad va acompañado de un lento deterioro. Cuando un plan hace referencia a actividades pecuarias y agrícolas en edificaciones, como sucede en el caso de las situadas en los núcleos rurales de Melida, Aldeyuso y Padilla de Duero y al propio barrio de San Vicente dentro de Peñafiel (PG 1999 pg 43), el Plan alude a ellas para decir que quedan reguladas por la normativa específica, no porque tenga ninguna idea propia al respecto. Mejorar la capacidad productiva dentro de la dinámica globalizadora y competitiva, se reduce a ofrecer suelo para atraer inversiones. Una estrategia que ha demostrado ser poco exitosa. 


\subsection{Actualización de la tipología de municipios y sus interrelaciones}

Todos los Planes de Ordenación pueden hacerse eco de la necesidad de tener en cuenta la alimentación y el tratamiento de los sistemas agroalimentarios (no solo de los espacios agrícolas) en sus propuestas. Pero estas propuestas deberían hacerse teniendo muy en cuenta las condiciones particulares de cada caso, ya que no hay una fórmula genérica con validez universal. Es importante considerar todo el proceso alimentario, no únicamente la actividad productiva a nivel de la finca agrícola o ganadera. En este sentido, la localización en las proximidades de un núcleo de primera referencia como Valladolid, y la conexión con el mismo mediante unas infraestructuras de comunicación de alta capacidad, ha cambiado por completo el carácter de municipios que habían sido considerados como vulnerables. Ya se explicó que las cualidades agrológicas y la capacidad de producción primaria han dejado de ser un factor clave para la evolución del municipio y para su categorización. Es decir, hay que seguir considerando las características agrológicas y la capacidad productiva del municipio, pero hay que hacerlo junto otros factores, como su proximidad y relación con los núcleos de referencia de primer nivel; o en términos de sistema agroalimentario por, su proximidad y relación a núcleos que concentran la demanda y cuyas necesidades de alimentación hay que satisfacer. Un tercer aspecto a considerar es la disponiblidad de infraestructuras y equipamientos para fijar cadena de valor local, incluido el capital humano y relacional. A partir de la combinación de estos factores se pueden reconocer cinco situaciones básicas características:

- Municipios metropolitanos, son los sumideros, que funcionan gracias a considerables extensiones territoriales y que movilizan en su derredor múltiples recursos. En este territorio únicamente Valladolid corresponde a esta categoría.

- Municipios del alfoz o periurbanos, en el entorno de algún municipio metropolitano, conservan parte de la actividad agropecuaria, pero están sometidos a una intensa presión urbanizadora.

- Municipios mediadores nodales, Aranda de Duero, Roa, Peñafiel y Tordesillas son núcleos de cabecera o referencia pero de carácter "mediador", no se constituyen en destinos de la producción sino que facilitan procesos agroalimentarios que tienen como destino los centros de primer nivel.

- Municipios de aprovisionamiento, concentran la actividad productiva y solo selectivamente algunas de las infraestructuras primarias de transformación y procesado.

- Municipios de reposición o de reserva, que incluyen a los municipios que quedan fuera del alcance directo de las áreas metropolitanas y de los municipios nodales.

No se trata de categorías estancas, según su evolución municipios de reposición pueden devenir en municipios de aprovisionamiento o viceversa. Pueden emerger nuevos mediadores nodales o alguno de los existentes perder ese papel, etc. La estabilidad demográfica de los grupos humanos no es posible lograrla a corto plazo 
para todos. Un papel clave tienen los municipios nodales y los de aprovisionamiento, pues son los entornos que cuentan con mejores condiciones de partida y cuentan con servicios de salud y cultura, mientras que el empleo se reforzaría con el proceso. Los municipios de reserva se benefician en cualquier caso de las mejoras en los municipios vecinos y potencialmente se puede paralizar el proceso de drenaje poblacional.

\subsection{Reconsideración de los instrumentos de planeamiento y ordenación espacial}

A la luz de los resultados de la investigación, se pueden identificar los factores clave de aprovechamiento de recursos locales para reducir la insostenibilidad del sistema agroalimentario sobre los que incidir desde la ordenación espacial. Es decir, se seleccionan aquellos factores que entran en el campo de acción del planeamiento y la ordenación territorial y urbana, y por tanto son factores sobre los que se puede indicir a través de estos instrumentos. Son factores relacionados con la definición y regulación de usos de suelo, la definición de la red de equipamientos e infraestructuras, la calificación y regulación de usos y del destino de las edificaciones. La identificación de los factores se hace trabajando dos ejes básicos que se ven afectados por las disposiciones del planeamiento: la capacidad productiva y la accesibilidad a los alimentos. Teniendo en cuenta las características de la región analizada y su condición de espacio rural de aprovisionamiento para las ciudades, el primer aspecto recibe más atención, mientras que el segundo se considera de manera genérica. Según la escala de análisis, varía cómo se consideran cada uno de los factores. Algunos cobran sentido únicamente a escala territorial supramunicipal, mientras que para otros es también relevante la escala municipal, en cuyo caso el tratamiento que convendría darle, dependerá del tipo de municipio sobre el que se esté actuando. Los factores que se señalan hacen referencia a las distintas etapas del sistema agroalimentario y territorial, aprendiendo de cada etapa histórica las variables y las consideraciones que redundan en un mejor desempeño del conjunto en cuanto a estabilidad, autonomía y resiliencia.

\section{Mejora de la capacidad productiva}

El primer eje de análisis se refiere a la capacidad de producción agraria, y también a la capacidad de transformación de la producción primaria para la elaboración de alimentos, entendiendo que asumir una mayor parte del proceso de producción de alimentos incrementa la autonomía del sistema productivo y permite aumentar la resiliencia a través de los encadenamientos productivos locales. Para abordar la capacidad productiva los planes pueden actuar sobre dos aspectos fundamentales: la mejora en el aprovechamiento de los recuros locales y la reducción de las necesidades de aportes externos.

\section{- Clasificación y regulación de usos}

Una mejor adecuación de los usos incide sobre ambos aspectos. Se trata de evitar, mediante la clasificación de suelo, la sobrecarga de los ecosistemas, 
aprendiendo de los métodos del pasado que adaptaban la explotación a la capacidad del terreno, minimizando la necesidad de aplicar insumos externos que trasladan la mochila ecológica' a otros territorios y también excluyendo de cultivos las zonas menos apropiadas que, por pendiente o por las características de los suelos, son muy vulnerables a la erosión o degradación. En esta clasificación de suelo se puede considerar la más adecuada distribución de tipos de cultivos, retomando una tradición de los tratados urbanísticos (ciudad jardín, ciudad lineal, etc), con huertas más intensivas en las proximidades urbanas.

Dentro de esta adecuación, otro factor a considerar es la regulación de los usos para favorecer la biodiversidad. No sería acertado que los Planes de Ordenación condicionaran lo que se cultiva. Aunque en parcelaciones urbanas es habitual fijar tamaños máximos de parcela y de ocupación, no es conveniente trasladar estas herramientas a la ordenación del medio agrario. Sin embargo, se puede considerar desde el planeamiento la interacción entre espacios agrarios y otros ecosistemas arbustivos 0 arbóreos y espacios naturalizados. Hay un reconocimiento generalizado a la importancia de los servicios ecosistémicos de los espacios naturalizados para el buen desempeño de los agroecosistemas ( $y$ viceversa, aunque en menor medida). Pues bien, la ordenación debería hacerse eco de ese reconocimiento al plantear los espacios agrarios también en relación con los espacios naturales, formando parte de la red de infraestructuras verdes y del sistema ecológico más amplio. Aumentar la biodiversidad y el funcionamiento de los ecosistemas mejoraría la resiliencia.

De cara a la estabilidad, sería importante la claridad en el destino de los suelos y plantear protecciones de espacios agrarios con vocación finalista. Los municipios clave en esta mejora de la autonomía a partir de la producción local son los municipios de aprovisionamiento y los mediadores nodales secundarios. Esta capacidad productiva en su conjunto sería superior a la necesaria para abastecer el ámbito considerado, hay que considerarla en relación también a otras áreas destinatarias de la producción (Madrid metropolitano, por ejemplo) y a las áreas con producciones complementarias (cítricos de Levante, etc). En cualquier caso no se trata de agotar la capacidad, en los municipios de reposición o de reserva la clasificación puede orientarse a su regeneración ecológica o agropecuaria ampliando la disponibilidad de terrenos de pasto.

\section{- Definición de la red de infraestructuras}

Minimizar aportes externos y aprovechar los recursos locales, pasa también por facilitar el cierre de ciclos, aumentando la relación entre los sistemas agrarios y los asentamientos urbanos. Los planes de urbanismo u otros instrumentos de ordenación tienen la posiblidad de abordar las redes hídricas y de tratamiento de residuos de una manera más integral. Se trata de incorporar por un lado, sistemas de compostaje para recuperación de la fracción orgánica, y con ella, de nutrientes que mejoren las condiciones de fertilidad del suelo. Un aspecto especialmente relevante teniendo en cuenta el problema de erosión y pérdida de fertilidad de los suelos en la zona y en general en la península y el agotamiento de los recursos de fósforo procedentes de extracción minera. La misma filosofía se aplicaría al diseñar las redes de abastecimiento y saneamiento de agua, considerando los sistemas de regueras para canalización de aguas de lluvia que 
posteriormente lleguen a las huertas periurbanas, o mediante el aprovechamiento de las aguas grises recicladas, también dentro de las competencias de los planes de urbanismo. La consideración de la red de caminos históricos se debería plantear en términos de recuperar la accesibilidad y ahondar en la valoración de vías pecuarias y caminos rurales. Aunque sea objeto de planes específicos, conviene señalar aquí que la concentración parcelaria no debería equivaler a regularización ortogonal. Un último aspecto a considerar para reducir aportes energéticos, se refiere a que se ha de abordar no solo el proceso productivo en finca, sino también lo relacionado con la conservación, transporte y distribución de alimentos, dando facilidades para el consumo de proximidad, según se explica en el siguiente apartado.

\section{Mejora de la accesibilidad a alimentos locales}

La revisión histórica de los sucesivos sistemas agroalimentarios ha puesto de manifiesto que no se trata solo de plantear medidas en torno a la agricultura o la ganadería, sino de insertar esa producción primaria en el sistema, en forma de alimentos. Para hacerlo de una manera localizada, además de tener campos y espacios para cultivar o criar animales, es necesario contar con infraestructuras de transformación de carácter local, como existían en la sociedad protoindustrial. Los planes de urbanismo deberían participar en la creación de esa red de proximidad.

\section{- Definición de la red de equipamientos}

En este punto se trata de reconocer que, cuando se habla de equipamientos y dotaciones necesarios, hay que adaptarse a los contextos específicos. Los esfuerzos invertidos en garantizar un centro cultural o un centro social en cada pueblo han sido considerables, y sin embargo apenas se ha prestado atención al apoyo de equipamientos productivos (históricamente mataderos, mercados municipales, potros de herrar, etc han formado parte de ese patrimonio público necesario para el funcionamiento del pueblo). La inclusión de infraestructuras o instalaciones productivas en las redes de equipamientos son necesarias al menos al principio, para romper con las dinámicas actuales. El objetivo, en definitiva, es fijar una mayor parte de la cadena de valor en el medio local, mediante la oferta de instalaciones de transformación, procesado, almacenamiento o comercialización planeadas estratégicamente por ámbitos comarcales.

Mantener parte del proceso productivo en los núcleos, distinguiendo su importancia y alcance según el tipo de municipio, y planteándolo como un sistema, no de manera aislada, permite reforzar las economías locales. Una agricultura inserta en procesos productivos y no mera suministradora de materias primas para industrias cada vez más lejanas y desligadas del territorio, permite reducir las necesidades de transporte. Estos sistemas productivos se plantean en relación con el abastecimiento de los núcleos urbanos de mayores dimensiones en las proximidades, en este caso Valladolid, pero también pueden alcanzar la cornisa cantábrica o Madrid, para determinados productos. La red, planteada como un sistema entre los municipios afectados, incluiría infraestructuras de acopio y de transformación, con instalaciones en diferentes escalas, y también infraestructuras o espacios de conocimiento y de intercambio. El patrimonio 
existente en desuso ofrece una oportunidad para su recuperación y puesta en carga, adaptándolo a las exigencias actuales. Especialmente relevante para los municipios de aprovisionamiento, que deberían contar con infraestructuras de proximidad, de apoyo al procesado, mientras que los municipios mediadores nodales albergan elementos clave de la red de cara a la distribución hacia los municipios metropolitanos. Por último, es oportuno considerar a su vez las redes de equipamientos para comercialización y consumo, en este caso con potenciación de mercados de abasto y puntos de venta con mejora de sus entorno, consideración de instalaciones de cocina colectivas, así como recuperación de envases y restos, acercando la producción al consumo, reduciendo las necesidades de transporte y en su caso, de envasado que resulta más fácil recuperable y reutilizable en dinámicas de circuitos cortos.

\section{- Regulación de usos}

Un último aspecto a considerar en la ordenación urbanística es la manera de minimizar interferencias y conflictos entre usos agrarios y el resto de usos diseminados por el territorio. Sería esencial dificultar nuevas construcciones, debilitando la tendencia a ocupar el medio agrario con otras edificaciones y usos que introducen, en el caso de los municipios de referencia de primer nivel, dinámicas ajenas a las propias de la actividad primaria en cuanto a expectativas de revalorización e interés en el mantenimiento de la actividad agraria. En el resto de los municipios no hay esas expectativas de revalorización pero sí interfieren con el funcionamiento de los agroecosistemas. La calificación y la regulación de usos en el medio urbano, permitirían poner en valor edificaciones en desuso, y sobre todo recuperar la compatibilidad de la producción agropecuaria en el núcleo rural, especialmente en las parcelas edificadas periféricas. Además el control de la ocupación de los suelos rústicos por segundas residencias reduciría los conflictos entre usos y las afecciones negativas para la producción agraria.

\section{Mejora de la resiliencia}

Dos aspectos fundamentales permitirían aumentar la resiliencia del sistema, por un lado el entendimiento del propio sistema tanto de la parte física como de la humana, que permite reconocer las alteraciones y reaccionar ante ellas. Planes que faciliten equipamientos al efecto, contribuyen a esa resiliencia, aunque es algo que fundamentalmente se promueve desde los agricultores, campesinos y consumidores concienciados. Otro aspecto a considerar para la mejora de la residencia consiste en evitar que se sigan perdiendo los caminos locales y potenciar las vías pecuarias, para la comunicación e interacción entre municipios que forman parte de un mismo sistema, empleando modos de transporte no contaminantes. Los planes urbanísticos y territoriales legitimaron en su momento la ruptura de las estructuras endógenas, ahora deberían plantearse su reconstrucción. Desde los municipios se podrían introducir medidas para bonificar la agricultura y ganadería ecológica, con la opción de incorporar en el cómputo de impuestos de rústica no solo la superficie real en explotación convencional sino también un porcentaje de la superficie virtual asociada a su funcionamiento. El segundo aspecto esencial para mejorar la resiliencia del sistema está vinculado a aumentar su biodiversidad (en todos los 
sentidos, también humana con pobladores de diferentes perfiles y situaciones vitales y con diversidad de habilidades productivas para reducir la vulnerabilidad). Desde el planeamiento se pueden regular los usos en las distintas clases de suelo de manera que aumente la biodiversidad. Se trata de integrar la ordenación de espacios agrarios y naturales. Apoyándose en medidas verdes impulsadas por la PAC, el planeamiento puede prever y fijar las áreas de movimiento para los suelos libres de cultivo y renaturalizados en las explotaciones. Diseños propios de la acupuntura urbana se trasladan al suelo no urbanizable y a la ordenación de bordes de los núcleos, con un enfoque de acupuntura agroecológica en los planes de ordenación.

\subsection{Oportunidad estratégica}

La producción local reduce la huella de carbono de la alimentación al reducir las necesidades de transporte. La adecuación de usos y cultivos reduce la huella hídrica, al gestionar el agua como un recurso escaso. El cierre de ciclos reduce la huella ecológica, contribuye al control de la erosión y contaminación de suelos, reduce los inputs energéticos y el empleo de pesticidas, antibióticos o fertilizantes químicos que repercuten negativamente en la salud y el bienestar. Las estrategias alimentarias, de carácter territorial, pueden actuar como catalizadores de un proceso que convierta ese potencial en una realidad, satisfaciendo las necesidades de alimentación de las poblaciones urbanas y mejorando el funcionamiento del conjunto del sistema urbano rural. Existen mecanismos de ordenación como la clasificación de suelo, la regulación de usos y el diseño de redes y equipamientos con un alto potencial de ser integrados en esas estrategias alimentarias, aportando la dimensión espacial y funcional. Con estos instrumentos se puede incidir sobre la autonomía y la estabilidad de los sistemas de alimentación locales, pueden contribuir a fomentar la biodiversidad, mejorando la resiliencia. Hasta ahora no se ha aprovechado ese potencial, pero hay indicios que apuntan que el momento para reconsiderar los sistemas agroalimentarios favoreciendo su relocalización y una transición agroecológica, ha llegado. Desde el urbanismo y la ordenación espacial podemos jugar un papel esencial en esa transición. 


\section{BIBLIOGRAFÍA}

ABAD BALBOA, C., et al (1994). "La agricultura española en el último tercio del siglo XX: principales pautas evolutivas" En Modernización y cambio estructural en la agricultura española (pp. 69-126). Madrid: Ministerio de Agricultura, Alimentación y Medio Ambiente.

ANDERIES, J. M. et al. (2004). "A framework to analyze the robustness of social-ecological systems from an institutional perspective", Ecology and Society 9(1): 18.

BARAJA RODRÍGUEZ, E. (2011). "Los paisajes del regadío en Castilla y León: Entidad, procesos y configuraciones", Polígonos revista de Geografía, (21), 51-84.

BARCIELA LÓPEZ, C. Y LÓPEZ ORTIZ, M. (2003). El fracaso de la política agraria del primer franquismo, 1939-1959. Veinte años perdidos para la agricultura española.

BARREIRO GIL, M. J. (2009). "O despegue ea reorientación do sistema de transporte terrestre en España: 1940-1975", Revista Galega de Economía, 18 (1), 119-138.

BRIZ ESCRIBANO, J. (1985). "Anotaciones al funcionamiento del mercado español del trigo", Revista de Estudios Agrosociales, (130), 89-114.

BUSQUETS FÁBREGAS, J. (2006). "Estudio del paisaje vitivinícola del Alt Penedés. Análisis y establecimiento de criterios e instrumentos para la gestión del paisaje vitivinícola de la comarca del Alt Penedés", En El paisaje y la gestión del territorio: criterios paisajísticos en la ordenación del territorio y el urbanismo (pp. 449-464). Barcelona: Diputació Provincial

CALLE COLLADO, A., et al (2012). "La desafección al sistema agroalimentario: ciudadanía y redes sociales", Interface, 4, 459-489.

CAÑAS, I., et al. (2012). "Bodegas subterráneas excavadas en tierra: Características de los suelos en la Ribera del Duero (España)", Informes de la Construcción, 64 (527), 287-296.

CASTRO RODRÍGUEZ, L. (1957). "Los fertilizantes en España", Revista de Estudios Agrosociales, (20), 49-73

COLLANTES, F. (2009). "La alimentación en la España del siglo XX: una perspectiva desde la historia económica", I Congreso Español de Sociología de la alimentación.

CUSSÓ SEGURA, X. \& GARRABOU SEGURA, R. (2010). "La globalización de la dieta en España en el siglo XX", X Congreso Español de Sociología. Pamplona.

DELGADO CABEZA, M. (2010). "El sistema agroalimentario globalizado: imperios alimentarios y degradación social y ecológica", Revista de Economía Crítica, (10), 32-61.

DE FELIPE, I. Y BRIZ, J. (2001). "Seguridad alimentaria y actitud del consumidor: el vacuno en la Unión Europea", IV Congreso Nacional de Economía Agraria. Pamplona.

FORTEZA, J. (1987). Mapa de Clases Agrológicas de Castilla y León. Valladolid: Junta de Castilla y León.

FRAX, E. Y MADRAZO, S. (2001). "El transporte por carretera", Transportes, Servicios y Comunicaciones, (01), 31-53.

FRIEDLAND, W. H. (2004). "Agrifood globalization and commodity systems", International Journal of Sociology of Agriculture and Food, 12 (1), 17-28. 
GARRABOU SEGURA, R. \& SANZ FERNÁNDEZ, J. (1985). Historia agraria de la España contempor ánea: expansión y crisis (1850-1900). Barcelona: Editorial Crítica.

GARVI, M. \& PELÁEZ HERREROS, O. (2009). "Proyección a largo plazo de la esperanza de vida en España", Estadística española, 51 (170), 193-219.

GÓMEZ BENITO, C. \& LUQUE PULGAR, E. (2007). "Modernización agraria, modernización administrativa y franquismo. El modelo educativo y administrativo del Servicio de Extensión Agraria (1955-1986)", Areas: Revista internacional de ciencias sociales, (26), 131-149.

GÓMEZ MENDOZA, J. (1987) "La agricultura periurbana: Su estudio, sus cambios, sus políticas", Agricultura y sociedad 42 (1987): 109-146.

GONZÁLEZ DE MOLINA, M. (1996). "Prólogo", En J. M. Naredo (Ed.): La evolución de la agricultura en España (1940-1990). Granada (España): Universidad de Granada.

GONZÁLEZ DE MOLINA, M., et al (2007). "La agricultura ecológica en España desde una perspectiva agroecológica", Revista Española de estudios agrosociales y pesqueros, (214), 47-73.

GONZÁLEZ DE MOLINA, M. \& INFANTE, J. (2010). "Agroecología y decrecimiento. una alternativa sostenible a la configuración del actual sistema agroalimentario español", Revista de Economía crítica, (10), 113-137

GUTIÉRREZ-FISAC, J. L. et al. (2003). "La epidemia de obesidad y sus factores relacionados: el caso de España", Cad Saúde Pública, 19 (S1), 101-10.

GUZMÁN CASADO, G. I., et al. (2000). Introducción a la agroecología como desarrollo rural sostenible. Madrid: Ediciones Mundi-Prensa.

HAIG, N. (2005). "Stephen Gliessman: sin la agroecología no hay desarrollo sostenible", Sustrai: revista agropesquera, (71), 4-9.

HERNÁNDEZ AJA, A. (2009). "Calidad de vida y Medio Ambiente Urbano: indicadores locales de sostenibilidad y calidad de vida urbana", INVI, 24 (65), 79-111.

HERNÁNDEZ AJA, A. \& VÁZQUEZ ESPÍ, M. (2010). "Urbanización contra sostenibilidad", Boletín CF+ S, (44).

JUNTA DE CASTILLA Y LEÓN. (1988). Análisis del medio físico: Delimitación de unidades y estructura territorial. Valladolid. Junta de Castilla y León. Consejería de Fomento.

KAUFMAN, F. (2010). "The Food Bubble: How Wall Street starved millions and got away with it", Harper's Magazine, July 2010, 32.

Keller, M. (2012). "Advertising and Consumerism in the Food Industry", Honors Theses Providence Campus. Paper 3.

LEAL, J. L., et al. (1975). Agricultura en el desarrollo capitalista español (1940-1970). Madrid: Siglo Veintiuno de España

LEVIN, S. A. (1992). "The problem of pattern and scale in ecology: the Robert H. MacArthur award lecture", Ecology, 73 (6), 1943-1967.

MAGRAMA. (2011). "Tendencias de consumo fuera del hogar", Análisis y Prospectiva - Serie AgrInfo, n. 23. 
MAGRAMA. (2013). "La contribución del sistema agroalimentario a la economía española: una propuesta metodológica", Análisis y Prospectiva - Serie AgrInfo, n. 23.

MATA OLMO, R. (2012). "Agricultura, paisaje y gestión del territorio", Polígonos. Revista de Geografía, (14), 97-137.

MALASSIS, L. (1994). Nourrir les hommes. Paris.

McMICHAEL, P. (2005). "Global development and the corporate food regime", Research in rural sociology and development, 11, 265

MOLINERO HERNANDO, F. (1979). "La Tierra de Roa: la crisis de una comarca vitícola tradicional" En Molinero Hernando, F. (1982). El regadío: ¿una alternativa a la agricultura castellano-leonesa? Burgos: Ámbito Ediciones.

MOLINERO HERNANDO, F. (2012). "Los paisajes del viñedo en castilla y león: tradición, renovación y consolidación", Polígonos. Revista de Geografía, (21), 85-117.

MONTAGUT, X. \& VIVAS, E. (2009). Del campo al plato. Los circuitos de producción y distribución de alimentos. Icaria Editorial.

NACIONES UNIDAS. (2000). Declaración del Milenio

NAREDO, J. M. (1996). La evolución de la agricultura en España (1940-1990). Granada: Universidad de Granada.

SCHUTTER, O. D. (2010). "Food Commodities Speculation and Food Price Crises", Briefing note by the United Nations Special Rapporteur on the right to food.

SIMÓN FERNÁNDEZ, X., et al. (2014). "Alimentos kilométricos y gases de efecto invernadero: Análisis del transporte de las importaciones de alimentos en el Estado español (1995-2007)", Revibec: revista iberoamericana de economía ecológica, 22, 1-16.

SIMÓN ROJO, M. (2010). "Transformaciones territoriales en regiones polarizadas: el caso del tramo medio del Duero", En Ciudad, territorio y paisaje: Reflexiones para un debate multidisciplinar (pp. 288-297)

SIMÓN ROJO, M. Y HERNÁNDEZ AJA, A. (2008). "Relaciones entre cambio de modelo urbano-territorial y consumo de suelo en los municipios españoles"

SIMPSON, J. (1989). "La producción agraria y el consumo español en el siglo XIX", Revista de Historia Económica, 7 (2), 863-871

TAMAMES, R. (2008). Estructura económica de España. Madrid: Alianza Editorial.

TELLO ARAGAY, E. (2006). "La transformación del territorio, antes y después de 1950: un lugar de encuentro transdisciplinar para el estudio del paisaje", Areas: Revista internacional de ciencias sociales, (25), 5-12.

VÁZQUEZ ESPÍ, M. (2000). "Arquitectura, economía y ecología", Boletín CF+ S, (14)

VERDAGUER, C. Y VELÁZQUEZ, I. (2012). "Pasos hacia la regeneración urbana ecológica: más allá de la eficiencia energética", Ciudad y Territorio, 44 (171), 97-113. 
LOS CUADERNOS DE INVESTIGACIÓN URBANÍSTICA publicados por el Departamento de Urbanística y Ordenación del Territorio desde el año 1993, difunden bimensualmente aquellos trabajos de investigación realizados en el área del Urbanismo, la Ordenación Territorial, el Medio Ambiente, la Planificación Sostenible y el Paisaje, que por sus características, muchas veces de investigación básica, tienen difícil salida en las revistas profesionales. Su objetivo es la difusión de estos trabajos, en el convencimiento de que es necesario potenciar el uso de este idioma entre el mundo científico para conseguir alcanzar ámbitos de difusión a los que, de otra forma, no se podría acceder.

Su formato no es el convencional de una revista de este tipo, con artículos de diferentes autores que, en realidad, abordan aspectos parciales de cada trabajo, muy adecuados para la difusión y el conocimiento rápido de los mismos, pero que no pueden profundizar demasiado debido a su limitada extensión, sino que se trata de amplios informes de la investigación realizada que ocupan la totalidad de cada número. Esto permite, sobre todo a aquellos investigadores que se inician, el tener accesibles los aspectos más relevantes del trabajo y conocer con bastante precisión el proceso de elaboración de los mismos.

La realización material de los Cuadernos de Investigación Urbanística está a cargo del Departamento de Urbanística y Ordenación del Territorio de la Escuela Técnica Superior de Arquitectura de Madrid, garantizándose el respeto de la propiedad intelectual, pues el registro es siempre en su totalidad propiedad del autor. Está permitida su reproducción parcial en las condiciones establecidas por la legislación sobre propiedad intelectual citando autor, previa petición de permiso al mismo.

\section{NORMAS DE PUBLICACIÓN}

Las condiciones para el envío de originales se pueden consultar en la página web:

http://www.aq.upm.es/Departamentos/Urbanismo/publicaciones/ciurpublicar.html

\section{FORMATO DE LAS REFERENCIAS}

Monografías: APELLIDOS (S), Nombre (Año de edición). Título del libro (No de edición). Ciudad de edición: Editorial [Traducción castellano, (Año de edición), Título de la traducción, № de la edición. Ciudad de edición: editorial].

Partes de monografías: APELLIDOS (S), Nombre (Año de edición). "Título de capítulo". En: Responsabilidad de la obra completa, Título de la obra (No de edición). Ciudad de edición: Editorial.

Artículos de publicaciones en serie: APELLIDOS (S), Nombre (Año de publicación). "Título del artículo", Título de la publicación, Localización en el documento fuente: volumen, número, páginas.

Asimismo, se recuerda que el autor tendrá derecho a tres ejemplares gratuitos.

\section{CONSULTA DE NÚMEROS ANTERIORES/ACCESS TO PREVIOUS WORKS}

La colección completa se puede consultar en color y en formato pdf en siguiente página web:

The entire publication is available in pdf format and full colour in the following web page:

http://www.aq.upm.es/Departamentos/Urbanismo/publicaciones/ciurnumeros.html

\section{ÚLTIMOS NÚMEROS PUBLICADOS:}

103 Emilia Román López: "Protección, gestión y ordenación del paisaje salinero en Andalucía", 94 páginas, Noviembre 2015.

102 Antonio Matres Barrio: "Masas dialogantes: el futuro del urbanismo social", 84 páginas, Septiembre 2015.

101 María del Puy Alonso Martínez: "Diseño de áreas verdes con criterios ecológicos", 80 páginas, Julio 2015.

100 Departamento de Urbanística y Ordenación del Territorio ETSAM: "Cien números de Cuadernos de Investigación Urbanística", 150 páginas, Mayo 2015.

99 María Teresa Broseta Palanca: "La catalogación del patrimonio arquitectónico de la ciudad de Valencia", 94 páginas, Marzo 2015. 
PROGRAMA OFICIAL DE POSGRADO EN ARQUITECTURA

MASTER PLANEAMIENTO URBANO Y TERRITORIAL

URB

Escuela Técnica Superior de Arquitectura de Madrid (UPM)

\author{
PREINSCRIPCIÓN DEL 15 DE MARZO AL 27 DE JUNIO DE 2014 \\ COORDINADORA DEL MÁSTER: Ester Higueras García \\ PERIODO DE DOCENCIA: Septiembre 2014 -Junio 2015 \\ MODALIDAD: Presencial y tiempo completo \\ NUMERO DE PLAZAS: 40 plazas \\ CREDITOS: 60 ECTS
}

El Máster se centra en la comprensión, análisis, diagnóstico y solución de los problemas y la identificación de las dinámicas urbanas y territoriales en curso, atendiendo a las dos dimensiones fundamentales del fenómeno urbano actual: por un lado, el proceso de globalización y, por otro lado, las exigencias que impone la sostenibilidad territorial, económica y social. Estos objetivos obligan a insistir en aspectos relacionados con las nuevas actividades económicas, el medio físico y natural, el compromiso con la producción de un espacio social caracterizado por la vida cívica y la relación entre ecología y ciudad, sin olvidar los problemas recurrentes del suelo, la vivienda, el transporte y la calidad de vida. Estos fines se resumen en la construcción de un espacio social y económico eficiente, equilibrado y sostenible. En ese sentido la viabilidad económica de los grandes despliegues urbanos y su metabolismo se confrontan con modelos más maduros, de forma que al estudio de las técnicas habituales de planificación y gestión se añaden otras nuevas orientaciones que tratan de responder a las demandas de complejidad y sostenibilidad en el ámbito urbano.

El programa propuesto consta de un Máster con dos especialidades:

- Especialidad de Planeamiento Urbanístico (Profesional)

- Especialidad de Estudios Urbanos (Investigación Académica)

Se trata de 31 asignaturas agrupadas en tres módulos:

MÓDULO A. Formación en Urbanismo.

MÓDULO B. Formación en Estudios Urbanos e Investigación.

MÓDULO C. Formación en Planeamiento.

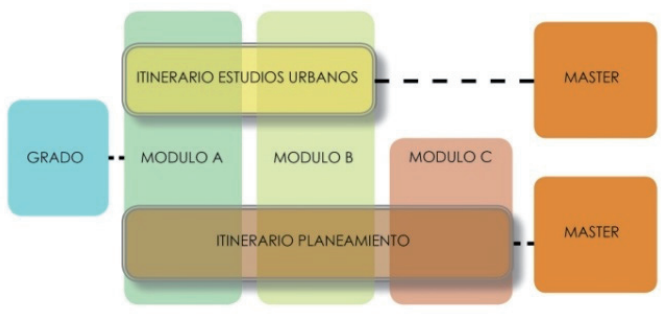

Beatriz Fernández Águeda Inés Sánchez de Madariaga José Fariña Tojo José Miguel Fernández Güell Isabel González García Agustín Hernández Aja
PROFESORADO:

Ester Higueras García

Francisco José Lamiquiz

Julio Pozueta

Fernando Roch Peña

Felipe Colavidas

Luis Moya

José María Ezquiaga
Llanos Masiá

Javier Ruiz Sánchez

Carlos Verdaguer

Enrique Villa Polo

Carmen Andrés Mateo

Álvaro Sevilla

ENTIDADES COLABORADORAS:

(3) 4 Ci[ur] $=$ urban

CONTACTO: masterplaneamiento.arquitectura@upm.es www.aq.upm.es/Departamentos/Urbanismo/masters/index.html 


\section{ALGUNAS DE LAS ACTIVIDADES REALIZADAS DURANTE EL CURSO 2014/15...}
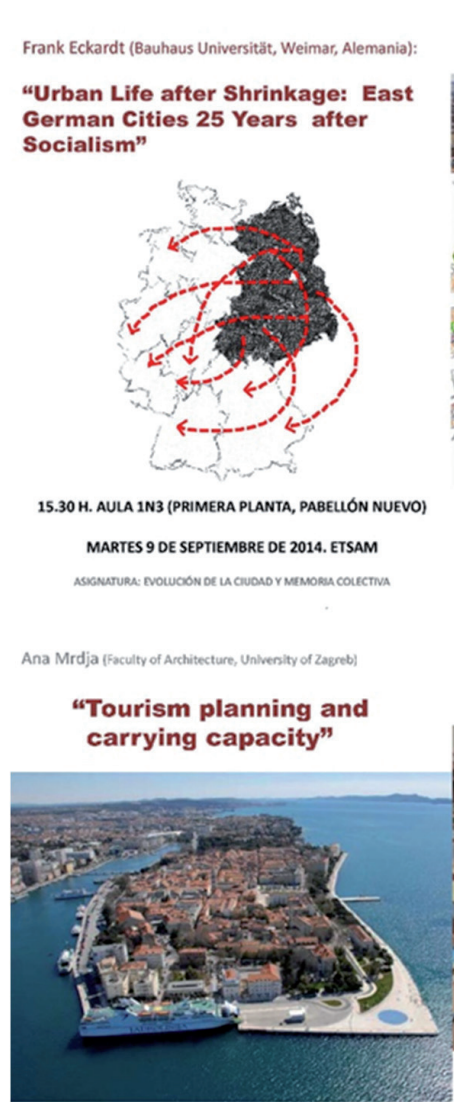

11.30 H. SALA de GRAdos B (PABELLón aNTIGUO) JUEVES 18 DE SEPTIEMBRE DE 2014. ETSAM ASTONATURA: SEM MAAIO EN UINEAS OE I INESTGGACON
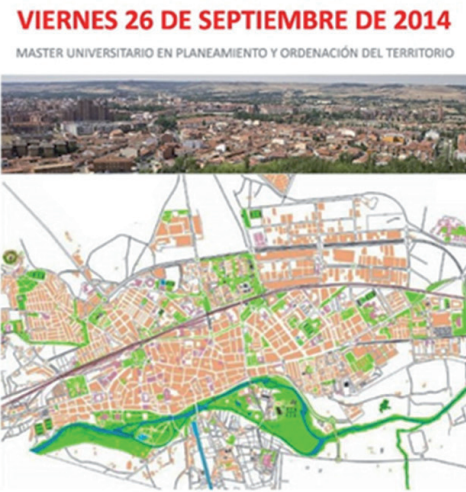

"Visita a la ciudad de Palencia"

RECEPCION EN EL AYUNTAMIENTO Y PASEO POR LA CIUDAD Y SUS BARRIOS

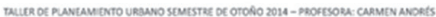

MIÉRCOLES 11 DE FEBRERO DE 2015. ETSAM MASTER UNVERSTIARIO EN PLANEAM ENIO Y ORDERACCÓN OEL TERRIORIO

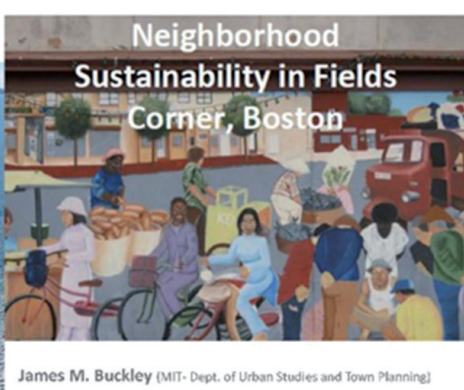

"Urban regeneration in USA"

11.30 H. AULA 1N3 (AULA MÁSTER)

INAUGURACON ACCOEMICA DEL STGUNDO SEMESTRE OEL MASTR
José Fariha Tojo (Cotedratico UPM, ouvor)

Luis Felipe Alonso Teixidor (Catedratico "Ad Honorem" UPM, Duron) Ramón López de Lucio (Catodratico "Ad Honorem" UPM, OU,OT)

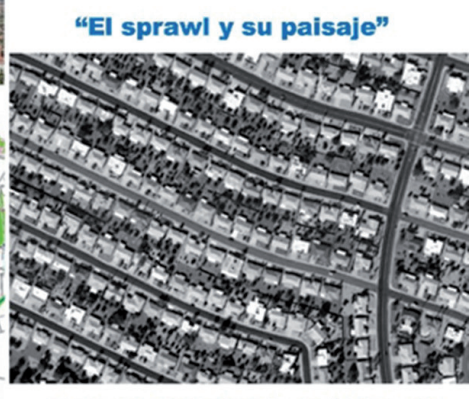

11.30 H. SALA DE GRADOS B (PABELLÓN ANTIGUO)

JUEVES 9 DE OCTUBRE DE 2014. ETSAM

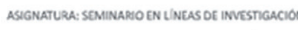

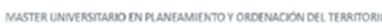

MIÉRCOLES 5 DE NOVIEMBRE DE 2014. ETSAM MASTER UNVERSTMR: O EN PLANEAMIENTO Y ORDEMACON OEL TERRTORIO

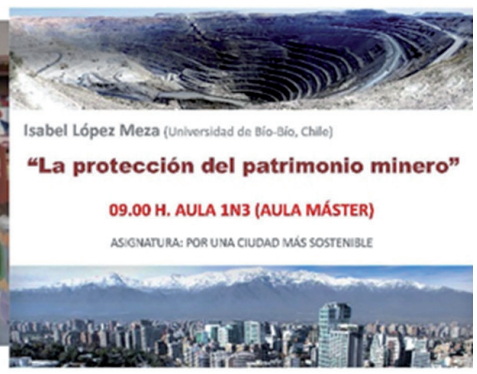

Mario Torres Jofré \{Universidad de Chile)

"La ciudad contemporánea.

1600 H. AULA 1N3 (AULA MÁSTER)

ASIGNUTUR: PAONECTAR LA CUDAD COMPIES

VIERNES 27 DE FEBRERO DE 2015 JUEVES 19 DE MARZO DE 2015 MIÉRCOLES 25 DE MARZO DE 2015

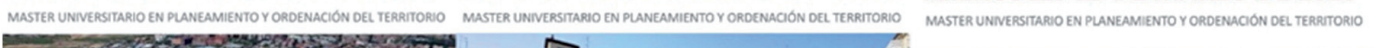

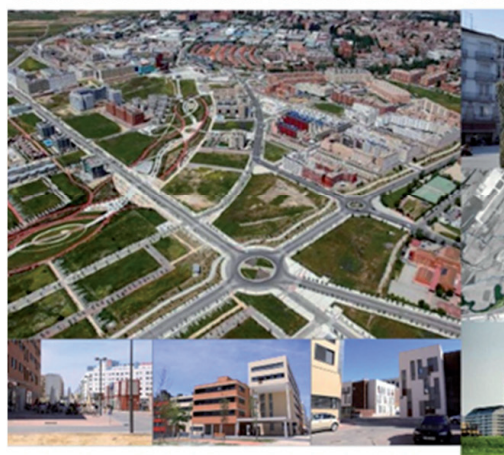

"Visita a Móstoles Sur (Madrid)"

15.30 H. MEtro MANUELA MALASAÑ (METROSUR)

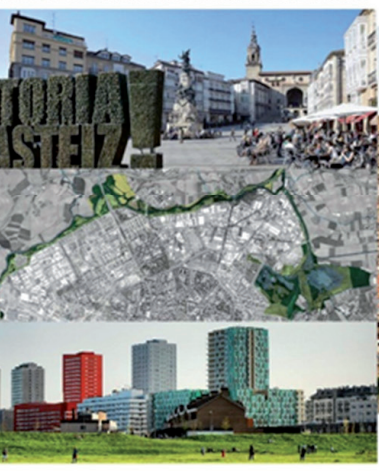

"Visita a Vitoria-Gasteiz"

$12.00 \mathrm{H}$. PLAZA DE LA VIRGEN BLANCA (CENTRO)

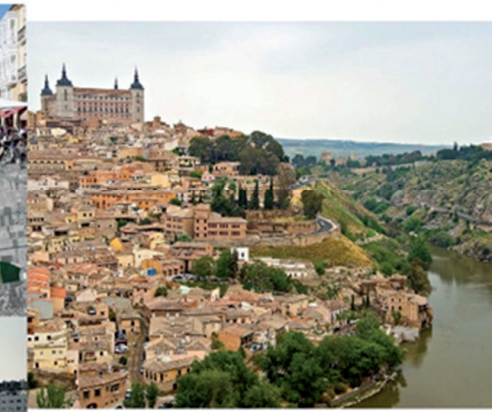

"Visita a Toledo"

16.00 H. PLAZA DE ZOCODOVER (CENTRO)

JOINT WORKSHOP - SPRING 2015 - EVOLVING CTIES

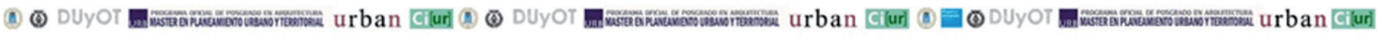


Otros medios divulgativos del Departamento de Urbanística y Ordenación del Territorio:

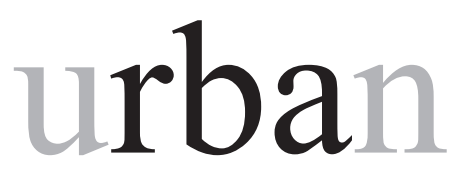

ReVISTA del Departamento de URBANÍStiCA y Ordenación del TerRITORIO ESCUELA TÉCNICA SUPERIOR DE ARQUITECTURA

\section{PRESENTACIÓN SEGUNDA ÉPOCA}

DESDE el año 1997, URBAN ha sido vehículo de expresión de la reflexión urbanística más innovadora en España y lugar de encuentro entre profesionales y académicos de todo el mundo. Durante su primera época la revista ha combinado el interés por los resultados de la investigación con la atención a la práctica profesional, especialmente en el ámbito español y la región madrileña. Sin abandonar dicha vocación de saber aplicado y localizado, la segunda época se centra en el progreso de las políticas urbanas y territoriales y la investigación científica a nivel internacional.

\section{CONVOCATORIA PARA LA RECEPCIÓN DE ARTÍCULOS:}

Urban mantiene abierta una convocatoria permanente para la remisión de artículos de temática relacionada con los objetivos de la revista: Para más información:

http://www2.aq.upm.es/Departamentos/Urbanismo/institucional/publicaciones/urban/ns/instrucciones-para-autores/

Por último, se recuerda que, aunque La revista URBAN organiza sus números de manera monográfica mediante convocatorias temáticas, simultáneamente, mantiene siempre abierta de forma contínua una convocatoria para artículos de temática libre.

\section{DATOS DE CONTACTO}

Envío de manuscritos y originales a la atención de Javier Ruiz Sánchez: urban.arquitectura@upm.es

Página web: http://www.aq.upm.es/Departamentos/Urbanismo/public/urban/info.html

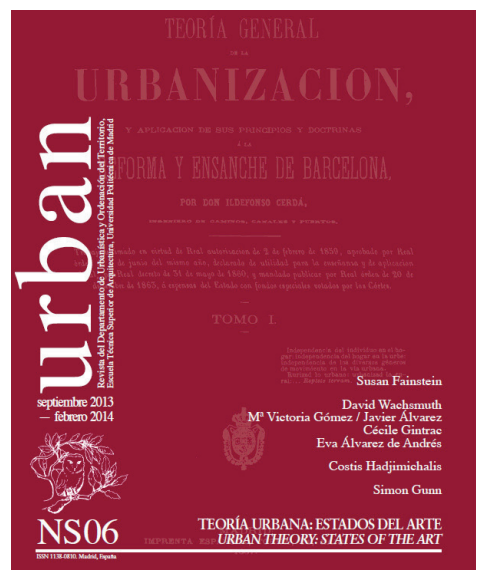

Consulta y pedido de ejemplares: ciur.urbanismo.arquitectura@upm.es

Web del Departamento de Urbanística y ordenación del Territorio:

http://www.aq.upm.es/Departamentos/Urbanismo

Donde figuran todas las actividades docentes, divulgativas y de investigación que se realizan en el Departamento con una actualización permanente de sus contenidos. 